\title{
7. Themenbereich grüne Gentechnologie: Pflanzenzüchtung und Agrarwirtschaft
}

\subsection{GV-Pflanzen in Forschung und Anwendung}

Pflanzenzüchtung und -biotechnologie gelten in Fachkreisen auch weiterhin als Schlüsseltechnologien zur Ernährungssicherung einer wachsenden Weltbevölkerung. Das Forschungsfeld hat sich in den letzten Jahren bei den Forschungsprojekten wie bei den Anwendungen weiter ausdifferenziert. Es sind deutliche Fortschritte bei der Entwicklung neuer Methoden und Züchtungsziele erreicht worden, auch wenn sich die rasanten Fortschritte in der Forschung bislang nicht in gleichem Maße für die praktische Anwendung beobachten lassen. Dies liegt unter anderem daran, dass die Produktentwicklung und die für eine Vermarktung notwendigen Zulassungsprozesse in diesem Bereich sehr zeitintensiv sind. In globaler Perspektive beherrschen deshalb immer noch klassische transgene Pflanzen der ersten Generation mit Herbizidtoleranzen und Insektenresistenzen den Anbau, wie sie seit den 1990er-Jahren kommerziell vermarktet werden. Nach Angaben der Organisation ISAAA (International Service for the Acquisition of Agro-Biotech Applications) $)^{1}$ nimmt der kommerzielle Anbau von gentechnisch veränderten Pflanzen seit 1996 global stetig zu. In $2013^{2}$ wurden weltweit rund 175 Millionen Hektar in insgesamt 27 Ländern angebaut, wobei jedoch der prozentuale Anteil an Flächen mit GV-Pflanzen gegenüber dem Vorjahr aufgrund eines noch stärkeren Anstiegs von Flächen mit konventionell gezüchteten Pflanzen abnahm. ${ }^{3}$ Die größten Anbauflächen befanden sich dabei in den USA (70,1 Mio. ha), Brasilien (40,3 Mio. ha), Argentinien (24,4 Mio. ha), Indien (11 Mio. ha) und Kanada (10,8 Mio. ha). Diese welt-

1 Die ISAAA ist eine internationale Non-Profit-Organisation, die Informationen zur Pflanzenbiotechnologie auf einem Internetportal (www.isaag.org) anbietet und nach eigenen Angaben den Technologietransfer in Schwellen- und Entwicklungsländer fördert. Sie veröffentlicht seit 1996 jährlich einen Bericht zum weltweiten kommerziellen Anbau von gentechnisch veränderten Pflanzen.

2 ISAAA Brief No. 46. https://www.isaaa.org/resources/publications/briefs/46/topfacts/default. asp [14.07.2014].

3 http://www.transgen.de/anbau/flaechen international/531,doku.html [14,07.2014] 
weit dynamische Entwicklung steht in deutlichem Kontrast zur Wahrnehmung der grünen Gentechnologie ${ }^{4}$ in der deutschen und europäischen Öffentlichkeit sowie zur Gestaltung der politischen Rahmenbedingungen in Deutschland und der EU. Deutschland wird im ISAAA-Bericht nicht mehr gesondert aufgeführt, da es bereits 2012 keinen kommerziellen Anbau von GV-Pflanzen mehr gab. ${ }^{5}$ Auch wenn kein europäisches Land zu den Top Ten der Anbauländer gehörte, sind heute eine ganze Reihe an gentechnisch veränderten Nahrungs- und Futtermitteln in der EU zugelassen, ${ }^{6}$ und die grüne Gentechnologie ist in Form von importierten gentechnisch veränderten Futtermitteln auch in Europa präsent.

Im Rahmen dieses Kapitels werden die aktuellen Entwicklungen auf dem Gebiet der grünen Gentechnologie anhand von repräsentativen Beispielen aufgezeigt: Dabei werden sowohl moderne Verfahren der Pflanzenzüchtung (siehe Kapitel 5.2) als auch relevante Weiterentwicklungen im Bereich molekularbiologischer Methoden (siehe Kapitel $5.3)^{7}$ vorgestellt. Die dargestellten Züchtungsziele (siehe Kapitel. 5.4) haben sich mittlerweile weit über die der klassischen transgenen Pflanzen der ersten Generation hinaus entwickelt. Die Ausführungen im vorliegenden Text knüpfen einerseits an das entsprechende Kapitel im „Zweiten Gentechnologiebericht“ (2009) an, andererseits an die umfassende Darstellung im Themenband „Grüne Gentechnologie“ (2013) und schreiben die dort bereits eingeführten Indikatoren fort. ${ }^{8}$ Da die hier aufgeführten Themen im Rahmen dieses Übersichtskapitels nicht in ihrer wissenschaftlichen Vollständigkeit erläutert werden können, ist zu jedem Thema weiterführende Literatur angegeben, die eine selbständige vertiefende Beschäftigung ermöglicht.

4 Im Rahmen dieses Buches wird die Bezeichnung „grüne Gentechnologie“ als Oberbegriff für Wissenschaft und Anwendung der Gentechnologie bei Pflanzen verwendet. Den auf die Anwendung zielenden Begriff „grüne Gentechnik“ schließen wir dabei in unsere Untersuchungen mit ein. Die Begriffe werden in der öffentlichen Debatte häufig synonym verwendet.

5 Es sind allerdings für Deutschland in 2012 noch Freilandversuche mit GV-Pflanzen zu Forschungszwecken verzeichnet, unter: www.transgen.de/aktuell/1670.doku.html [2201.2014]. Diese wurden 2013 dann komplett eingestellt. Unter: www.transgen.de/anbau/deutschland/1714.doku.html [15.01.2014]. 6 http://ec.europa.eu/food/dyna/gm_register/index_en.cfm [22.01.2014].

7 Die rasanten Fortschritte auf dem Gebiet der Pflanzenbiotechnologie wurden durch die Weiterentwicklung einer Reihe wichtiger Hilfstechnologien ermöglicht. Diese wurden im Themenband „Grüne Gentechnologie“ ausführlich beschrieben (Müller-Röber et al., 2013:60 ff.). Hierzu gehören z. B Metabolomics und Proteomics, die Entstehung einschlägiger und spezialisierter Datenbanken, die Entwicklung neuer Detektionsmethoden für gentechnische Modifikationen sowie die Systembiologie. 8 Die Ausführungen basieren in Teilen auf dem Kapitel zum „Stand der Wissenschaft und Technik“ im Themenband „Grüne Gentechnologie“ (Müller-Röber et al., 2013:39-94). Der Text wurde jedoch gekürzt, neu bearbeitet und ergänzt. Einen Überblick über weitere neue Technologien der Pflanzenforschung bieten Ehrhardt/Frommer, 2012. 


\subsection{Neue Züchtungsmethoden}

Der Einsatz gentechnischer Verfahren und molekularer Marker spielt in der modernen Pflanzenzüchtung seit langem eine wichtige Rolle. Dabei kommen ganz unterschiedliche Methoden zum Einsatz. Neben den klassischen Methoden der Modifikation des Kerngenoms mittels des Bakteriums Agrobacterium tumefaciens oder der biolistischen Transformation gibt es eine Vielzahl weiterer Methoden, zum Beispiel mittels Viren, durch Nukleinsäure-Injektion, chemische Reize oder mit Hilfe von Liposomen. ${ }^{9}$

Im Folgenden sollen alternative neue Verfahren vorgestellt werden, die das Spektrum der Methoden in der Pflanzenzüchtung in den letzten Jahren erweitert haben. Zum einen wird dabei die fortschreitende technische Entwicklung im Bereich der Gentechnik genutzt, um klassische Kreuzungs- oder Mutageneseverfahren - ohne eigentlichen Gentransfer - zu optimieren (z. B. via SMART Breeding und genomischer Selektion, TILLING, Reverse Breeding). Auch die konventionelle Kreuzung von transgenen Sorten untereinander (Trait Stacking) hat zunehmend an Bedeutung gewonnen. Zum anderen wurden Methoden entwickelt, die gezielter und kalkulierbarer genetische Veränderungen in Pflanzen ermöglichen (z. B. Plastidentransformation, RNA-Interferenz und CRISPR-Technologie) bzw. gewollt auf artfremdes genetisches Material verzichten (Cisgenetik und Intragenetik).

\subsubsection{Cisgene und intragene Pflanzen}

Cisgene Pflanzen sind Pflanzen, die zwar mit gentechnischen Methoden erzeugt wurden, für deren Herstellung jedoch ausschließlich auf arteigenes genetisches Material (bzw. das von kreuzbaren nahen Verwandten) zurückgegriffen wurde. ${ }^{10}$ Die entstehende Neukombination der Erbinformation wäre theoretisch also auch auf natürlichem Wege erreichbar - anders als bei transgenen Pflanzen, bei denen bei der Übertragung von Genen (zum Teil weite) Artgrenzen überschritten werden. Für die Verwendung von neuen Genkombinationen, welche in vitro durch die Neuanordnung arteigener funktioneller Elemente (wie etwa Promotoren, kodierende Regionen oder terminale Re-

9 Siehe hierzu ausführlich Müller-Röber et al., 2009:242 f. Übersichtsartikel zu aktuellen Fortschritten der Pflanzentransformation bieten Barampuram/Zhang, 2011; Rafsanjani et al.,2012 und Rivera et al., 2012.

10 Auf die grundlegenden biologischen Prinzipien der Cisgenetik und ihre potentiellen Vorteile gegenüber der Herstellung transgener Pflanzen wurde bereits im „Zweiten Gentechnologiebericht“ (Müller-Röber et al., 2009) sowie in den erschienenen Themenbänden zur grünen Gentechnologie (Müller-Röber et al., 2007, 2013) ausführlich eingegangen 
gionen $)^{11}$ als Konstrukt entstanden sind, wurde der Begriff der Intragenese etabliert (Holme et al., 2013; siehe Abbildung 1). Ein weiteres Merkmal cis- und intragener Pflanzen ist, dass für deren Herstellung auf Markergene entweder von Anfang an verzichtet wird oder diese zunächst in das Genom der Zielpflanze eingebracht, dann aber durch molekulare Techniken oder Auskreuzung wieder entfernt werden. Somit besitzen die so erzeugten Pflanzen keine artfremden Gene für Antibiotikaresistenzen oder Herbizidtoleranzen (Vanblaere et al., 2011).

Der Vorteil der Cis- und Intragen-Technologie gegenüber konventioneller Züchtung liegt dabei darin, dass nur das gewünschte Gen oder eine gewünschte Kombination von regulatorischen und proteinkodierenden Regionen der DNA aus der Spenderpflanze in die Zielpflanze eingebracht wird, nicht jedoch weitere Gene, die unerwünschte Effekte wie etwa bitteren Geschmack oder geringes Wachstum vermitteln. So kommt es bei der Kreuzung mit einer Wildpflanze regelmäßig zur Übertragung unerwünschter Erbinformationen in die Kulturpflanze, die dann arbeits- und zeitintensiv durch Rückkreuzung mit Hochleistungssorten wieder entfernt werden müssen. Bei cisgenen Pflanzen bleiben die positiven Eigenschaften der Zielsorte im Allgemeinen erhalten. Auch die Gefahr, dass das neu eingebrachte Gen auskreuzen könnte, sich also unkontrolliert in der Natur verbreitet, ist bei cisgenen Pflanzen weniger problematisch, da es sich bereits im Genpool der jeweiligen Art befindet und nicht neu hinzugefügt wurde.

Es gibt daher Vorschläge, cisgene Pflanzen zukünftig von der strengen Regulierung, wie sie für transgene Pflanzen gilt, auszunehmen. ${ }^{12}$ Da jedoch die Methodik ihrer Erzeugung bis auf die Herkunft des Gens mit der Erzeugung transgener Pflanzen identisch ist, ist die Technologie nicht unumstritten und fällt derzeit unter dieselbe Gesetzgebung. Die Cisgenetik könnte jedoch möglicherweise für die Pflanzenbiotechnologie

11 Die hier aufgeführten funktionellen Elemente sind DNA-Abschnitte, welche Beginn und Stärke der Genexpression determinieren (Promotoren), die genetische Information für Proteine tragen (kodierende Regionen) und Stoppsignale umfassen (Terminatoren).

12 Wie cisgene Pflanzen langfristig rechtlich im Vergleich zu transgenen Pflanzen zu behandeln sind, ist derzeit noch offen und wird aktuell diskutiert. Sollten sie als gentechnisch veränderte Organismen eingestuft und hinsichtlich Freisetzungen, Zulassung, Sicherheitsnachweis und Kennzeichnung so bewertet werden wie diese, könnten sie auch denselben Akzeptanzproblemen begegnen. Die Europäische Behörde für Lebensmittelsicherheit (EFSA) hat hierzu eine Expertenmeinung publiziert (EFSA, 2012). Darin werden die Risiken der Cisgenese und der Intragenese mit denen konventioneller Züchtung und der Transgenese verglichen. Nach Ansicht dieser Kommission können alle vier Techniken mit Risiken verbunden sein. Dabei sind die Risiken der Cisgenese mit denen der konventionellen Züchtung vergleichbar, während Intragenese und Transgenese neuartige Risiken mit sich bringen können, die über diejenigen der konventionellen Züchtung hinausgehen (ebd.). Ob sich diese Auffassung durchsetzen und dazu führen wird, dass cisgene Pflanzen rechtlich anders behandelt werden als transgene Pflanzen, bleibtjedoch offen. 
in Deutschland (und Europa) richtungsweisend werden, da die Akzeptanz cisgener Pflanzen in der EU derzeit höher zu sein scheint als die transgener Sorten. Eine repräsentative Umfrage der Europäischen Kommission ${ }^{13}$ für alle Mitgliedsstaaten (EU27) im Jahr 2010 zeigte, dass nur 33 \% der Befragten transgene Äpfel befürworten, bei cisgenen Äpfeln waren es hingegen 55 \% (Gaskell et al., 2010). Die Cisgenese wird auch als „Neue Generation“ der Herstellung gentechnisch modifizierter Pflanzen bezeichnet (z. B. Vanblaere et al., 2011).

Abbildung 1: Methoden der Pflanzenzüchtung mit und ohne Gentransfer

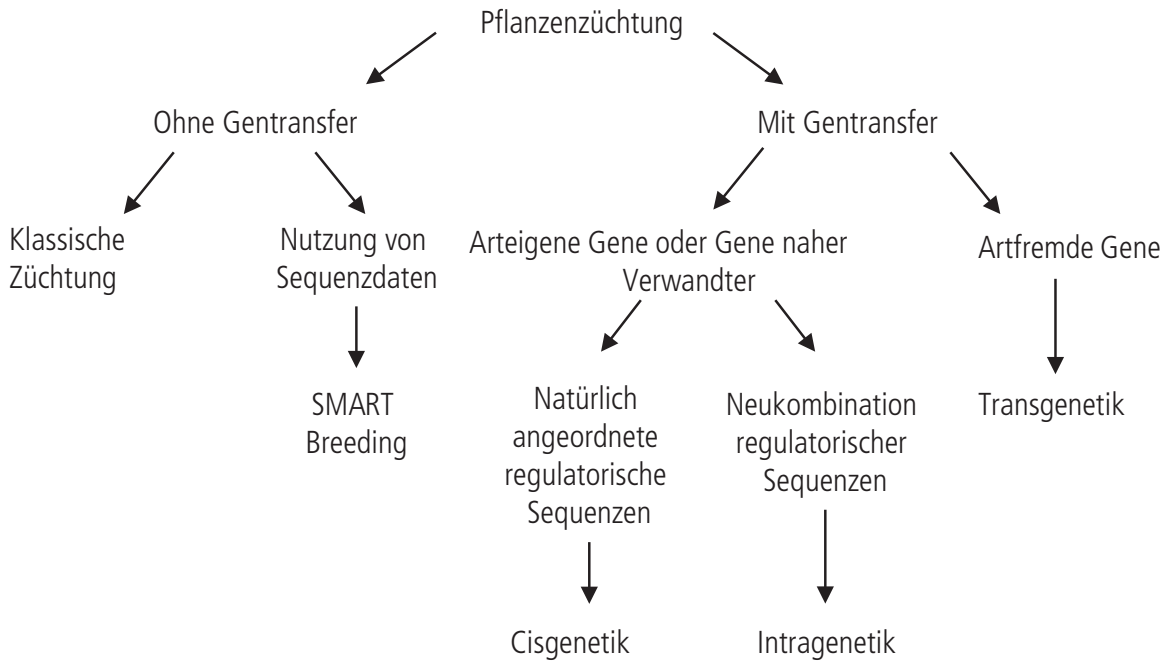

Quelle: leicht abgewandelt nach Müller-Röber et al., 2013:43.

Bisher werden weltweit keine cisgenen Pflanzen auf dem Markt angeboten. Es gibt jedoch inzwischen einige weit entwickelte Projekte, welche zeigen, dass die neuen Konzepte prinzipiell funktionieren. ${ }^{14}$ Deren Funktionalität wird derzeit in Freilandversu-

13 Eurobarometer-Untersuchungen sind Bevölkerungsumfragen, die seit 1973 in den Mitgliedstaaten der Europäischen Union durchgeführt werden, um Einstellungen der europäischen Bürgerinnen und Bürger zu ausgewählten Themen ermitteln zu können. Eurobarometer-Befragungen, die sich mit Aspekten der modernen Biotechnologie beschäftigen, wurden 1991, 1993, 1996, 1999, 2002, 2005 und zuletzt 2010 durchgeführt.

14 Es ist wahrscheinlich, dass zusätzlich zu den bereits veröffentlichten Studien zahlreiche Züchtungsversuche noch unveröffentlicht sind und möglicherweise Geheimhaltungspflichten in Firmeninteressen unterliegen (Holme et al $\mathrm{l}_{\mathrm{y}}$ 2.013). 
chen systematisch überprüft. Eine Übersicht über Freilandversuche mit cisgenen und intragenen Pflanzen in der EU und den USA bieten Holme et al. (2013).

Gearbeitet wird beispielsweise an der Entwicklung von Kartoffelsorten, die durch das Einbringen von mehreren Genen aus nah verwandten Arten resistent gegenüber Phytophthora infestans, dem Erreger der Kraut- und Knollenfäule, werden; über erste Erfolge wurde kürzlich berichtet (Jo et al., 2014). Um der unerwünschten Entstehung von Resistenzen auf Seiten des Krankheitserregers zu begegnen, wird dabei auch die Entwicklung austauschbarer Gen-Kassetten angestrebt, die die Züchtung immer neuer cisgener Pflanzen in Analogie zu den jährlich wechselnden Grippe-Impfstoffen für den Menschen ermöglichen sollen.

Eine weitere Kartoffelzüchtung ist in ihrem natürlichen Stärkeprofil (Amylose und Amylopektin) zugunsten industrieller Anwendungen verändert. Sie enthält einen hohen Amylopektin-Gehalt, da ein Gen in der Kartoffel stillgelegt wurde, welches für die Amylose-Synthese zuständig ist. Dies ist für Industrieprozesse interessant, da die Trennung der beiden Bestandteile der Kartoffelstärke, Amylose und Amylopektin, aufwendig und teuer ist. Die Kartoffelsorte „Modena“ wurde von der niederländischen Firma Avebe entwickelt und bereits seit 2002 in Freiland getestet. Die Sorte wurde 2011 an die Firma BASF verkauft, welche die Freilandversuche fortsetzte (Holme et al., 2013). BASF hat sich jedoch 2012 aus dem europäischen Pflanzenbiotechnologie-Markt weitestgehend zurückgezogen und stoppte Anfang 2013 laufende Zulassungsanträge in Europa, darunter auch den für „Modena“15.

Ein weiteres Beispiel ist die Entwicklung cisgener bzw. intragener Apfelsorten, die resistent gegenüber dem Apfelschorf sind, der durch den Pilz Venturia inaequalis hervorgerufen wird (Joshi et al., 2011; Vanblaere et al., 2011; Vanblaere et al., 2014). Diese werden seit 2011 in den Niederlanden getestet (Holme et al., 2013).

Bei Pappeln ist es gelungen, durch cisgene Veränderungen in den Stoffwechsel des Pflanzenhormons Gibberellinsäure einzugreifen, wodurch sowohl die Wachstumsrate, als auch die Morphologie und Holzeigenschaften von Keimlingen beeinflusst werden (Han et al., 2011).

Holme und Kollegen berichteten von der Entwicklung wirksamer Methoden zur Herstellung markerfreier, cisgener Gerste und der erfolgreichen Züchtung einer cisgenen Gerstenlinie mit erhöhter Aktivität des Enzyms Phytase. Dies führt bei den Pflanzen zu einer besseren Bioverfügbarkeit von Phosphat und soll bei damit gefütterten Tieren

15 www.basf.com/group/corporate/de/content/products-and-industries/biotechnology/plant-biotechnology/index [15.01.2014]. 
den Zusatz von Phosphaten in Futtermitteln reduzieren oder ersetzen (Holme et al., 2012). Seit 2012 wird diese Gerste in Dänemark im Freiland getestet (Holme et al., 2013).

In den USA und Kanada wurden 2013 Zulassungen für mehrere neue Produkte aus cisgenen Pflanzen beantragt. Hierzu gehören zum Beispiel die von der Firma Okanagan Specialty Fruits Inc. (OSF) entwickelten Arctic Äpfel, bei denen die Bildung des Enzyms Polyphenoloxidase (PPO) durch RNA-Interferenz (siehe Kapitel 7.2.7) unterdrückt wird. Das Enzym reguliert Oxidationsprozesse, die für die bräunliche Verfärbung angeschnittener oder angestoßener Äpfeln verantwortlich sind. PPO ist in den cisgenen Arctic-Äpfeln nicht oder nur in geringer Menge vorhanden, sodass diese nach dem Aufschneiden nicht mehr braun werden. Die Firma arbeitet nach eigenen Angaben aktuell an ähnlichen Konzepten für Birnen und Kirschen. ${ }^{16}$ Von der J. R. Simplot Company wurden Kartoffeln entwickelt, in denen ebenfalls die enzymatische Verfärbung unterbunden ist. Zusätzlich ist die Bildung von Asparagin und Einfachzucker in den Knollen - ebenfalls durch RNA-Interferenz - reduziert worden, was beim Erhitzen u. a. weniger gesundheitsschädliche Acrylamide entstehen lässt. Diese Sorten könnten 2015 oder 2016 auf den nordamerikanischen Markt kommen. Ob diese neuen Entwicklungen sich nach ihrer Zulassung auf dem Markt durchsetzen werden und ob sie auch Kritikerinnen und Kritiker überzeugen können, ist jedoch derzeit noch unklar.

\subsubsection{Plastidentransformation}

Gegenüber der gentechnischen Veränderung des Kerngenoms besitzt die Veränderung des Genoms von Plastiden (grüne Chloroplasten und andere nicht-grüne Plastiden) ${ }^{17}$ auch als Transplastomtechnologie bezeichnet - mehrere Vorteile:

1. Da Plastiden in den meisten Pflanzenarten mütterlich vererbt werden und somit nicht mit dem männlichen Pollen verbreitet werden, gelangt das Transgen in der Regel nicht ungewollt in die Umwelt. ${ }^{18}$ So lassen sich Auskreuzungen zwischen ge-

16 www.okspecialtyfruits.com/ [15.01.2013].

17 Chloroplasten sind Zellorganellen von Grünalgen und höheren Pflanzen, die Photosynthese betreiben. Neben den grün gefärbten Chloroplasten gibt es jedoch auch weitere Plastiden, wie die farblosen Leukoplasten oder die rot oder orange gefärbten Chromoplasten. Die Grenzziehung ist dabei fließend, da die unterschiedlichen Plastiden unter bestimmten Bedingungen ihre Zusammensetzung und damit Farbe ändern können.

18 Um zu verhindern, dass ein Transgen in die Umwelt gelangt, gibt es einerseits physikalische Maßnahmen (,transgene containment“, etwa Gewächshäuser, räumliche Trennung der Felder) oder biologische Maßnahmen (,transgene confinement"), wie etwa Terminatorgene, welche die Fortpflanzungsfähigkeit verhindern, oder auch die Plastidentransformation. 
netisch veränderten Pflanzen und konventionellen Varietäten oder deren nah verwandten Arten vermeiden.

2. Da jede Zelle mehrere Plastiden enthält und jedes Plastid viele Genome, lassen sich die von den eingebrachten Genen kodierten Proteine oft in großer Menge herstellen (hohe Proteinexpressionsstärke).

3. Es lassen sich mehrere Gene in sogenannten Operons (funktionellen Einheiten) koexprimieren.

4. Gene-Silencing-Effekte treten vermindert auf.

5. Ein weiterer Vorteil liegt darin, dass die für die Transformation eingesetzte DNA nicht zufällig in das Plastidengenom (Plastom) integriert wird, sondern mittels homologer Rekombination (Rekombination an DNA-Stellen mit ähnlicher DNASequenz), sodass der Integrationsort bekannt ist und unbeabsichtigte Positionseffekte reduziert werden (Day/Goldschmidt-Clermont, 2011; Gao et al., 2012).

Vorteile der Plastidentransformation ${ }^{19}$ wurden bereits im „Ersten Gentechnologiebericht" (Hucho et al., 2005) beschrieben. Inzwischen ist sie zu einer Technologie mit unterschiedlichen Anwendungen gereift. ${ }^{20}$ Bis heute sind bereits mehr als 50 verschiedene Transgene stabil in Plastidengenome integriert worden, weiterhin jedoch ist die gentechnische Modifikation der Plastidengenome von monokotylen Pflanzen, zu denen die wichtigen Getreidepflanzen wie beispielsweise Mais, Reis oder Weizen gehören, nicht möglich (Gao et al., 2012; Bock, 2014).

Die Transplastomtechnologie wird unter anderem für die Produktion von pharmakologisch relevanten Proteinen (Plant-Made Pharmaceuticals, PMPs, vgl. Kapitel 7.4.2) sowie von technischen (industriellen) Enzymen eingesetzt. Das Interesse an mittels Transplastomtechnologie erzeugten PMPs hat in den letzten Jahren stark zugenommen, jedoch befinden sich derzeit nur wenige PMPs in klinischen Studien (siehe Kapitel 7.4.2). Weiterhin bezieht sich die überwiegende Mehrheit der Publikationen im Berichtszeitraum auf die Modellpflanze Tabak; dies ist dadurch begründet, dass das Plastidengenom dieser Pflanze im Vergleich zu denen vieler anderer Pflanzen relativ leicht einer gentechnischen Modifikation zugänglich ist. Aufgrund von toxischen Alkaloiden im Tabak eignet er sich jedoch nicht für die orale Impfung. Kommerzielle Anwendungen der Plastidentransformation sind bislang noch in der Entwicklung, ein kommerzieller Anbau solcher Pflanzen erfolgt derzeit nicht (Maliga/Bock, 2011; Gao et al., 2012; Bock, 2014).

$19 \mathrm{Zu}$ Vorteilen siehe auch ausführlich Lössl/Waheed, 2011.

20 Eine Übersicht über aktuelle Entwicklungen bieten etwa Maliga und Bock, 2011; Scotti et al., 2012; Rigano et al., 2012; Gao et al.g 2012 sowie Venkatesh/Bark 2012.04.2023, 12:51:10 
Eine interessante Weiterentwicklung der Transplastomtechnologie stellt die Entwicklung von induzierbaren Expressionssystemen dar, welche das Transgen nur bei Anwesenheit eines bestimmten Reizes exprimieren, etwa während einer bestimmten Reifephase oder nach der Ernte. ${ }^{21}$ Diese Methoden könnten Verbraucherinnen und Verbraucher vor dem unfreiwilligen Verzehr pharmakologisch aktiver Proteine schützen.

\subsubsection{SMART Breeding und genomische Selektion}

Das auch als Präzisionszüchtung bekannte SMART Breeding (Selection with Markers and Advanced Reproductive Technologies) ist eine inzwischen etablierte Methode, um die Anwesenheit einzelner Gene und Genvarianten in Kreuzungsnachkommen mit molekularbiologischen Methoden zu testen. Beim SMART Breeding werden Pflanzen mit den erwünschten Genvarianten miteinander gekreuzt und anhand von molekularen Markern auf der Genomebene für die Weiterzüchtung ausgewählt.

Eine Variante des SMART Breeding von zunehmender Bedeutung stellt die genomische Selektion (,genomic selection“, im Folgenden: GS) 22 dar, bei der sehr viele, über das gesamte Genom verteilte Marker parallel untersucht werden, um den züchterischen Wert einer Pflanze abzuschätzen. Hierzu werden Einzelnukleotid-Polymorphismen ${ }^{23}$ als Marker verwendet, die sich heute sehr leicht technisch erfassen lassen.

Die kontinuierlich fallenden Kosten für Informationen, die durch DNA-Marker gewonnen werden können, haben den Einsatz der GS in den letzten Jahren finanziell attraktiv gemacht. Da gewünschte pflanzliche Eigenschaften wie ein verbesserter Ertrag und eine höhere Toleranz gegenüber (a-)biotischem Stress sehr komplex sind und im Regelfall nicht von einzelnen Genen gesteuert werden, ist die traditionelle markerassoziierte Selektion (MAS) für entsprechende Vorhersagen wenig geeignet, da diese sich auf bestimmte, mit einem Merkmal in Verbindung gebrachte Gene konzentriert. Im Gegensatz dazu werden bei der GS möglichst viele (sämtliche) über das gesamte Genom verteilte Markerinformationen genutzt und mit entsprechenden Eigenschaften verknüpft, womit prinzipiell weitaus genauere Züchtungsvorhersagen und die Berechnung von Züchtungswerten (,genomic estimated breeding values“, GEBVs/genomgestützte

21 Vgl. Lössl/Waheed, 2011, für eine Übersicht über induzierbare Systeme.

22 Vgl. zur Entwicklung der GS und ihrer Chancen in der Pflanzenzucht Jannink et al., 2010 und Nakaya/Isobe, 2012. Verschiedene Modelle in ihrer Umsetzung siehe Heslot et al., 2012. Einen Vergleich zwischen Hochdurchsatz-Phänotypisierung und genomischer Selektion bieten Cabrera-Bousquet et al., 2012.

23 Bei Einzelnukleotid-Polymorphismen (Single Nucleotide Polymorphisms, SNPs) handelt es sich um Basenaustausche auf der DNA-Sequenz (Mutationen), sodass verschiedene Zustandsformen (Allele) des betreffenden Gens vorliegen. 
Zuchtwertschätzung) möglich sind. ${ }^{24}$ So wird beispielsweise an der Entwicklung von Markern für die genomische Selektion von Gerste, Weizen, Roggen, Zuckerrübe und anderen Kulturpflanzen geforscht (Poland et al., 2012; Würschum et al., 2013; Daetwyler et al., 2014; Wang et al., 2014; für einen aktuellen Übersichtsartikel siehe Desta und Ortiz, 2014). GS ist auch bei Pflanzen von großem Interesse, die lange Generationszyklen haben, wie zum Beispiel Obstbäume.

\subsubsection{TILLING}

Nach der gescheiterten Einführung der gentechnisch veränderten Kartoffel Amflora ${ }^{25}$ des Unternehmens BASF gewinnt die Züchtungsmethode TILLING (Targeting Induced Local Lesions In Genomes) an Bedeutung. Mit dieser Methode ist es dem FraunhoferInstitut für Molekularbiologie und Angewandte Ökologie (Aachen) in Zusammenarbeit mit den Firmen Bioplant (Ebstorf) und Emslandstärke (Emlichheim) gelungen, eine Amylose-freie Kartoffel herzustellen, die in ihren Eigenschaften der Amflora-Kartoffel ähnelt, jedoch nicht als gentechnisch verändert gilt (Muth et al., 2008). Den Grund hierfür stellt die Tatsache dar, dass beim TILLING kein fremdes Gen eingeführt wird, sondern durch bestimmte physikalische und chemische Reize Mutationen in den arteigenen Genen ausgelöst werden. Die „TILLING-Kartoffel“ darf auch von Rechts wegen unbegrenzt auf deutschen Äckern angebaut werden. ${ }^{26}$

Beim Vergleich mit der Gentechnik zeigen sich aber auch die Grenzen der TILLINGMethode. Durch die Behandlung der Pflanzen mit mutagenen Chemikalien entsteht eine Vielzahl von Punktmutationen, die über das gesamte Genom verteilt sind. Dies hat zur Folge, dass viele Gene betroffen sind und potenziell in ihrer Funktion verändert werden. Die behandelten Pflanzen können somit auch erwünschte Eigenschaften, etwa Ertrags- und Leistungsfähigkeit, verlieren. In diesen Fällen müssen Züchter daher nach der Mutagenese Pflanzen mit der erwünschten Punktmutation im Ziel-Gen erst mit

24 GEBVs sind Bewertungen, die durch mathematische Berechnungen den einzelnen Haplotypen oder auch dem erwarteten Phänotyp der Pflanze zugeordnet werden können und die dann zur Grundlage der Zuchtentscheidungen herangezogen werden.

25 Amflora ist eine transgene Kartoffel, deren Stärkeprofil für industrielle Anwendungen gentechnisch verändert wurde. Sie wurde 2010 in der EU zugelassen und lediglich auf kleineren Flächen in einigen Ländern angebaut. BASF Plant Science stellte jedoch mit seinem Rückzug aus dem europäischen Markt (siehe Kapitel 7.2.4) auch die Vermarktung von Amflora ein. Die Anbauzulassung in der EU wurde Ende 2013 widerrufen, unter: http://europa.eu/rapid/press-release_CJE-13-160_en.htm [15.01.2014].

26 www.fraunhofer.de/presse/presseinformationen/2009/12/super-kartoffel.jsp [15.01.2014]. 
Hochleistungssorten rückkreuzen, um wieder ertragreiche Pflanzen zu erhalten. Diese Prozedur benötigt in der Regel mehrere Jahre.

Eine weitere Beschränkung der TILLING-Methode bildet die Tatsache, dass nur Eigenschaften verändert werden, die auf den pflanzeneigenen Genen beruhen. Eine Insektenresistenz wie bei gentechnisch veränderten Bt-Pflanzen kann nicht erzeugt werden. Bei einigen Pflanzenarten fehlen entsprechende Gene für Resistenzen gegen Pilzkrankheiten oder Dürretoleranz, zwei wichtige Züchtungsziele. Auch die Einführung neuer Stoffwechselwege zur Produktion neuer Inhaltsstoffe ist mit TILLING nicht zu erreichen.

Trotz seiner Nachteile ist TILLING ein wichtiges Werkzeug in der Pflanzenzüchtung geworden (Wang et al., 2012; Chen et al., 2014; Sharp und Dong, 2014). In der Entwicklung befinden sich weltweit salzresistente Tomaten, dürreresistente Sojabohnen, länger haltbare Erdbeeren, glutenfreier Weizen oder pilzresistente Gerste. TILLING-Populationen wurden bereits für eine Vielzahl von Nutzpflanzen beschrieben, darunter Tomate, Speiserübe, Weizen, Gerste, Sonnenblume oder Reis. ${ }^{27}$

\subsubsection{Reverse Breeding}

Pflanzenhybride, die aus einer Kreuzung zweier homozygoter Elternpflanzen entstehen und heterozygot sind, weisen oft besonders vorteilhafte Ertragseigenschaften im Vergleich zur Elterngeneration auf, was auch als Heterosis-Effekt bezeichnet wird (Dirks et al. 2009). Dabei sind jedoch die Eigenschaften der entstehenden Hybride nur schwer vorherzusagen. Außerdem lassen sich nicht charakterisierte Hybride mit klassischen Methoden nur unzuverlässig reproduzieren, da ihr Erbmaterial bei Rückkreuzungen natürlichen Rekombinationsvorgängen (Durchmischung der mütterlichen und väterlichen Chromosomen sowie interchromosomales „Crossover“, s. u.) unterworfen ist und ertragssteigernde Heterosis-Effekte damit verloren gehen.

Als „reverse breeding“ (RB) wird eine neue Züchtungsmethode bezeichnet, mit der das Genom eines als erfolgreich ausgewählten Hybrids so fixiert werden kann, dass seine positiven Eigenschaften erhalten bleiben. Dabei werden Elternlinien erzeugt, mit denen genau diese heterozygote Pflanze wieder erzeugt werden kann.

Beim RB werden zunächst durch Kreuzung homozygoter Elternlinien Populationen von heterozygoten Nachkommen erzeugt und auf ihre Eigenschaften hin untersucht. Die besten Hybriden werden für die weitere Züchtung ausgewählt und reproduziert.

27 Eine Übersicht über TILLING-Populationen für verschiedene Modell- und Nahrungspflanzen und öffentlich zugängliche TILLING-Plattformen und -Dienstleistungen bieten Kurowska et al., 2011, sowie Chen et al., 2014 
Erreicht wird dies in zwei Schritten: Zuerst werden durch die Unterdrückung des meiotischen Crossovers $^{28}$ nicht-rekombinierte Chromosomen auf die Keimzellen verteilt. Diese Keimzellen können dann in einem zweiten Schritt in vitro kultiviert und durch Verdoppelung der Genome zur Erzeugung doppelt-haploider ${ }^{29}$ (DH) und damit homozygoter Linien genutzt werden. Die so entstehenden DHs werden dann miteinander gekreuzt, um den gewünschten heterozygoten Genotyp (Ausgangsgenotyp) zu erhalten. So konnten im Rahmen einer Proof-of-Concept-Studie anhand der Modellpflanze Arabidopsis thaliana homozygote Elternlinien aus einem Hybridindividuum gewonnen werden (Wijnker et. al., 2012; Wijnker et. al., 2014).

Wendet man dieselbe Technologie bei bereits bekanntem genetischen Hintergrund an, lassen sich Linien züchten, in denen nur ein einziges Chromosom homozygot oder nur ein einziges Chromosom heterozygot ist (Chromosomen-Substitutionslinien). Nachkommen dieser Linien unterscheiden sich dann nur in Merkmalen, die durch dieses eine Chromosom beeinflusst werden (Dirks et al., 2009).

\subsubsection{Trait Stacking}

In den letzten Jahren hat der Anbau von transgenen Pflanzen mit mehr als einem veränderten Merkmal (,stacked traits“) stark zugenommen (Que et al., 2010). ${ }^{30}$ Mehrere gentechnisch veränderte Eigenschaften wie zum Beispiel Herbizidtoleranz und Schädlingsresistenz sind hier in einer Pflanze kombiniert.

Die meisten dieser Pflanzen mit „stacked traits“ sind durch Kreuzung unterschiedlicher transgener Sorten mit jeweils eigenen, agronomisch relevanten Eigenschaften

28 Bei der Entstehung der Keimzellen (Gameten) kommt es in einem als Meiose (Reduktionsteilung) bezeichneten Prozess zur sogenannten intrachromosomalen Rekombination, also zum Austausch von Chromosomenabschnitten zwischen homologen Chromosomen von Mutter- und Vaterpflanze („,crossing over"). Dadurch weichen die entstehenden Tochterchromosomen von denen der Eltern ab. Beim „reverse breeding“ wird dieser Prozess unterdrückt, sodass die Chromosomen auch in den Keimzellen so bleiben wie in der Elternpflanze. Der während der Meiose entstehende einfache (haploide) Chromosomensatz muss dann noch verdoppelt werden (doppelt haploider Chromosomensatz), um Pflanzen für die Weiterzucht zu erhalten. Die Unterdrückung des Crossovers kann auf verschiedene Weise erreicht werden, etwa durch die Auswahl von Pflanzen mit Mutationen in den entsprechenden Genen, durch die Stilllegung von Genen mittels RNAi (siehe Kap. 7.2.7) oder durch Virus-vermittelte Genstillegung (Dirks et al., 2009).

29 Ein einfacher Chromosomensatz wird als haploid, der normale von zwei Elternteilen stammende als diploider Chromosomensatz bezeichnet. Doppelt-haploid ist der Satz, da der in der Keimzelle vorliegende haploide Satz verdoppelt wurde, um auf einen doppelten Chromosomensatz zu kommen, der für die Weiterzüchtung wichtig ist.

30 http://wwwisaaa.org/resources/publications/briefs//16/executivesummary/ [14.07.2014]. 
(,events“) entstanden, daher werden sie auch als „breeding stacks“ bezeichnet (Que et al., 2010). Vorteile dieser Methode sind die Flexibilität in der Neukombination und eine gute Effizienz. Durch Auswahl geeigneter Sorten können an lokale Bedingungen angepasste neue Sorten entwickelt werden. Der Nachteil liegt jedoch darin, dass die Einkreuzung mehrerer Merkmale zeitintensiv und teuer ist.

Eine neue Entwicklung im „trait stacking“ ist die Verwendung von in vitro hergestellten DNA-Bausteinen - sogenannte ,transgene arrays “ oder auch „molecular stacks“ - mit denen multiple Transgene mittels verschiedener Methoden in eine Zielpflanze eingebracht werden können (Bock, 2013). Hierzu werden zum Beispiel künstlich hergestellte und nicht in das Pflanzengenom integrierende Minichromosomen benutzt. ${ }^{31}$

In einigen Ländern gibt es teilweise niedrigere Hürden bei der Zulassung gentechnisch veränderter Pflanzen mit kombinierten Merkmalen. ${ }^{32}$ Wie diese Pflanzen regulatorisch behandelt werden sollen und ob sie ebenso streng getestet werden sollen wie andere transgene Pflanzen, auch wenn sie durch konventionelle Kreuzung zwischen zwei bereits getesteten Linien entstehen, ist umstritten (Pilacinski et al., 2011).

Gerade beim "trait stacking“ kommt der Entfernung der verwendeten Selektionsmarker eine besondere Bedeutung zu (siehe Kapitel 7.2.6), da es in aufeinanderfolgenden Selektionsschritten sonst zu einer Anreicherung der verschiedenen Marker im Genom führen kann (Tuteja et al., 2012).

Der International Service for the Aquisition of Agri-Biotech Applications (ISAAA) schätzt, dass 2013 GV-Pflanzen mit „stacked traits“ auf insgesamt 47,1 Millionen Hektar angebaut wurden - das entspricht mittlerweile einem Anteil von 27 \% an der Gesamtfläche von 175 Millionen Hektar der kommerziell angebauten GV-Pflanzen in 2013. ${ }^{33}$ Vor allem die USA nutzen transgene Pflanzen mit kombinierten Merkmalen. In 2012 wurden 70 \% aller ,stacked traits“ dort angebaut, mit Abstand folgten Brasilien (12,8\%) und Argentinien (3,4\%). ${ }^{34}$

31 Eine Übersicht über die historische Entwicklung und Möglichkeiten dieser Methode bieten Gaeta und Krishnaswamy (2011), Dhar et al. (2011) sowie Gaeta et al. (2012).

32 In den USA benötigt eine Kreuzung aus zwei zugelassenen Events keine weitere Zulassung. In der EU hingegen ist eine eigene Zulassung als neuer gentechnisch veränderter Organismus (GVO) notwendig.

33 ISAAA Pocket K No. 42: Stacked Traits in Biotech Crops. Unter: www.isaaa.org. [20.01.2014]. Siehe auch http://www.isaaa.org/resources/publications/briefs/46/executivesummary/ [14.07.2014].

34 ISAAA Biotech Traits Annual Updates 2013. Unter: www.isaaa.org/resources/publications/ biotech_traits_annual_updates/download/Biotech\%20Traits\%20Annual\%20Updates\%202013.pdf [20.01.2014]. 
Ein Beispiel für eine Neuentwicklung ist eine seit 2010 in den USA gehandelte ${ }^{35}$ Maispflanze mit acht veränderten Genen, die von den Firmen Monsanto und Dow Agrosciences entwickelt wurde, unter dem Namen „SmartStax“ vermarktet wird und seit November 2013 auch in der EU zugelassen ist. ${ }^{36}$ Sie entstand aus Kreuzungen verschiedener Biotech-Maislinien und kombiniert zwei Herbizidtoleranzgene mit sechs BtGenen, welche den Pflanzen verschiedene Insektenresistenzen verleihen.

\subsubsection{RNA-Interferenz und Micro-RNAs}

RNA-Interferenz (im Folgenden: RNAi) ist ein sequenzspezifischer Mechanismus der Genstilllegung („gene silencing“), der durch kleine RNAs („small interfering RNAs“, siRNAs) moderiert wird, die sich an Boten-RNAs (mRNAs) anlagern und zu deren Abbau führen oder deren Translation blockieren. RNAi ist ein natürlicher Mechanismus, der in allen höheren Organismen zur Genregulation sowie zur Abwehr von Krankheitserregern beiträgt (Jagtap et al., 2011). Die Entdeckung von RNAi gilt als Durchbruch für die Verbesserung von Pflanzeneigenschaften. RNAi wird heute zum Beispiel zur Etablierung der Resistenz gegen Pflanzenparasiten eingesetzt (Runo, 2011; Runo et al., 2011) ${ }^{37}$ und für die Optimierung anderer pflanzlicher Eigenschaften wie beispielsweise die Steigerung der Trockentoleranz diskutiert (Kumar et al., 2014).

Es besteht die Hoffnung, dass RNAi-Strategien in der Öffentlichkeit besser akzeptiert werden könnten als bisherige transgene Pflanzen, da sie zu einer spezifischeren, dominanten und sequenzbasierten Genregulierung genutzt werden könnten (Jagtap et al., 2011) und sich für cis- bzw. intragenische Ansätze eignen. Ein Beispiel für eine am Verbraucher orientierte Entwicklungsrichtung ist die Unterdrückung der Expression von bekannten Lebensmittel-Allergenen, zum Beispiel in Äpfeln, Tomaten und Erdnüssen (ebd.). Weitere Anwendungen sind Änderungen des Pflanzenaufbaus, biotische und abiotische Stresstoleranz, verbesserte Inhaltsstoffe, Reduzierung von Giftstoffen, verlängerte Haltbarkeit, verändertes Aussehen, Entwicklung männlich-steriler Linien, kernlose Früchte sowie die Optimierung sekundärer Metabolite (Jagtab et al., 2011; Katoch/Thakur, 2013).

Eine weitere Klasse von kleinen RNAs stellen die sogenannten Mikro-RNAs (miRNAs) dar. Der Kenntnisstand über die elementare regulatorische Bedeutung von miRNAs hat im Berichtzeitraum beträchtlich zugenommen. ${ }^{38}$ Auch die Bandbreite der aufgedeck-

35 www.transgen.de/aktuell/1165.doku.html [20.01.2014].

36 www.transgen.de/zulassung/gvo/137.doku.html [21.01.2014].

37 Eine Übersicht über die Nutzung von RNAi für die Pflanzenbiotechnologie bieten Jagtap et al., 2011. Vgl. zur historischen Einordnung der RNAi-Technologie in Pflanzen Lindbo, 2012.

38 Vgl. hierzu ausführlich Xie et al, 2012 . 
ten physiologischen Prozesse, die durch miRNAs reguliert werden, hat stark zugenommen, darunter Blattentwicklung, Keimzellentwicklung, Blütenbildung, Samen- und Fruchtbildung, Zellzyklus-Regulation, DNA-Methylierung, Alterungsprozesse, Wurzelentwicklung und die Toleranz gegenüber abiotischem und biotischem Umweltstress (Khraiwesh et al., 2012; Sun et al., 2014; Zhang und Wang, 2014).

Eine wesentliche Neuerung war die Entwicklung künstlicher Mikro-RNAs (,artificial micro RNAs“, amiRNAs). Dabei werden in vitro erzeugte genspezifische miRNA-Vorläufer mittels Transformation in Pflanzen eingebracht, wo sie zu einem Abbau des entsprechenden Zieltranskripts führen. ${ }^{39}$ Diese Methode hat sich als Alternative zu den bisherigen Methoden für eine Gensuppression (Antisense-Technik und RNAi) etabliert und besitzt gegenüber diesen den Vorteil einer oft höheren Spezifität beim Abbau der Zieltranskripte (Sablok et al., 2011). Vereinfachte Methoden zur Herstellung von amiRNAs wurden von Wang et al., 2012 und Zhou et al., 2013 publiziert. Eine Übersicht über die mögliche Verwendung von miRNAs für die Optimierung von Nutzpflanzen geben Zhang und Wang, 2014.

\subsection{Wichtige Hilfstechnologien}

Die rasanten Fortschritte in der Pflanzenbiotechnologie wurden erst durch die Entwicklung verschiedener Technologien und neuer Forschungsbereiche möglich, die daher in diesem Zusammenhang auch als Hilfstechnologien oder -wissenschaften bezeichnet werden können. Diese Bezeichnung soll jedoch keinesfalls darüber hinwegtäuschen, dass es sich um eigenständige Entwicklungsfelder handelt, die auch in zahlreichen anderen Kontexten, wie in der medizinischen Forschung oder der industriellen Biotechnologie, von großer Relevanz sind.

\subsubsection{Chemical Genetics}

Der Begriff „chemical genetics“ beschreibt ein relativ neues Arbeitsgebiet in den molekularbiologisch orientierten Wissenschaften. Dabei werden niedermolekulare, bioaktive Moleküle (,small molecules“) verwendet, um die zelluläre Funktion von Proteinen zu verändern und damit die biologische Rolle dieser Zielproteine aufzudecken. Die kleinen Moleküle können Naturstoffe oder chemisch synthetisierte Verbindungen sein. In Verbindung mit modernen „omics“-Ansätzen, wie etwa Hochdurchsatz-Screenings, Next Generation Sequencing, Phänotypisierung und dem Einsatz von molekularbiolo-

39 Vereinfachte Methoden zur Herstellung von amiRNAs wurden von Wang et al., 2012 und Zhou et al., 2013 publiziert. 
gischen Datenbanken wird auch der Begriff „chemical genomics“ verwendet (Hicks/ Raikhel, 2012; Sadhukhan et al., 2012; Rodriguez-Furlán et al., 2014).

Vom Prinzip her erlauben kleine Moleküle eine schnelle, kontrollierte und reversible Änderung von biologischen Funktionen, ihre Verwendung kann daher andere und oft komplementäre Informationen zu klassischen genetischen Studien liefern. Kleine Moleküle können aber auch Einschränkungen von genetischen Ansätzen umgehen wie Letalität, funktionelle Redundanz oder pleiotrope Effekte ${ }^{40}$ - die man oft in genetischen Mutanten findet. Aufgrund komplexer Vorgänge - wie beispielsweise dem alternativen Splicing von prä-mRNAs und der posttranslationalen Modifikation von Proteinen - übersteigt die Anzahl der Proteine, die mögliche Angriffspunkte kleiner Moleküle sein können, die Anzahl der Gene im Organismus. Daher kann eine größere Zahl unterschiedlicher Phänotypen erzeugt werden. Mit kleinen Molekülen kann die Aktivität von Proteinen reversibel verändert werden, sodass in vivo und in Echtzeit Phänotypen generiert werden können, die über eine dauerhafte genetische Änderung nicht möglich wären (Hicks/Raikhel, 2012; Rodriguez-Furlán et al., 2014).

Mit der Weiterentwicklung von automatisierten Methoden und der Datenverarbeitung bieten sich schon jetzt völlig neue Möglichkeiten, wie etwa die Untersuchung ganzer regulatorischer Netzwerke. So wurden bereits recht umfangreiche Protein-ProteinInteraktionsnetzwerke in Pflanzen identifiziert (Arabidopsis Interactome Mapping Consortium, 2011; Mukhtar et al., 2011).

\subsubsection{Next Generation Sequencing}

Mit den technischen Fortschritten, die in den letzten Jahren auf dem Gebiet der Mikrofluidik, Nanotechnologie und Informatik gemacht wurden, kamen auch innovative Sequenzierungstechnologien auf den Markt. Dabei werden generell alle neuen Verfahren, die sich von der herkömmlichen Sanger-Technologie ${ }^{41}$ unterscheiden, als „next

40 Von Letalität spricht man, wenn eine genetische Mutation tödlich wirkt. Wenn dies zum Beispiel in der Embryonalentwicklung geschieht, können Wirkungen auf den adulten Organismus nicht erforscht werden, weil der Organismus dieses Stadium nie erreicht. Kleine Moleküle können stattdessen in jedem Lebensalter verabreicht werden, sodass auch solche Effekte untersucht werden können. Funktionell redundante Mutationen sind solche, deren Effekte durch andere Mutationen oder Stoffwechselwege kompensiert werden können. Von pleiotropen Effekten spricht man, wenn eine Mutation mehrere Merkmale beeinflusst.

41 Die konventionelle Sequenzierung von DNA-Molekülen (nach der sog. Kettenabbruchmethode) wurde bereits in den 70er-Jahren entwickelt (Sanger et al., 1977). Auch wenn die Methode über die Jahrzehnte hinweg weiterentwickelt wurde, ist sie im Vergleich zu den NGS-Plattformen arbeits- und zeitintensiv und mit einem Vielfachen an Kosten verbunden 6.04.2023, 12:51:10 
generation sequencing“ (im Folgenden: NGS) bezeichnet. NGS-Verfahren überzeugen mit einer wesentlich höheren Geschwindigkeit und höherem Probendurchsatz bei vergleichsweise geringeren Kosten für Sequenzierungen.

NGS-Verfahren haben in den letzten Jahren eine kaum noch wegzudenkende Rolle in der Pflanzenforschung eingenommen, und zwar in unterschiedlichen Anwendungsbereichen, von der Neu- und Resequenzierung pflanzlicher Genome über die Analyse epigenetischer Prozesse bis hin zur Untersuchung von Genaktivitätsmustern auf Genomebene (RNA-seq). Schon heute stehen die Referenzgenome vieler Modell- und Kulturpflanzen für die biologische Forschung und die Pflanzenzüchtung zur Verfügung. In aktuellen Arbeiten wurden beispielsweise die Genome der Fichte (Picea abies; Nystedt et al., 2013), des Spanischen Pfeffers (Capsicum annuum; Kim et al., 2014), der Bohne (Phaseolus vulgaris; Schmutz et al., 2014), des Gemüsekohls (Brassica oleracea; Liu et al., 2014), oder der Europäischen Birne (Pyrus communis; Chagné et al., 2014) publiziert. Eine Übersicht über den Stand der Sequenzierung von Pflanzengenomen bieten verschiedene Webseiten. ${ }^{42}$

Auch die Charakterisierung von pflanzlichen Pathogenen oder wachstumsfördernden Mikroorganismen auf Genomebene hat in den letzten Jahren erheblich an Schub gewonnen (für aktuelle Beispiele siehe z. B. Hane et al., 2014; Srivastava et al., 2014). Außerdem kann mittels NGS gezielt nach Genen gesucht werden, die dann zur Verbesserung von Nutzpflanzen oder Mikroorganismen genutzt werden können (Schneeberger/ Weigel, 2011).

Auf dem Gebiet der Genexpressionsanalyse hat sich NGS durch stetig fallende Kosten zur Methode der Wahl entwickelt und ist derzeit dabei, Microarray-basierte Expressionsanalysen abzulösen. Innerhalb kürzester Zeit hat die Zahl der RNA-seq-Studien eine kaum noch zu überblickende Vielfalt angenommen. Der Vorteil der NGS-basierten Verfahren gegenüber Microarray-basierten Techniken ist dabei, das Erstere nicht auf vorab definierte Detektionssonden eingeschränkt sind, sondern prinzipiell „offen“ sind für die Identifizierung aller, d. h. auch zuvor unbekannter, Transkripte. Die Fortschritte im „next generation sequencing“ ermöglichen nun auch die Rekonstruktion vollständiger Transkriptome ${ }^{43}$ sogar dann, wenn ein Referenzgenom noch nicht verfügbar ist (Martin/Wang, 2011). Dabei müssen jedoch die vielen Milliarden oft sehr kurzen RNAseq-Sequenzen zu einem Transkriptom zusammengesetzt werden.

42 www.phytozome.net [14.07.2014]. http://genomevolution.org/wiki/index.php/Plant_Genome_ Statistics [21.01.2014] und http://genomevolution.org/wiki/index.php/Sequenced_plant_genomes [21.01.2014].

43 Mit herkömmlichen Methoden konnten oft nur Teil-Transkriptome erstellt werden (Martin/ Wang, 2011). 
Aber auch auf dem wachsenden Forschungsfeld der Epigenetik und Epigenomik (siehe Kapitel 3) spielt NGS eine große Rolle - auch speziell für die Pflanzen-Epigenetik. Eine Zusammenfassung der Analysen genomweiter DNA-Methylierungsmuster durch NGS geben Schmitz und Zhang (2011). ${ }^{44}$ Beispiele für die funktionelle Bedeutung der DNA-Methylierung in Pflanzen finden sich in Niederhuth und Schmitz (2014).

NGS-Technologien werden seit einigen Jahren auch zur Bestimmung von Quantitativen Trait Loci (QTL) genutzt. QTL sind Chromosomen-Regionen, die einen nachgewiesenen Einfluss auf quantitative phänotypische Merkmale ${ }^{45}$ haben. QTL-Analysen werden mit einer Vielzahl von Individuen durchgeführt. Dabei werden genetische Marker mit der Ausprägung eines ausgewählten Merkmals korreliert. Als Marker dienen Polymorphismen (Sequenzvariationen). QTL-Analysen wurden zum Beispiel für die Biofortifizierung (Anreicherung von Mikronährstoffen) von Maiskörnern durchgeführt (Simić et al., 2012, siehe Kapitel 7.4.5). Weitere Beispiele sind die Erforschung von QTL zur Trockentoleranz von Maispflanzen (Rahman et al., 2011) oder auch zur Ertragssteigerung von Reis (siehe Miura et al., 2011 für eine Übersicht).

\subsubsection{Genetische Genomik}

Als genetische Genomik (,genetical genomics“) wird die Kombination aus Genetik und Genexpressionsanalysen bezeichnet. Sie ermöglicht die Analyse regulatorischer Netzwerke und erlaubt es, Genotyp-Phänotyp-Korrelationen zu analysieren (Flassig et al., 2013). Dabei werden sogenannte „expression QTLs“ (eQTLs) erstellt, welche es ermöglichen, phänotypische Variation mit genotypischer Diversität zu verbinden (Joosen et al., 2009). So können Stoffwechselwege oder Entwicklungsprozesse aufgeklärt werden. Ansätze der genetischen Genomik wurden zunächst in der Modellpflanze Arabidopsis thaliana erprobt und auch bei Nutzpflanzen wie Eukalyptus, Weizen oder BrassicaArten eingesetzt (Joosen et al., 2009; Xiao et al., 2014). Auch die komplexen Wechselwirkungen zwischen molekulargenetischen Faktoren und der Umwelt, die die Genexpression beeinflussen, können aufgedeckt werden, wenn „genetical genomics“-Studien unter unterschiedlichen Umweltbedingungen wiederholt werden (Snoek et al., 2013; Joosen et al., 2013). So konnte gezeigt werden, dass die Veränderung der Lichteinstrah-

44 Für Übersichtsarbeiten zu epigenetischen Regulierungen und transgenerationaler Vererbung bei Pflanzen siehe Hauser et al., 2011; zu DNA-Methylierungen bei Pflanzen siehe Vanyushin/Ashkapin, 2011. Vgl. Richards, 2011 für natürlich vorkommende epigenetische Variationen in Wildpopulationen von Pflanzen.

45 Quantitative phänotypische Merkmale, wie z. B. Gewicht oder Durchmesser, variieren graduell und damit messbar zwischen einzelnen Individuen im Gegensatz zudiskreten qualitativen Merkmalen. 
lung (Schatten) zu Genotyp-Umwelt-Interaktionen führte, die mit einer veränderten Genexpression in bestimmten Genregionen einhergingen (Snoek et al., 2013). Phänotypische Variationen sind also sowohl genetisch determiniert als auch abhängig von Umweltbedingungen sowie Genotyp-Umwelt-Interaktionen (ebd.).

Auch in Deutschland werden Untersuchungen durchgeführt, die auf diese Methode zurückgreifen. Ein Beispiel ist das Verbundvorhaben FraGENOMIC ${ }^{46}$ zur Verbesserung der ernährungsphysiologischen Qualität der Erdbeerfrucht, das im Rahmen der translationalen Förderinitiative PLANT-KBBE ${ }^{47}$ von 2009 bis 2012 vom BMBF gefördert wurde.

\subsubsection{Selektierbare Marker}

In der Vergangenheit wurde zum Nachweis erfolgreicher Integration eines fremden DNA-Konstruktes ins Pflanzengenom auch auf Antibiotikaresistenz-Gene zurückgegriffen, die als Marker mit dem Konstrukt zusammen in die Pflanze eingebracht wurden. Da die gesundheitliche Unbedenklichkeit dieser Marker jedoch umstritten war, werden derzeit überwiegend alternative Markergene - die zum Beispiel für Herbizidtoleranzen codieren - verwendet.

Die Anzahl an selektierbaren Markern, die nicht auf einer Antibiotikum- oder Herbizidresistenz beruhen, hat im Untersuchungszeitraum beträchtlich zugenommen. Inzwischen sind für Pflanzen bereits mehr als 50 Markergene beschrieben worden (Manimaran et al., 2011; Rosellini, 2011; Tuteja et al., 2012). ${ }^{48}$

Neben der Verwendung alternativer Markergene kommt auch der Erzeugung markerfreier transgener Pflanzen eine steigende Bedeutung zu. Hierbei wird das verwendete Selektionsmarker-Gen durch unterschiedliche Mechanismen nach erfolgter Transformation wieder aus dem Genom entfernt (Khan et al., 2011; Yau/Stewart, 2013). ${ }^{49}$ Das nachträgliche Ausschneiden von Markern wird besonders für die Weiterentwicklung von „stacked traits“ eine wichtige Rolle spielen (vgl. Kapitel 7.2.6).

46 www.kooperation-international.de/detail/info/plant-kbbe-verbundvorhaben-genetische-genomik-zur-verbesserung-der-ernaehrungsphysiologischen-quali.html [20.01.2014].

47 PLANT-KBBE (Transnational PLant Alliance for Novel Technologies - towards implementing the Knowledge-Based Bio-Economy in Europe) ist eine seit 2003 bestehende, translationale Förderinitiative zwischen Deutschland, Frankreich, Portugal und Spanien mit dem Ziel, anwendungsnahe Forschungsprojekte in der Pflanzenbiotechnologie voranzutreiben. Laut BMBF war bzw. ist Deutschland hier mit ca. 100 Teilprojekten beteiligt, unter: www.bmbf.de/de/19748.php [20.01.2014].

48 Eine tabellarische Übersicht über die Entwicklung markerfreier Pflanzen mit Angaben der Publikationen (Stand: 2011, mehr als hundert Publikationen seit 1985) bieten Tuteja et al., 2012.

49 Eine anschaulich bebilderte Erläuterung dieser und anderer Methoden bieten Tuteja et al., 2012. 


\subsubsection{TALENs und CRISPR-Cas: Gezielte Eingriffe ins Genom}

Natürlich auftretende Mutationen sind eine Grundvoraussetzung für die Weiterentwicklung von Pflanzenarten. Traditionelle Zuchtverfahren, die die natürliche Mutationsrate - zum Beispiel durch Verwendung von bestimmten Chemikalien oder Röntgenstrahlung - künstlich erhöhen, kommen zwar ohne den Einsatz von Gentechnik aus, aber erlauben nur zufällige Erbgutveränderungen. Die Entwicklung neuer Sorten gestaltet sich damit zeitaufwendig. Eine bereits erwähnte Weiterentwicklung stellt hier das TILLING dar (vgl. Kapitel 7.2.4), bei dem die klassische - zufällige - Mutagenese mit einem effizienten Hochdurchsatz-Selektionssystem kombiniert wird.

In den letzten Jahren sind innovative Methoden gereift, die es ermöglichen, präzise Eingriffe in das pflanzliche Genom vorzunehmen. Diese molekularbiologischen Methoden bieten den grundsätzlichen Vorteil, dass die Veränderungen in der Erbinformation zielgenau (d. h. an zuvor definierten Positionen im Genom) durchgeführt werden können.

\section{TALENS}

Ganz neue Möglichkeiten der zielgerichteten Genomänderung bieten die sogenannten TALEs („transcription activator-like effectors“). TALEs sind Proteine, die für bestimmte pflanzenpathogene Bakterien beschrieben wurden. Sie haben eine charakteristische Struktur, die es ihnen erlaubt, an ausgewählte DNA-Sequenzen im Kerngenom der befallenen Wirtspflanzen zu binden und darüber die Expression von Genen zu modulieren. Der Bindungsmechanismus ist mittlerweile so weit verstanden, dass künstliche TALEs für spezifische DNA-Sequenzen maßgeschneidert werden können. Gekoppelt mit aktiven Bereichen von Enzymen können sie für unterschiedliche molekularbiologische Anwendungen sequenzspezifisch eingesetzt werden. So entstehen beispielsweise durch Fusion von TALEs mit einer Schnittfunktionseinheit („cleavage domain“) der FokI-Nuklease ${ }^{50}$ sogenannte TALE-Nukleasen (TALENs). TALENs generieren gezielt Doppelstrangbrüche im Genom des Zielorganismus, die durch interne Reparaturmechanismen dann zu gezielten Genomänderungen führen.

TALENs werden als eine Möglichkeit zur Erzeugung nicht-transgener, aber genetisch modifizierter Organismen gesehen. Eine Übersicht über die Nutzung dieser Technologie für die Erzeugung genetisch modifizierter Nutzpflanzen bieten Mahfouz und Li (2011) sowie Chen und Gao (2013). Zur Methodik der Erzeugung sequenzspezifischer TALE-basierter Transkriptionsregulatoren sowie TALENs zur Genommodifikation siehe Zhang et al. (2013).

50 Als Nukleasen werden Enzyme bezeichnet die Nukleinsäuren abbauen. 


\section{CRISPR-Cas}

Aufsehen erregte 2012 die Publikation einer weiteren neuen Möglichkeit zur Genomveränderung (Jinek et al., 2012), die auch als „next generation genome editing“ (Horvath/ Barrangou, 2013) bezeichnet wird: das CRISPR-Cas-System. Die Abkürzungen CRISPR und Cas stehen dabei für Clustered Regularly Interspaced Short Palindromic Repeats (CRISPR) und CRISPR-assoziierte (Cas)-Systeme. Dabei wird die Fähigkeit des adaptiven Immunsystems von Bakterien und Archaebakterien genutzt, fremde Nukleinsäuren etwa von Viren oder Plasmiden - zu zerstören und dies RNA-geleitet sequenzspezifisch zu tun. Es wurde bereits gezeigt, dass die Streptokokken-Cas9-Endonuklease gezielt und sequenzspezifisch DNA schneiden kann, wenn synthetische RNA - deren Sequenz partiell komplementär zur zu schneidenden DNA ist - hinzugegeben wird (Jinek et al., 2012). Die Nuklease wird also von einer künstlich hergestellten „guide-RNA“ an die vorher (durch die Sequenz der RNA) bestimmte Stelle der zu schneidenden DNA dirigiert. Dabei können sowohl Einzelstrangbrüche als auch Doppelstrangbrüche entstehen. So können künstliche Restriktionsenzyme hergestellt werden, welche theoretisch an jeder beliebigen Stelle die DNA gezielt schneiden. Die Wirksamkeit dieses Systems wurde zunächst für Hefe-, Mäuse- und menschliche Zellen gezeigt (z. B. Dicarlo et al., 2013; Cong et al., 2013; Hsu et al., 2014). Dabei ist es möglich, mehrere RNA-Führungssequenzen gleichzeitig zu verwenden (Cong et al., 2013; Jinek et al., 2013). Da Cas9-Nukleasen deutlich leichter herzustellen sind als TALENs, könnten sie einen Paradigmenwechsel in der Genomveränderung einleiten (Segal, 2013; Hsu et al., 2014).

Überaus rasche Fortschritte hat es auch bei der Erprobung der CRISPR-Technik zur gezielten Veränderung pflanzlicher Genome gegeben. Dies schließt den erfolgreichen Einsatz der Technologie in unterschiedlichen Modell- und Nutzpflanzen, wie beispielsweise Ackerschmalwand (Feng et al., 2014), Reis (Xu et al., 2014), Mais (Liang et al., 2014) und Orange (Jia und Wang, 2014) ein. Aktuelle Übersichten zu den Möglichkeiten der CRISPR-Technologie und ihrer zukünftigen Verwendung in der Pflanzenzüchtung finden sich bei Liu und Fan (2014) sowie Lozano-Juste und Cutler (2014).

Ein weiteres Verfahren der ortsgenauen Mutagenese ohne Herstellung transgener Organismen ist die Chimeraplasten-Technologie, bei der RNA/DNA-Oligonukleotide in Zellen eingebracht werden, in denen sie sich an die zu verändernden Zielsequenzen anlagern und durch Wirkung zelleigener Mechanismen die Mutation bewirken. Die genannten molekularbiologische Methoden (TALENs, CRISPR-Cas, Chimeraplasten) erlauben die Entwicklung neuer Eigenschaften (,traits“), ohne dass ein Gentransfer in das Genom der Pflanze erforderlich ist. Sie werden als eine Möglichkeit zur Erzeugung nicht-transgener, aber genetisch modifizierter Organismen gesehen. Damit verwischen die Grenzen zwischen klassischer und moderner züchterischer Veränderung der pflanzlichen Erbinformation. 


\subsubsection{Plant Phenotyping}

Die Phänotypisierung von Pflanzen („plant phenotyping”) ist ein neuer Schwerpunkt innerhalb der Pflanzenforschung, der strukturelle und funktionelle Merkmale einer Pflanze quantitativ misst und analysiert. Als Phänotyp bezeichnet man den funktionellen Pflanzenkörper, der aus einem Zusammenspiel von genetischem Hintergrund und Umwelteinflüssen während des Pflanzenwachstums entsteht. Ein umfassendes Verständnis, wie Genom, Umwelt und Phänotyp einander beeinflussen, ist sowohl für die Grundlagenforschung wie auch für die Anwendung im Agrarbereich und die Pflanzenökophysiologie von großer Wichtigkeit.

Die systematische Erfassung phänotypischer Merkmale stellte bisher einen Flaschenhals der funktionellen Genomik dar, da sie sehr zeitaufwendig ist (Cobb et al., 2013). ${ }^{51} \mathrm{Neu}$ ist die Entwicklung automatisierter (rechnergestützter) Bild- und Datenanalysen von Pflanzen-Phänotypen, welche die Phänotypisierung hochdurchsatzfähig macht. Diese Weiterentwicklung wird von einer neuen Teildisziplin der Bioinformatik begleitet, die als „bioimage informatics“ bezeichnet wird (Myers, 2013). Ein Beispiel ist die Entwicklung einer Phänotypisierungsmethode zur Hochdurchsatzanalyse des Wurzelwachstums (Slovak et al., 2014). ${ }^{52}$ Die bildgebenden Verfahren werden ergänzt durch vielfältige Methoden der molekularen und biochemischen Phänotypisierung, die umfangreiche Informationen auf der Transkript-, Protein- und Metabolitenebene liefern. ${ }^{53}$

Das Projekt EPPN (European Plant Phenotyping Network) ${ }^{54}$ umfasst ein internationales Netzwerk aus insgesamt 14 Projektpartnern aus Europa, Australien und Israel. Das Projekt läuft noch bis 2015 und beschäftigt sich insbesondere mit der quantitativen Analyse von pflanzlichen Phänotypen. Die Leitung des wissenschaftlichen Konsortiums liegt beim Forschungszentrum Jülich in Deutschland. Dort wird auch das Deutsche Pflanzen Phänotypisierungsnetzwerk (DPPN) ${ }^{55}$ seit 2013 koordiniert, welches in Zusammenarbeit mit dem Forschungszentrum Jülich, dem Leibniz-Institut für Pflanzengenetik und Kulturpflanzenforschung Gatersleben sowie dem Helmholtz Zentrum München an der Implementierung von Phänotypisierungsanlagen an diesen drei Zentren arbeitet. Es wird

51 Eine Übersicht über Technologien, die diese Engstelle überwinden sollen (,phenomics“ oder auch „next generation plant phenotyping“), bieten Furbank/Tester, 2011 sowie Cobb et al., 2013.

52 Ein Marktführer auf dem Gebiet der automatisierten Phänotypisierung (z. B. Scanalyzer 3D Plant Phenomics) ist das deutsche Unternehmen LemnaTec. Unter: www.lemnatec.com [28.01.2014].

53 Vgl. Cabrera-Bosquet et al., 2012 für eine kurze Übersicht zur Hochdurchsatz-Phänotypisierung und genomischer Selektion mit Blick auf ihre Anwendung in der Pflanzenzüchtung.

54 www.plant-phenotyping-network.eu/eppn/home [20.01.2014].

55 www.dppn.de/dppn/DE/Home/home nodehtml[28.01.2014]. 
vom BMBF für fünf Jahre mit 34,6 Millionen Euro gefördert und ist mit dem europäischen EPPN sowie mit dem International Plant Phenotyping Network (IPPN) vernetzt. ${ }^{56}$

\subsection{Praktische Anwendungen und Züchtungsziele}

Ebenso wie die verwendeten Methoden haben sich auch die Ziele in der Pflanzenzüchtung in den letzten Jahren stark ausdifferenziert. Ein zunehmend wichtiges Ziel ist die Erforschung der Widerstandsfähigkeit gegen abiotischen Stress, zum Beispiel gegen Trockenheit oder hohe Salzkonzentrationen im Boden. Weitere Forschungsziele betreffen Insektenresistenzen, Pathogenresistenzen (Viren, Pilze), Unempfindlichkeit gegenüber niedrigen und hohen Temperaturen, verbesserte Nährstoffnutzung, Ertragssteigerung sowie Qualitätsverbesserungen für die Bereitstellung von Rohstoffen, Medikamenten, Biotreibstoffen und die Biofortifizierung.

\subsubsection{Pflanzen für die Biomasseproduktion}

Unter dem Stichwort „Biomasseproduktion“ werden von Seiten der Forschung und Industrie große Anstrengungen unternommen, Pflanzen als natürlich nachwachsende Rohstoffe für die Herstellung von Treibstoffen oder anderen wichtigen Rohstoffen ${ }^{57}$ nutzbar zu machen. ${ }^{58}$ In den letzten Jahren wurde eine Vielzahl unterschiedlicher Pflanzen als Ausgangsmaterial für die Biomasseproduktion erforscht, darunter Gräser, Bäume, Nahrungspflanzen sowie darüber hinaus Algen und Cyanobakterien.

Das Interesse, Pflanzen für die Gewinnung von Treibstoff (Biodiesel und Bioethanol) zu nutzen, hat in den letzten Jahren sowohl in Deutschland als auch weltweit stark zugenommen, was auch der exponentielle Anstieg an Publikationen auf dem Gebiet illustriert. Während eine Suche in der Literaturdatenbank Scopus für das Jahr 2006 nur 54 Veröffentlichungen zu den Stichworten „Biokraftstoff“ und „Pflanze“ zeigt, war die Anzahl an verfügbaren Publikationen zum Recherchezeitpunkt auf 2.475 Publikationen

56 www.bmbf.de/de/21116.php [18.01.2014].

57 Neben der Gewinnung von Bioenergie wird pflanzliche Biomasse auch für eine Reihe unterschiedlicher organischer Moleküle verwendet, zusammengefasst in Marshall/Alaimo, 2010.

58 Der Bioökonomierat hat Empfehlungen zur nachhaltigen Nutzung von Bioenergie veröffentlicht: www.biooekonomierat.de/fileadmin/templates/publikationen/empfehlungen/BioOEkonmieRatEmpfehlungen-Bioenergie.pdf [28.01.2014]. Auch die Nationale Akademie der Wissenschaften Leopoldina hat eine Stellungnahme zum Thema publiziert: www.leopoldina.org/uploads/tx_leopublication/201207_Stellungnahme_Bioenergie_kurz_de_en_final.pdf [30.01.2014]. 
angestiegen. ${ }^{59}$ Wirtschaftlich rentabel ist momentan nur die Gewinnung von Bioethanol aus Maisstärke und Rohrzucker. ${ }^{60}$

Vor allem die Herstellung von Bioethanol der sogenannten zweiten Generation ${ }^{61}$ gewinnt zunehmend an Bedeutung. Die Nutzung von lignozellulosehaltigen ${ }^{62}$ Rohstoffen erlaubt die Gewinnung von Biokraftstoff direkt aus Pflanzen oder auch Bioabfällen, die für die menschliche Ernährung nicht geeignet sind, zum Beispiel Stroh, Holz, Gräser oder Papierabfälle. ${ }^{63}$

Um die Effizienz der Bioethanolgewinnung zu steigern, werden gezielt gentechnische Methoden genutzt, zum Beispiel um den störenden Anteil an schwer aufzuschließendem Lignin in den Pflanzen künstlich zu verringern. Ein Ansatz zielt darauf ab, die hochkomplexe Zusammensetzung des Lignins sowie die Ligninbiosynthese in vivo zu verändern, um damit einen vereinfachten späteren Abbau des Pflanzenmaterials zu ermöglichen (Harfouche et al., 2010; 2011). Unter anderem ist es bereits gelungen, die Ligninbiosynthese mit Hilfe eines RNAi-Ansatzes (vgl. Kapitel. 7.2.7) in Zuckerrüben zu unterdrücken, was zu einer Reduzierung der zur Weiterverarbeitung nötigen Zeit beziehungsweise der nötigen Enzymmenge führt (Jung et al., 2013). Da eine Modifikation der Ligninzusammensetzung häufig zu ungewollten und nicht immer erklärbaren Veränderungen des pflanzlichen Phänotyps führt, ist weitere Forschung notwendig, um die Prozesse der Ligninbildung besser zu verstehen.

Auch die Nutzung von Cyanobakterien für die direkte Produktion von Bioethanol der sogenannten dritten Generation und anderer organischer Rohstoffe wird immer stärker erforscht. ${ }^{64}$ Die Erzeugung entsprechend modifizierter Mikroorganismen, die als sogenannte „cell factories“ genutzt werden können, spielt in den Bereich der

59 Lizenzpflichtige Recherche unter www.scopus.com [16.12.2013]. Für die Recherche relevanter Fachpublikationen wurde nach „biofuel AND plant“ in Titel, Zusammenfassung und/oder angegebenen Schlagwörtern in der Scopus-Datenbank gesucht. Es wurden alle Publikationstypen berücksichtigt.

60 Vgl. Erdei et al., 2012 zu wirtschaftlichen Aspekten wie Logistik, Infrastruktur und Verarbeitungskosten bei der Nutzung von Biomasse für die Ethanolgewinnung.

61 Als erste Generation wird die Gewinnung aus zuckerreichen Rohstoffen wie Zuckerrohr und stärkereichen Rohstoffen wie Mais bezeichnet. Bei der ersten Generation von Biotreibstoffen wird nur ein kleiner Teil der Pflanze für die Energiegewinnung verwendet. Dabei wurde jedoch die Konkurrenz der Energiepflanzen mit Nahrungsmittelpflanzen kritisiert, siehe z. B. Banerjee, 2011. Bei der zweiten Generation kann fast die gesamte Pflanze genutzt werden, auch lignozellulosehaltige (verholzte) Teile. Die dritte Generation (Gewinnung aus Algen und Cyanobakterien) weist eine auf die Fläche bezogene höhere Biomasseproduktivität im Vergleich zu den beiden früheren Generationen auf.

62 Lignozellulosehaltig bedeutet, dass die Pflanzen oder Teile davon verholzt sind.

63 Eine Übersicht über verschiedene mögliche Substrate und ihre bioenergetische Verwertung liefern Chandel/Singh, 2011 sowie Byrt et al., 2011.

64 Für eine Übersicht siehe Lindblad et al, 2012. 
synthetischen Biologie (Wang et al. 2012; Berla et al., 2013; vgl. auch Kapitel 8). ${ }^{65}$ Auch von Firmen wird mit Hochdruck an der Verwertung von Algen und Cyanobakterien geforscht, da sie im Vergleich zu Pflanzen der ersten und zweiten Generation auf die Fläche bezogen eine erhöhte Biomasseproduktivität aufweisen. Beispiele hierfür sind etwa die US-Biotech-Firmen Joule Unlimited ${ }^{66}$ und das BAL Biofuels Consortium ${ }^{67}$. Neben Cyanobakterien können auch Mikroalgen - wie etwa die Grünalge Chlamydomonas reinhardtii - als Lieferanten verschiedener komplexer Naturstoffe genutzt werden. ${ }^{68}$ Besonders prominente Zielprodukte sind derzeit Biowasserstoff, Bioethanol, Biodiesel und Biogas (Ducat et al., 2011; Parmar et al., 2011). Zunehmend finden Algen Interesse, die natürlicherweise hohe Menge an Öl produzieren; mittels der omics-Technologien werden nunmehr die diesem Prozess zugrunde liegenden Mechanismen erforscht, um sie dann z. B. mittels gentechnischer und synthetisch-biologischer Methoden zu optimieren (Liu und Benning, 2013; Wang et al., 2014).

Biofuels der dritten Generation haben ähnliche Eigenschaften wie erdölbasierte Kraftstoffe (Peralta-Yaha et al., 2012). Da sie über natürliche Photosynthesevorgänge von Algen und Cyanobakterien unter Ausnutzung von Sonnenlicht und Kohlendioxid erzeugt werden, sind sie im Gegensatz zu fossilen Treibstoffen potenziell $\mathrm{CO}_{2}$-neutral und erneuerbar. Außerdem können die Mikroorganismen auf nicht für die Landwirtschaft nutzbarem Gelände und sogar mittels Abwasser, Brack- und Salzwasser sowie in geschlossenen Kreisläufen gezüchtet werden (Larkum et al., 2012). Über Systeme, die gleichzeitig Abwasser klären und Biodiesel oder andere organische Verbindungen synthetisieren, können verschiedene Zielsetzungen miteinander verbunden und dadurch die Kosteneffizienz erhöht werden. ${ }^{69}$

Auch an der Entwicklung von Biorohstoffen und Chemikalien wird gearbeitet, wie beispielsweise durch transgene Pflanzen erzeugte Seide, Kollagen, neuartige Kohlenhydrate oder andere niedermolekulare Substanzen sowie Biopolymere als Ersatz für die erdölbasierte Kunststoffproduktion (Mittal 2011; Fesenko und Edwards, 2014). ${ }^{70}$

65 Neben Cyanobakterien werden auch andere Mikroorganismen genutzt, siehe Lee et al., 2013.

66 www.jouleunlimited.com [29.01.2014].

67 www.ba-lab.com/ [29.01.2014].

68 Übersichtsartikel bieten Sasso et al., 2012; Larkum, et al., 2012 sowie Menetrez, 2012.

69 Vgl. dazu Dalrymple et al., 2013 oder Olguín, 2012.

70 So wurde 2012 in Deutschland eine Kartoffel auf Versuchsfeldern getestet, die durch ein aus Cyanobakterien stammendes Gen zur Produktion von Bioplastik genutzt werden kann. www.transgen. de/pflanzenforschung/bioenergie/1017,doku, html [29.01,2014]. 


\subsubsection{Plant-Made Pharmaceuticals (PMPs)}

Die Technologie, pharmakologisch wirksame Stoffe von Pflanzen synthetisieren zu lassen (Plant-Made Pharmaceuticals, PMPs), ist in den letzten Jahren bedeutend vorangeschritten und wird weiterhin in einer Vielzahl von akademischen Instituten sowie in Biotechnologieunternehmen verfolgt. Pflanzen werden zur Herstellung von Impfantigenen, therapeutischen Proteinen, Antikörpern und Enzymen genutzt. ${ }^{71}$ Sie haben gegenüber anderen Produktionssystemen, wie zum Beispiel Bakterien oder tierischen Zellkulturen, verschiedene Vorteile: Sie übertragen keine menschlichen Pathogene, weisen eine hohe Leistungsfähigkeit und Lagerungsfähigkeit auf, ${ }^{72}$ sind skalierbar und kosteneffizient. Herausforderungen, an denen intensiv geforscht wird, sind die Glycosylierungsmuster von Proteinen, ${ }^{73}$ Produktionssteigerungen sowie die Produktionssysteme selbst.

Ein Produktionssystem ist die zur Herstellung von PMPs genutzte Plattform. Dies kann also eine Pflanze auf dem Feld sein wie Tabak, verschiedene Getreide- oder Gemüsesorten, aber auch geschlossene Systeme basierend auf kultivierten Pflanzenzellen werden erforscht. Ein Beispiel für letztere ist die Produktion des Enzyms Taligurase alfa (ein Pflanzen-Analogon des bei Menschen vorkommenden Enzyms Glucocerebrosidase, das für die Therapie von Morbus Gaucher eingesetzt wird) in Karottenzellen (Shaaltiel et al., 2007) durch die israelische Firma Protalix. Durch die Produktion in Fermentern fielen die regulatorischen Hürden im Vergleich zu transgenen Pflanzen deutlich geringer aus, sodass nach Angaben der Firma bereits im Februar 2012 erfolgreich abgeschlossene Phase-III-Studien ${ }^{74}$ vorlagen (Hollak 2012). ${ }^{75}$ Das Enzym, welches von der Firma Pfizer unter dem Produktnamen Elelyso vermarktet wird, war am 1. Mai 2012

71 Siehe Übersichtsartikel von Gao et al., 2012; Egelkrout et al., 2012 sowie Lico et al., 2012. Eine hohe Produktion von Fremdproteinen ermöglicht insbesondere die Plastidentransformation. vgl. dazu Scotti et al., 2012, siehe auch Kapitel 7.2.2).

72 Gerade bei Impfstoffen können Pflanzen einen großen Vorteil bieten, wenn für Lagerung und Transport keine lückenlose Kühlkette mehr benötigt wird (Penney et al., 2011).

73 Als Glycosylierungsmuster bezeichnet man die Modifizierung von Proteinen mit verschiedenen Zuckeranhängen, die bei unterschiedlichen Organismen verschieden ausfallen können und die für die Produktion von PMPs an die menschlichen Muster angepasst werden müssen.

74 Bei der Arzneimittelentwicklung durchlaufen neue Wirkstoffe verschiedene klinische Testphasen, die auf den Erkenntnissen aus Grundlagenforschung, Wirkstoffidentifizierung und Labortests (inklusive Tierversuchen) aufbauen. In Phase I werden sie erstmals an Menschen (in der Regel gesunden Probanden) getestet. Verhalten sowie unerwünschte Reaktionen des Körpers werden dokumentiert. In Phase II geht es um die Erhebung von Daten zu Effizienz, Sicherheit und Dosierung des Medikaments an einer relativ kleinen Zahl Probanden. Phase III soll den Nachweis der Wirksamkeit des Medikaments erbringen und umfasst eine große Anzahl Probanden, um statistisch aussagekräftige Daten zu erhalten. Nach erfolgter Zulassung können weitere Daten erhoben und Studien durchgeführt werden, was auch als Phase IV bezeichnet wierden kann. 
das erste für den Menschen zugelassene Medikament, welches in gentechnisch veränderten Pflanzenzellen produziert wird. ${ }^{76}$ Ein weiteres Beispiel ist die Produktion eines Antigens des Humanen Papilloma-Virus in der Grünalge Chlamydomonas reinhardtii (Demurtas et al., 2013). ${ }^{77}$ Pflanzenzellen in Kultur zur Produktion rekombinanter Proteine werden auch als „pharmaceutical factories“ bezeichnet (Rischer et al., 2013).

Die ursprüngliche Vision von essbaren Impfungen, für die lediglich das Impf-Antigen enthaltene Obst verzehrt werden müsste, hat sich aufgrund des geringen Impf-Antigengehalts, der fehlenden Standardisierbarkeit der Dosis sowie der mangelnden ImpfAntigenstabilität, aber auch wegen der Schwierigkeit einer zielgenauen Verteilung als schwer umsetzbar erwiesen, sodass neben ihrer weiteren Erforschung - etwa in Kartoffeln und Tomaten (Rigano et al., 2013) - nun auch Alternativen erforscht werden. ${ }^{78}$

Das Potential von PMPs wurde sehr beeindruckend deutlich, als es 2009 gelang, in weniger als einem Monat nach der Veröffentlichung der H1HA-Sequenz des Schweinegrippevirus H1N1 das Protein durch transiente Expression in der Wildtabakart Nicotiana benthamiana zu synthetisieren (D‘Aoust et al., 2010). Dies stellt die schnellste Produktion eines Impfstoffes dar, die jemals bei einer Pandemie oder auch einer saisonalen Grippe erreicht wurde.

Bis Mai 2012 wurden schon über zweihundert Anträge auf Freisetzungen von PMPs gestellt, davon die ersten in den USA bereits 1991. Aber auch europäische Firmen sind intensiv mit der Entwicklung von PMPs beschäftigt. ${ }^{79}$ Es laufen zahlreiche präklinische und klinische Studien (Yusibov et al., 2011). Für eine Vielzahl verschiedener Krankheiten wie Gebärmutterhalskrebs, Tuberkulose, Hepatits B, Cholera, HIV sowie Durchfallerkrankungen und viele weitere werden weltweit PMPs entwickelt. ${ }^{80}$ Die Gewinnung von humanem Serum Albumin (HSA) aus Reis ist chinesischen Forschern gelungen (He et al., 2011). HSA ist für zahlreiche medizinische Anwendungen wichtig und konnte bisher nur aus Blutspenden gewonnen werden. Jones et al. berichteten kürzlich über die Produktion eines Proteins in Pflanzen, das erfolgreich zur Antikörperbildung einge-

75 www.protalix.com/development-pipeline/overview-development-pipeline.asp [22.01.2014]. Auf dieser Homepage sind weitere aktuell laufende Studien aufgelistet. Die weitere Entwicklung und Vermarktung erfolgt außerhalb Israels über die Firma Pfizer.

76 www.pflanzenforschung.de/index.php?cID=5494 [22.01.2014]. Das erste PMP für die Impfung von Tieren wurde von Dow AgroSciences hergestellt und Anfang 2006 in den USA zugelassen. Siehe Thomas et al., 2011 oder www.biosicherheit.de/fokus/483.pharmapflanzen-stand.html [22.01.2014].

77 Eine Übersicht über die Nutzung von Algen zur Produktion rekombinanter Proteine bieten Gong et al., 2011.

78 Vgl. Übersichtsartikel von Thomas et al., 2011 oder Mason/Herbst-Kralovetz, 2012.

79 www.biosicherheit.de/fokus/483.pharmapflanzen-stand.html [22.01.2014].

80 Vgl. Clemente/Corigliano, 2012; Waheed et al.4 2012; A hmad et al., 2012; Yusibov et al., 2011. 
setzt wurde und Wirksamkeit gegenüber dem Malaria-Erreger Plasmodium falciparum zeigte (Jones et al., 2013). Eine umfangreiche Darstellung bisheriger Arbeiten zur Produktion von Vakzinen in transgenen Pflanzen findet sich in Guan et al. (2013).

Verschiedene Pflanzen kommen als Expressionssysteme in Frage, darunter beispielsweise Erbsen (Mikschofsky/Broer, 2012), die Grünalge Chlamydomonas reinhardtii (RosalesMendoza et al., 2012), Reis (Kuo et al., 2013), verschiedene Nachtschattengewächse wie Kartoffel und Tomate (Rigano et al., 2013), oder Mais (Yusibov et al., 2011). Auch die Produktion von Vakzinen in pflanzlichen „hairy roots“, die durch Transformation mit Agrobacterium rhizogenes gewonnen werden, wird diskutiert (Skarjinskaia et al., 2013)

Kritik an PMPs wird vor allem in Bezug auf die Möglichkeit der Auskreuzung von Pharmapflanzen geäußert, die dazu führen könnte, dass Nicht-Betroffene pharmakologisch wirkende Pflanzenbestandteile zu sich nehmen und es zu unbeabsichtigten Überdosierungen kommen könnte. Aber auch andere gegen transgene Pflanzen vorgebrachte Argumente werden im Zusammenhang mit Pharmapflanzen geäußert. Eine Lösungsmöglichkeit bietet die Nutzung geschlossener Systeme wie Zellkulturen in Fermentern (siehe oben) oder die Verwendung von modernen gentechnischen Methoden, die eine Auskreuzung weitestgehend unterbinden, wie zum Beispiel die Plastidentransformation (vgl. Kapitel 7.2.2).

\subsubsection{Stresstoleranz am Beispiel Trockenstress}

Trockenheit gehört zu den stärksten Umweltstressoren für die globale Landwirtschaft. Wegen der immer wieder durch Dürren ausgelösten Hungersnöte und des in vielen Regionen knappen Wassers ist die Widerstandsfähigkeit von Pflanzen gegen abiotischen Stress wie Wassermangel und hohen Salzgehalt von Böden ein sehr wichtiges Züchtungsziel. Dabei werden unterschiedliche Wege gegangen (zusammengefasst in Agarwal et al., 2013). Einer liegt darin, Schutzmechanismen und damit in Zusammenhang stehende Gene von Organismen, die gut an Trockenheit angepasst sind, zu identifizieren und mittels gentechnischer Methoden auf Nutzpflanzen zu übertragen (Thao und Tran, 2012; Jogaiah et al., 2013). In zahlreichen Veröffentlichungen der letzten Jahre konnte gezeigt werden, dass das Einbringen einzelner (fremder) Gene in Pflanzen zu einer erhöhten Trocken- und Salzstresstoleranz führen kann (Bengough et al., 2011; Nakashima et al., 2014). Doch auch wenn es bereits erste Erfolge in der Züchtung trockentoleranter Nutzpflanzen gibt (z. B. bei Reis, Mais und Raps), stellt die Umsetzung der Erkenntnisse für die praktische Anwendung in der Landwirtschaft noch eine große Herausforderung dar. ${ }^{81}$

81 Die Nutzung der gewonnenen Erkenntnisse für die Landwirtschaft ist das Thema eines Über- 
Trotz der großen Komplexität des Phänomens Trockentoleranz werden einige transgene Linien trockentoleranter Nutzpflanzen bereits in Freilandversuchen getestet. ${ }^{82}$ Besonders weit sind die Entwicklungen von Mais und Weizen. Ab 2013 ist trockentoleranter Mais in den USA kommerziell erhältlich. ${ }^{83}$ Er wurde dort zum Anbau zugelassen und ist das Ergebnis einer 2007 begonnenen Kooperation von Monsanto und BASF. Von den dabei entwickelten Genkonstrukten werden einige für das humanitäre Projekt Water Efficient Maize for Africa (WEMA) zur Verfügung gestellt. ${ }^{84}$ Die intensiven Forschungsaktivitäten gehen weltweit weiter. Im besonders von Dürreperioden betroffenen Australien werden beispielsweise transgene, trockentolerante Weizensorten erforscht. ${ }^{85}$ In einem Verbundprojekt zwischen Pakistan und den USA (Pakistan-US Science and Technology Cooperation Program) werden ebenfalls verschiedene transgene Weizenlinien in Freilandversuchen auf eine erhöhte Trockentoleranz getestet. ${ }^{86}$

Das Züchtungsziel Trockentoleranz ist auch ein Einsatzgebiet von Methoden des „next generation phenotyping“ (zusammengefasst in Cobb et al., 2013:857 ff.; siehe auch Kapitel 7.3.6). Diese und zahlreiche weitere Projekte legen den Schluss nahe, dass mit der zunehmenden Marktreife trockentoleranter Nutzpflanzen in den kommenden Jahren zu rechnen sein wird. Da Trockentoleranz jedoch ein sehr komplexes Phänomen ist, für das die Veränderung mehrerer Gene und/oder Mechanismen gleichzeitig nötig sein könnte, muss die Praxistauglichkeit in den meisten Fällen noch nachgewiesen werden (Deikman et al., 2012).

82 www.transgen.de/pflanzenforschung/klimawandel/1600.doku.html [22.01.2014]. Auf der Homepage von Transgen (www.transgen.de [22.01.2011]) lassen sich mit dem Suchbegriff „Trockentoleranz“ ausführliche Informationen über trockentolerante Pflanzen und ihren Anbau finden.

83 www.transgen.de/pflanzenforschung/klimawandel/1601.doku.html [22.01.2014] sowie www. transgen.de/pflanzenforschung/klimawandel/1600.doku.html [22.01.2014].

84 Das Projekt WEMA wird von der African Agricultural Technology Foundation (AATF) organisiert und von der Bill and Melinda Gates Foundation sowie der Howard G. Buffett Foundation kofinanziert. (http://www.transgen.de/pflanzenforschung/klimawandel/1683.doku.html [22.01.2014]).

85 In Australien werden seit 2007 Freilandversuche mit trockenresistentem Weizen durchgeführt. Dabei wurde jeweils eines von 15 mit Trockentoleranz in Verbindung gebrachten Genen aus Arabidopsis, Mais, Hefe und Moos in Weizen transformiert. Von 24 getesteten Linien konnte in sieben Linien ein erhöhter Ertrag unter Trockenstress erzielt werden, bei zwei Linien übertraf der Ertrag den der nicht veränderten Ausgangspflanze sogar um $20 \%$. Mit der Markteinführung solcher Linien ist jedoch erst in 5-10 Jahren zu rechnen. www.biosicherheit.de/forschung/getreide/583.trockentoleranter-weizen-versprechende-ergebnisse.html [22.01.2014].

86 www.bayercropscience.com/bcsweb/cropprotection.nsf/id/DE_20061031?open\&l=DE\&c$\mathrm{cm}=500020870$ [24.04.2012]. 


\subsubsection{Schädlingsresistenzen}

Ein weiteres wichtiges Züchtungsziel stellen die Schädlingsresistenzen dar. Während Insektenresistenzen durch Einschleusung von Genen des Bakteriums Bacillus thuringiensis (Bt-Toxine) insbesondere bei Mais und Baumwolle bereits seit langem etabliert sind, wird nun zunehmend auch an alternativ vermittelten Insektenresistenzen geforscht. Neuere Beispiele sind Proteinase-Inhibitoren, um den Proteinstoffwechsel der Insekten zu unterbinden, und Lectine, die eine Schutzfunktion gegen Pflanzenfresser (Herbivoren) haben. ${ }^{87}$ Auch an der Nutzung biochemischer Duftstoffe (Pheromone) zur Abwehr von Blattläusen wird geforscht. ${ }^{88}$ Neben Insektenresistenzen wird auch die Vermittlung von Pilzresistenzen intensiv erforscht, wie beispielsweise gegenüber Phytophthora infestans, dem Erreger der Kraut- und Knollenfäule bei der Kartoffel, Fusarium beim Weizen und Mehltau bei der Weinrebe. ${ }^{89}$ Trotz intensiver Anstrengungen gibt es bislang jedoch noch keine anwendungsreifen, pilzresistenten Sorten. ${ }^{90}$ Eine virenresistente transgene Gartenbohne wurde mittels RNAi-Technologie (siehe Kap.7.2.7) von der brasilianischen Forschungsgesellschaft EMBRAPA (Empresa Brasileira de Pesquisa Agropecuária/Brazilian Agricultural Research Corporation) entwickelt und diese im September 2011 zugelassen. Sie könnte 2014 erstmals in Brasilien angebaut werden (Tollefson, 2011). ${ }^{91}$

\subsubsection{Biofortifizierung}

Mikronährstoffe wie Vitamine (organisch), Mineralien (anorganisch) und Spurenelemente sind für die menschliche Ernährung essentiell, da sie nicht selbst hergestellt werden und nur über die Nahrung aufgenommen werden können. In Ländern mit Mangelernährung, wo die Nährstoffzufuhr oft über ein Hauptnahrungsmittel wie Reis oder Mais erfolgt, kommt es zu Mangelerscheinungen, da diese Nahrungsmittel oft nicht ausreichend Mikronährstoffe enthalten. Um diesem Mangel entgegenzuwirken, wird an der sogenannten Biofortifizierung, also der Anreicherung dieser Pflanzen mit essentiellen Nährstoffen, geforscht. Das prominenteste Beispiel ist der „Goldene Reis“, der bereits 1999 von Ingo Potrykus et al. entwickelt wurde, um dem Vitamin-A-Mangel zu

87 www.biosicherheit.de/lexikon/795.insektenresistenz.html [22.01.2014].

88 Am Rothamsted Research Institute wurde Weizen entwickelt, der über Pheromone Blattläuse abwehren kann. www.transgen.de/datenbank/pflanzen/78.weizen.html [22.01.2014].

89 Eine Übersicht über gentechnische Eingriffe zur Erhöhung von Resistenz gegen Pilze bieten Ceasar/Ignacimuthu, 2012.

90 www.biosicherheit.de/lexikon/737.pilzresistenz.html [22.01.2014].

91 www.nature,com/news/2011/111012/full/478168a.html[22.01.2.014 
begegnen (Potrykus, 2012). Er enthält eine Vorstufe des Vitamins A und wird 2013/2014 auf den Philippinen im Freiland getestet. ${ }^{92}$ Eine Übersicht über die biotechnologische Biofortifizierung von Reis bieten Bhullar und Gruissem (2013) sowie Bashir et al. (2013).

Mais ist eines der Hauptnahrungsmittel in vielen Entwicklungsländern, in denen Eisenmangelanämie als Folge von mangelndem bioverfügbaren Eisen $(\mathrm{Fe})$ auftritt. ${ }^{93}$ Daher wird auch die Biofortifizierung von Mais entweder durch Konzentrations- oder Bioverfügbarkeitserhöhung von Eisen in Maiskörnern anvisiert (Lung'aho et al., 2011; Simić et al., 2012). Die Ergebnisse deuten darauf hin, dass dies mit PhänotypisierungsWerkzeugen und konventionellen Züchtungsmethoden möglich sein könnte. Es wurden bereits erfolgreiche QTL-Analysen (siehe Kapitel 7.3.2) für Gene, welche die Konzentration von Phosphor (P), Eisen ( $\mathrm{Fe}$ ), Zink ( $\mathrm{Zn}$ ) und Magnesium (Mg) in Mais beeinflussen, durchgeführt (Simic et al., 2012). Es ist inzwischen auch gelungen, mittels „multigene engineering“ gleich drei verschiedene metabolische Stoffwechselwege zu verändern und dadurch Maiskörner mit höherem Gehalt an Carotinoiden, Folat und Ascorbat ${ }^{94} \mathrm{zu}$ entwickeln (Farré et al., 2011). Auch an Biofortifizierungen von Reis, Maniok, Hirse und Banane sowie Mungbohnen wird geforscht. ${ }^{95}$ Anhand der Modellpflanze Arabidopsis thaliana gelang die Erhöhung des Vitamin-B6-Gehaltes, was mit einer Verbesserung des Wachstums und der Toleranz gegenüber oxidativem Stress verbunden war (Raschke et al., 2011). Strategien zur Erhöhung des Vitamin-B6-Gehaltes in Kulturpflanzen werden von Vanderschuren et al. (2013) diskutiert.

92 www.irri.org [30.01.2014]. Geplant ist die Einführung in den nächsten Jahren auch für Bangladesh, Indien, Vietnam, Indonesien und China (Potrykus, 2012). Das Projekt wird von verschiedenen Seiten (u. a. Greenpeace) kritisiert und als „trojanisches Pferd“ zur Einführung gentechnisch veränderter Lebensmittel in Entwicklungsländern gesehen. Zur Kritik siehe als Beispiel den Bericht von Testbiotech unter: www.stiftung-gekko.de/wp/wp-content/uploads/2012/01/Report-Golden-Lies_ gen-reis_2012.pdf [30.01.2014]. Zuletzt geriet der Goldene Reis in die Kritik, nachdem eine Studie zur Bioverfügbarkeit des Provitamin A an chinesischen Schulkindern (Tang et al., 2012) durchgeführt wurde, wobei chinesische Regelungen umgangen wurden. Unter: www.nature.com/news/chinasacks-officials-over-golden-rice-controversy-1.11998.

93 Man spricht beim Mangel von Mikronährstoffen wie Eisen auch von „verstecktem Hunger“.

94 Salze der Folsäure und der Ascorbinsäure.

95 www.grandchallenges.org [30.01.2014]. Zum Thema ethische Aspekte und öffentliche Akzeptanz der grünen Gentechnologie vor dem Hintergrund des Welternährungsproblems siehe etwa MarxStölting, 2012, sowie www.grandchallenges.org/ImproveNutrition/Challenges/NutrientRichPlants/ Pages/default.aspx [30.01.2014]. 


\subsubsection{Biotechnologische Verbesserung von Bäumen, Zier- und Gemüsepflanzen}

Aufgrund von Wasser- und Landknappheit, Bevölkerungswachstum und Klimawandel sind in den letzten Jahren zunehmend auch Waldbäume als mögliche zukünftige Lieferanten von Holz, Biomasse, Papier aber auch Biotreibstoffen und Biomaterialien ins Blickfeld der Biotechnologie geraten (Harfouche et al., 2012). Aufgrund ihrer langen Generationszeiten dauern traditionelle genetische Methoden zu lange, sodass die Integration moderner Technologien notwendig ist, um komplexe Merkmale zu züchten (Harfouche et al., 2012). Ein Beispiel sind Versuche zur Verbesserung von Wachstumseigenschaften und Holzqualität in Eukalyptus mittels genomischer Selektion (GS) (Resende et al., 2012) oder mittels Cisgenetik in Pappeln (Han et al., 2011). Es wird erwartet, dass die Züchtung von Waldbäumen durch die neuen Technologien und die Verfügbarkeit von Genomsequenzen revolutioniert wird (Resende et al., 2012; Dubouzet et al., 2013). Diese Methoden werden auch zur Verbesserung von Obstbäumen genutzt (vgl. Gambino/Gribaudo, 2012). Über die Erforschung von Krankheitsresistenzen hinaus wird dabei auch an der Toleranz gegen abiotischen Stress, verbessertem Wachstum und verbesserter Fruchtqualität geforscht (ebd.).

Neben Bäumen werden auch Zierpflanzen mit Methoden der Genomik erforscht (vgl. Chandler/Sanchez, 2012). Beispiele sind die Verbesserung der Blütenentwicklung von Rosen (vgl. Bendahmane et al., 2013) oder die Entwicklung besonders langlebiger und männlich-steriler Pelargonien (García-Sogo et al., 2012). Vermittelt werden neben Farben und Düften auch Krankheitsresistenzen, Stresstoleranzen und bessere Haltbarkeit der Pflanzen. Auch Gemüsepflanzen werden im Hinblick auf ihre Qualitäten (Toleranz gegenüber abiotischem und biotischem Stress, Ertragsparameter, Fruchtqualität) verbessert (Orzaez et al., 2010; Barrell et al., 2013; Martin, 2013).

\subsubsection{Pflanzenwachstum fördernde Nutzbakterien}

Pflanzen leben in enger Beziehung zu Mikroorganismen, die sich sowohl innerhalb als auch außerhalb des Pflanzengewebes befinden können. Dabei lassen sich die Rhizosphäre (unterirdisch) und die Phyllosphäre (oberirdisch) unterscheiden, die beide von mikrobiellen Gemeinschaften besiedelt werden (Berlec, 2012). Ausgewählte Stämme nützlicher Bodenbakterien (,plant beneficial bacteria“) können Pflanzen gegen abiotischen Stress und eine Reihe von Pflanzenpathogenen schützen und so das Pflanzenwachstum fördern (Zamioudis et al., 2013). Mit den neuen Methoden der Genom- und Phänotypisierungsanalyse werden die dabei involvierten Stoffwechsel- und Signaltransduktionswege der Pflanzen sowie der Mikroorganismen erforscht (Zamioudis et al., 2013). Dabei werden „next-generation sequencing“" DNA Microarrays und Proteomik genutzt (Berlec, 
2012). So konnte etwa gezeigt werden, dass Nutzbakterien die Wurzelentwicklung von Pflanzen beeinflussen (ebd.). Dabei bilden die Gemeinschaften aus Pflanzen und Mikroorganismen ein komplexes Geflecht von Interaktionen aus. Die Aktivierung bestimmter Stoffwechselwege in der Pflanze beeinflusst etwa die Zusammensetzung der Bakteriengemeinschaft im Wurzelbereich (Carvalhais et al., 2013). Andererseits werden bestimmte Signaltransduktionswege in der Pflanze erst durch die Interaktion mit bestimmten nützlichen Mikroben aktiviert. So werden nach einem Angriff auf die Pflanze durch Pathogene oder Insekten Pflanzen-Bakterien-Interaktionen im Boden ausgelöst, welche die Widerstandsfähigkeit der Pflanzen gegen diese Angriffe positiv beeinflussen (ebd.).

Auch das Überleben der Mikroben hängt von der Pflanze ab und wird von dieser reguliert (Berlec, 2012). Weiterhin können Umwelteinflüsse wie Pestizide, Anbaumethoden und die umgebende Atmosphäre die Zusammensetzung der mikrobiellen Gemeinschaften verändern (Berlec 2012). Solche Pflanzen-Mikroben-Boden-Interaktionen werden zunehmend erforscht (Reddy/Saravanan, 2013).

Natürlich im Boden vorkommende Bakterien werden auch als umweltfreundliche, nachhaltige und kostengünstige Alternative zu chemischen Düngern und Pestiziden gesehen (Reddy/Saravanan, 2013). Ein Beispiel hierfür ist das Bakterium Bacillus subtilis, das als Biodünger genutzt wird (Beauregard et al., 2013).

Es wird derzeit an Mischungen von Mikroben (im Sinne einer Art „Impfstoff“) geforscht, die gemeinsam ausgebracht werden könnten und unterschiedliche nützliche Eigenschaften wie Stickstofffixierung, Phosphatnutzung oder Widerstandsfähigkeit gegen Krankheiten vermitteln (Reddy/Saravanan, 2013). ${ }^{96}$

\subsubsection{Sicherheitsforschung}

Für die kritische Haltung der europäischen Bevölkerung gegenüber der grünen Gentechnologie spielen Sicherheitsbedenken und wahrgenommene Risiken eine wichtige Rolle (siehe Müller-Röber et al., 2013). Zu unterscheiden sind dabei:

1. Risiken im Sinne möglicher Gefahren für die Umwelt: Hierzu gehören Auswirkungen auf Nicht-Zielorganismen und auf Ökosysteme, Folge- und Anwendungsprobleme wie Auskreuzen beziehungsweise Verbreitung von veränderten Genen auf andere Lebewesen, Resistenzbildungen, Entstehung von „Superunkräutern“ und

96 Eine Übersicht über die umfangreiche Literatur zu Pflanzen-Nutzbakterien (auch „plant probiotics“ genannt) bieten Reddy/Saravanan, 2013 iund Berlec, 2012. 
Biodiversitätsverlust. Dabei wird vor einer prinzipiellen Unberechenbarkeit und Irreversibilität der Gentechnik gewarnt.

2. Risiken für die Gesundheit: $\mathrm{Zu}$ den diskutierten Gesundheitsrisiken gehören neuartige Allergien, möglicherweise in GVO enthaltene toxische Produkte sowie durch horizontalen Gentransfer vermittelte Antibiotika-Resistenzen.

3. Risiken für den ökologischen Landbau: Dabei geht es um die Möglichkeit der Koexistenz von gentechnikfreier und gentechniknutzender Landwirtschaft, um Haftungsfragen sowie die Wahlfreiheit für Landwirte.

4. Verbraucherschutz: Kennzeichnung und Wahlfreiheit für Verbraucher.

5. Sozioökonomische Auswirkungen: Diskutiert werden Folgen für soziale und wirtschaftliche Strukturen der Landwirtschaft, das Patentrecht sowie die damit verbundene Abhängigkeit der Landwirte von Konzernen.

Vermutlich gerade auch wegen der großen Vorbehalte der Bevölkerung ist die biologische Sicherheitsforschung zu gentechnisch veränderten Pflanzen in Deutschland zentraler Bestandteil der Forschung. ${ }^{97}$ So förderte etwa das BMBF entsprechende Untersuchungen bereits seit $1979 .{ }^{98}$ Auch Wissenschaftsorganisationen betonen die Potenziale der grünen Gentechnologie und gehen von der Möglichkeit erfolgreichen Risikomanagements aus, mit dem möglichen Problemen begegnet werden könnte. ${ }^{99}$ Ein Beispiel hierfür ist eine Broschüre der DFG zum Thema. ${ }^{100}$ Auch die Nationale Akademie der Wissenschaften Leopoldina, die Deutsche Akademie der Technikwissenschaften acatech und die Berlin-Brandenburgische Akademie der Wissenschaften (für die Union der Deutschen Akademien der Wissenschaften) haben sich bereits in einer gemeinsamen Stellungnahme vom 13.10.2009 für eine neue, offenere Politik gegenüber der grünen Gentechnologie ausgesprochen. ${ }^{101}$ Es lässt sich daher feststellen, dass eine Mehrheit der Pflanzenforscher die grüne Gentechnologie für ein geeignetes Werkzeug für die

97 Eine Übersicht über Projekte und ihre Ergebnisse bietet die Internetplattform des Bundesministeriums für Bildung und Forschung (BMBF) unter www.biosicherheit.de/ [22.01.2014].

98 www.bmbf.de/press/2098.php [22.01.2014].

99 Siehe hierzu die Studie „Grüne Gentechnik“ der DFG (2011) unter www.dfg.de/download/pdf/dfg_ magazin/forschungspolitik/gruene_gentechnik/broschuere_gruene_gentechnik.pdf [22.01.2014].

100 Die Broschüre wurde von einigen Wissenschaftlerinnen und Wissenschaftlern kritisiert, da sie bestimmte kritische Forschungsvorhaben und Ergebnisse nicht ausreichend berücksichtigt und gewürdigt habe. Auch diese Kritik wurde wiederum kritisiert. Dies zeigt, dass trotz einer deutlichen Tendenz zur Befürwortung transgener Pflanzen keine Einigkeit in der Sicherheitsbewertung unter Wissenschaftlerinnen und Wissenschaftlern besteht.

101 www.leopoldina.org/de/politik/empfehlungen-und-stellungnahmen/nationale-empfehlungen/ gruene-gentechnik, html [2,2,01,2014] 
Pflanzenzüchtung hält. Dennoch bleibt die Sicherheitseinschätzung umstritten und die positive Bewertung des Problemlösungspotenzials wird nicht von allen Wissenschaftlerinnen und Wissenschaftlern geteilt. ${ }^{102}$ So wird etwa kritisiert, die Risikoabschätzung sei unzureichend und es würden nicht die richtigen Experimente durchgeführt, etwa Langzeitstudien. ${ }^{103}$ Eine Übersicht über die Literatur zur Sicherheitsabschätzung bieten Domingo und Bordonaba (2011). Eine Auswertung wissenschaftlicher Studien bietet eine Studie der Europäischen Kommission (2010). ${ }^{104}$ Die EU-Kommission hat 2013 das Zulassungsverfahren für gentechnisch veränderte Lebens- und Futtermittel gesetzlich neu geregelt und verschärft. So müssen nun unter anderem 90-Tage-Fütterungsstudien an Nagetieren obligatorisch durchgeführt werden. ${ }^{105}$ Für den Nachweis (möglicherweise nicht deklarierter) gentechnischer Veränderungen in Futter- und Lebensmitteln werden unterschiedliche Methoden eingesetzt (beschrieben beispielsweise in Broeders et al., 2012, Holst-Jensen et al., 2012, Kamle /Ali, 2013). ${ }^{106}$

\subsection{Fazit}

Die Vielfalt der vorgestellten Methoden und Anwendungen sowie die im Berichtszeitraum erzielten Erfolge deuten darauf hin, dass die Bedeutung der Gentechnologie und molekularer Analyseverfahren für die Pflanzenzüchtung auch in den kommenden Jahren erheblich weiter wachsen wird. Wie sich diese Entwicklung auf den kommerziellen

102 Der Verein Deutscher Wissenschaftler sieht die grüne Gentechnologie deutlich kritischer; www. vdw-ev.de/ [22.01.2014]. Angemahnt wird vor allem eine Technikentwicklung im „inter- und transdisziplinären Diskurs [...], der der Tatsache Rechnung trägt, dass die Forschungsziele in einem gesellschaftlichen Kontext stehen“ (www.vdw-ev.de/images/stories/vdwdokumente/aktuelles/stellungnahme_agrarforschung.pdf [22.01.2014].

103 www.zeit.de/wissen/umwelt/2012-02/gruene-gentechnik-debatte-gastbeitrag [22.01.2014].

104 Siehe unter http://ec.europa.eu/research/biosociety/pdf/a_decade_of_eu-funded_gmo_research.pdf [22.01.2014].

105 Zum Vorschlag der EU-Kommission siehe Durchführungsverordnung EU Nr. 503/203 vom 3. April 2013 unter: http://eur-lex.europa.eu/LexUriServ/LexUriServ.do?uri=OJ:L:2013:157:0001:0048:DE:PDF [30.01.2014]. Die Mehrheit der Mitgliedstaaten stimmte diesem Vorschlag der EU-Kommission $2013 \mathrm{zu}$. Unter: www.transgen.de/sicherheit/gesundheit/544.doku.html [29.8.2013]; www.haccp.de/handwerk/ mikrobiologie/item/fuetterungsstudien-fuer-gvo-zulassungen-verpflichtend [30.1.2014]. Der EUMinisterrat hat darüber hinaus im Juni 2014 einer nationalen Ausstiegsklausel beim Anbau gentechnisch veränderter Pflanzen zugestimmt. Das bedeutet, dass die einzelnen Länder entscheiden können, ein nationales Anbauverbot zu verhängen, auch wenn der GVO in der EU zugelassen und als sicher bewertet wurde. Das Gesetz muss jedoch mit dem EU-Parlament und der EU-Kommission im Wortlaut abgestimmt sowie rechtskräftig werden. Unter: www.transgen.de/aktuell/1790.doku.html [14.07.2014]. 106 Zum Zulassungsverfahren unter Beteiligung der europäischen Behörde für Lebensmittelsicherheit (EFSA) siehe www.transgen.de/recht/gesetze/641.doku.html [12.01.2014]. 
Anbau in Deutschland auswirken wird, ist jedoch zum jetzigen Zeitpunkt unklar. Viele der neuen Züchtungsmethoden werden als weniger problematische und besser akzeptierte Alternativen zur „klassischen“ Gentechnik und den damit hergestellten transgenen Pflanzen gesehen und sind mit der Hoffnung verbunden, dass sie die ablehnende Haltung der europäischen Bevölkerung gegenüber der grünen Gentechnologie ändern könnten. Ob die neuen Ziele und Wege tatsächlich zu einer besseren Akzeptanz bei Verbrauchern führen werden, bleibt jedoch offen. ${ }^{107}$

\subsection{Problemfelder und Indikatoren im Bereich der grünen Gentechnologie}

\subsubsection{Einführung und Übersicht}

Um die komplexen Diskussionsstränge in der öffentlichen Debatte rund um die grüne Gentechnologie sichtbar und mittels belastbarer Indikatoren auch quantitativ messbar zu machen, erfolgte analog der in Kapitel 2 beschriebenen Methodik die Erhebung eines Text-Korpus ${ }^{108}$ : Die recherchierten Texte wurden inhaltsanalytisch ausgewertet, verschlagwortet und zu Problemfeldern zusammengefasst. Abbildung 2 zeigt die so eruierten Problemfelder sowie deren quantitative Gewichtung in den untersuchten Texten innerhalb der gesetzten vier Leitdimensionen des Gentechnologieberichts. Die

107 Eine repräsentative Umfrage von Dicomm und Dimap im Auftrag des Vereins Forum Grüne Vernunft im Juni 2013 stellte eine im Vergleich zur Gesamtbevölkerung deutlich erhöhte Akzeptanz der grünen Gentechnologie bei Befragten der Altersgruppe 18 bis 29 Jahre fest. Diese Ergebnisse könnten - so das Fazit der Studie - einen Meinungswandel der Gesamtbevölkerung in der Zukunft andeuten. Ob es sich tatsächlich um einen stabilen Trend handelt, bleibt jedoch offen. Zwar überwog bei vier von fünf Fragen in dieser Altersgruppe die befürwortende Perspektive; dennoch waren 65 \% der Befragten dieser Gruppe der Meinung, man solle die Gentechnik in der Landwirtschaft verbieten, weil sie Risiken berge, die wir nicht überblicken könnten. Bericht unter: www.gruenevernunft.de/sites/default/files/meldungen/ Bericht-Gentechnik\%20in\%20der\%20Landwirtschaft.pdf [22.01.2014]. Tabellarische Übersicht aller Ergebnisse unter: www.gruenevernunft.de/sites/default/files/meldungen/Tabellarische\%20\%C3\%9Cbersicht\%20der\%20Studie\%20Gentechnik\%20in\%20der\%20Landwirtschaft\%5B2\%5D.pdf [22.01.2014].

108 Für die Printmedien (a) wurde für den Zeitraum vom 01.6.2011 bis 31.05.2012 eine Volltextsuche (Stichwort: „Grüne Gentechnik“) in den Leitmedien SÜDDEUTSCHE ZEITUNG, FRANKFURTER ALLGEMEINE ZEITUNG, DER SPIEGEL sowie DIE ZEIT durchgeführt. Für die Internetrecherche (b) wurde am 04.06.2012 via der Suchmaschine Google eine Suche nach dem Stichwort „Grüne Gentechnik“ durchgeführt; berücksichtigt wurden die ersten zehn Treffer. Mögliche Stellungnahmen (c) wurden ebenfalls online via Stichwortsuche („Grüne Gentechnik“, „Grüne Gentechnologie“ sowie „Agrogentechnik“ in Verbindung mit „Stellungnahme“) am 04.06.2012 via Google recherchiert; berücksichtigt wurden diejenigen Texte unter den jeweils ersten zehn Treffern, die als Stellungnahmen im engeren Sinne identifiziert wurden. 
Abbildung illustriert dabei die Komplexität und Vernetzung der verschiedenen Diskussionsstränge, auch wenn die Darstellung immer eine Momentaufnahme bleiben muss, da Themen- und Anwendungsfelder für die grüne Gentechnologie - wie im Kapitel vorangehendend dargelegt - gegenwärtig sehr dynamisch sind.

Für den Themenbereich grüne Gentechnologie steht die öffentliche Wahrnehmung im Sinne einer geringen Akzeptanz der grünen Gentechnologie in der Bevölkerung im Vordergrund. Diese hängt unter anderem mit angenommenen ökologischen oder gesundheitlichen Risiken zusammen, obwohl auch mögliche ökologische Vorteile und der Beitrag der grünen Gentechnologie zur nachhaltigen Ernährungssicherung einer wachsenden Weltbevölkerung in besonderem Maße öffentlich diskutiert werden. Auch ökonomische Aspekte spielen in der Diskussion eine große Rolle. Der Wunsch nach einem Ausgleich widersprechender Interessen und Schutzgüter beeinflusst dabei auch den europäischen und deutschen Rechtsrahmen und schlägt sich in der Pflicht zur Kennzeichnung gentechnisch veränderter Waren und der damit verbundenen Wahlfreiheit für Verbraucher nieder.

Abbildung 2: Aktuelle Problemfelder zur Grünen Gentechnologie in Deutschland

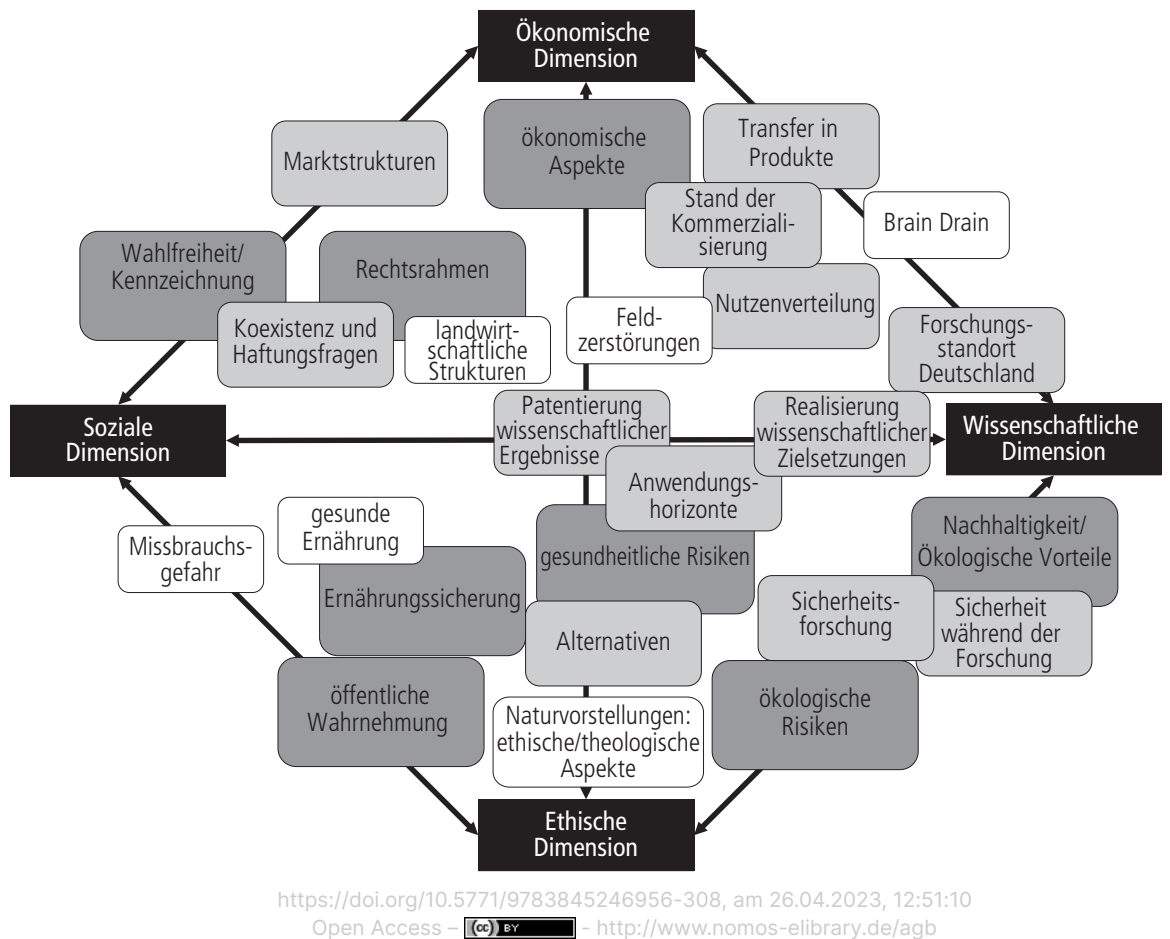


Die ermittelten Problemfelder werden in der Tabelle 1 mittels Thesen inhaltlich beschrieben und eingegrenzt. Ihre tabellarische Listung ergibt sich aus ihrer Verortung innerhalb der gesetzten Leitdimensionen (vgl. Abbildung 2). Den Problemfeldern sind in einem zweiten Schritt ausschließlich diejenigen Indikatoren zugeordnet, die sie real quantitativ ausleuchten können und die im Folgenden in standardisierten Datenblättern aufbereitet sind. Dabei ist zu beachten, dass die unterschiedlichen Problemfelder zum einen in Abhängigkeit vom zugrunde liegenden Sachverhalt unterschiedlich mit Indikatoren gefüllt werden können, zum anderen sind nicht für alle denkbaren Indikatoren für ein jeweiliges Problemfeld tatsächlich belastbare und transparente Daten zugänglich. Da die IAG primär auf externe Daten zurückgreift, kann zudem kein Einfluss auf Modus und Intervall ihrer Erhebung genommen werden - mit entsprechenden Konsequenzen für die Fortschreibung. Berücksichtigt werden allgemein also nur diejenigen Problemfelder, die sich quantitativ präzisieren lassen. Die hier nicht mit Indikatoren ausgeleuchteten Aspekte müssen qualitativ beschrieben werden und gehen, wo möglich, in dem entsprechenden Kapitel auf.

Tabelle 1: Problemfelder zur grünen Gentechnologie in Deutschland und Indikatoren zu ihrer Beschreibung

\begin{tabular}{|c|c|c|}
\hline Problemfeld & These & Indikatoren \\
\hline \multicolumn{3}{|c|}{ im Kreuzfeld aller Dimensionen } \\
\hline $\begin{array}{l}\text { Patentierung } \\
\text { wissenschaftli- } \\
\text { cher Ergebnisse }\end{array}$ & $\begin{array}{l}\text { Patente sind in anwendungsnahen Disziplinen } \\
\text { ein Ausdruck innovativen Forschungsgesche- } \\
\text { hens. Sie stellen in besonderem Maß eine } \\
\text { Vernetzung von Wissenschaft und Wirtschaft } \\
\text { dar, die durchaus nicht spannungsfrei ist. Bei } \\
\text { Biopatenten, die Organismen oder Teile von } \\
\text { innen wie z. B. einzelne Gene betreffen, stellt } \\
\text { sich zudem die Frage, inwiefern und in welcher } \\
\text { Form Leben kommodifiziert werden kann. Als } \\
\text { Anreiz für Investitionen in die grüne Gentech- } \\
\text { nologie ist die Patentierung von Genkonstruk- } \\
\text { ten und GMOs von großer Bedeutung. Unter } \\
\text { der Überschrift „Patente auf Leben“ wird über } \\
\text { die Zulässigkeit solcher Patente gestritten. }\end{array}$ & $\begin{array}{l}\text { Anzahl der Patentanmeldungen im Bereich } \\
\text { grüner Gentechnologie (GG-09) } \\
\text { Anzahl der patentanmeldenden Unternehmen } \\
\text { und öffentlichen Einrichtungen im Bereich } \\
\text { grüner Gentechnologie (GG-10) }\end{array}$ \\
\hline
\end{tabular}




\begin{tabular}{|c|c|c|}
\hline Problemfeld & These & Indikatoren \\
\hline \multicolumn{3}{|c|}{ Wissenschaftliche Dimension <> Ethische Dimension } \\
\hline $\begin{array}{l}\text { Nachhaltigkeit/ } \\
\text { ökologische } \\
\text { Vorteile }\end{array}$ & $\begin{array}{l}\text { Der Einsatz der Gentechnik in der Pflanzen- } \\
\text { züchtung kann mit positiven Effekten auf } \\
\text { die Umwelt verbunden sein (z.B. verringerter } \\
\text { Einsatz von Pflanzenschutzmitteln). Aufgrund } \\
\text { dessen stellt sich die Frage, ob bestimmte An- } \\
\text { wendungen als nachhaltig eingestuft werden } \\
\text { und mit dem ökologischen Landbau vereinbar } \\
\text { sein könnten. }\end{array}$ & \\
\hline $\begin{array}{l}\text { ökologische } \\
\text { Risiken }\end{array}$ & $\begin{array}{l}\text { Der Einsatz der Gentechnologie in der Pflan- } \\
\text { zenzüchtung kann mit negativen Auswirkun- } \\
\text { gen auf die Umwelt verbunden sein. Diskutiert } \\
\text { werden Auswilderung und Auskreuzung, } \\
\text { Wirkungen auf Nicht-Zielorganismen und } \\
\text { Artenvielfalt sowie resistente Unkräuter und } \\
\text { Schädlinge. }\end{array}$ & \\
\hline $\begin{array}{l}\text { Sicherheitsfor- } \\
\text { schung }\end{array}$ & $\begin{array}{l}\text { Die Sicherheitsforschung untersucht mögliche } \\
\text { ökologische und gesundheitliche Risiken von } \\
\text { gv-Pflanzen. Diskutiert wird, welche Art der } \\
\text { Prüfung ausreichend ist und ob bisherige } \\
\text { Prüfverfahren Lücken aufweisen. }\end{array}$ & $\begin{array}{l}\text { Öffentliche Ausgaben für die Risikoforschung } \\
\text { im Bereich grüner Gentechnologie (GG-11) }\end{array}$ \\
\hline $\begin{array}{l}\text { Sicherheit } \\
\text { während der } \\
\text { Forschung }\end{array}$ & $\begin{array}{l}\text { Für die Forschung an gv-Pflanzen im Gewächs- } \\
\text { haus und besonders im Freiland sind spezielle } \\
\text { Sicherheitskonzepte nötig. Befürchtet wird eine } \\
\text { unkontrollierte Ausbreitung von Versuchs- } \\
\text { pflanzen. }\end{array}$ & \\
\hline \multicolumn{3}{|c|}{ Wissenschaftliche Dimension <> Soziale Dimension } \\
\hline $\begin{array}{l}\text { Anwendungs- } \\
\text { horizonte }\end{array}$ & $\begin{array}{l}\text { Anwendungshorizonte werden bereits heute } \\
\text { diskutiert, sind aber in der Praxis bislang } \\
\text { noch nicht realisiert. Sie schließen gleichfalls } \\
\text { visionäre Ziele mit hohem Innovationspotenzial } \\
\text { ein, deren Durchführbarkeit dementsprechend } \\
\text { ungewiss ist. Anwendungshorizonte im Bereich } \\
\text { der grünen Gentechnologie umfassen etwa die } \\
\text { Vision, langfristig einen wesentlichen Beitrag } \\
\text { zur Welternährung leisten zu können. }\end{array}$ & \\
\hline
\end{tabular}




\begin{tabular}{|l|l|l|}
\hline Problemfeld & These & Indikatoren \\
\hline $\begin{array}{l}\text { Realisierung } \\
\text { wissenschaft- } \\
\text { licher Zielset- } \\
\text { zungen }\end{array}$ & $\begin{array}{l}\text { Wissenschaftliche Forschung will neue } \\
\text { Erkenntnisse und Technologien generieren. Zu } \\
\text { ihrem Wesen gehört eine begrenzte Planbar- } \\
\text { keit und Ergebnisoffenheit. Nichtsdestotrotz } \\
\text { beeinflussen die vorhandenen Rahmenbedin- } \\
\text { gungen - wie die wissenschaftliche Infrastruk- }\end{array}$ & $\begin{array}{l}\text { Anzahl der Traits in Freisetzungsversu- } \\
\text { chen (GG-02) } \\
\text { Anzahl der Freisetzungsversuche (GG- } \\
\text { tur, Förderungsmöglichkeiten oder geltendes }\end{array}$ \\
& $\begin{array}{ll}\text { Recht - die Realisierung von gesetzten } \\
\text { Forschungszielen, die sich quantifizierbar z. B. }\end{array}$ & \\
& $\begin{array}{l}\text { in Veröffentlichungen, Forschungspreisen oder } \\
\text { akademischen Abschlüssen niederschlagen. }\end{array}$ & \\
& Wissenschaftliche Zielsetzungen und konkret \\
& etablierte Anwendungen sind für Nichtfach- & \\
& leute schwer zu unterscheiden. Zum Wesen & \\
& $\begin{array}{l}\text { der wissenschaftlichen Forschung gehört, dass } \\
\text { nicht alle wissenschaftlichen Zielsetzungen } \\
\text { erreicht werden. }\end{array}$ & \\
\hline
\end{tabular}

\section{Wissenschaftliche Dimension <> Ökonomische Dimension}

Braindrain

\begin{tabular}{|l|l} 
& $\begin{array}{l}\text { schungslandschaft mit ihrer Mobilitäts-Anfor- } \\
\text { derung läuft Deutschland Gefahr, wissen- } \\
\text { schaftliche Talente zu verlieren, ohne dass im } \\
\text { vergleichbaren Maß Wissenschaftlerinnen und } \\
\text { Wissenschaftler gewonnen werden können. } \\
\text { Die Abwanderung hochqualifizierter Wissen- } \\
\text { schaftlerinnen und Wissenschaftler ins Ausland } \\
\text { könnte zu einer Schwächung des Wissen- } \\
\text { schafts- und Wirtschaftsstandorts Deutschland } \\
\text { auf dem Gebiet der grünen Gentechnologie } \\
\text { führen. }\end{array}$ \\
\hline Forschungs- & $\begin{array}{l}\text { Die internationale Attraktivität eines For- } \\
\text { standort } \\
\text { seutschungsstandortes hängt von einer Vielzahl } \\
\text { an Faktoren ab, z. B. der vorhandenen } \\
\text { wissenschaftlichen Infrastruktur, dem Ausmaß } \\
\text { und der Art an Fördermaßnahmen oder auch } \\
\text { von nationalen rechtlichen Regelungen, die } \\
\text { die wissenschaftliche Praxis beeinflussen. } \\
\text { Der internationale Ruf und die Vernetzung } \\
\text { innerhalb der globalisierten Forschungsland- } \\
\text { schaft spielen ebenfalls eine Rolle. Für die } \\
\text { grüne Gentechnologie in Deutschland wird vor } \\
\text { dem Hintergrund internationaler Entwick- } \\
\text { lungen und rechtlicher Rahmenbedingungen } \\
\text { eine Abkopplung Deutschlands (z.B. aufgrund } \\
\text { politisch-rechtlicher Rahmenbedingungen) von } \\
\text { der internationalen Entwicklung befürchtet. }\end{array}$ \\
&
\end{tabular}

Öffentliche Forschungsaufwendungen für die grüne Gentechnologie (GG-06) Ausgaben zur Forschung und Entwicklung in Deutschland (GG-07) Anteil der öffentlichen Forschungsaufwendungen für die grüne Gentechnologie an den Ausgaben des BMBF (GG-08) Anzahl der Patentanmeldungen im Bereich grüner Gentechnologie (GG-09) Anzahl der patentanmeldenden Unternehmen und öffentlichen Einrichtungen im Bereich grüner Gentechnologie (GG-10) Neuerscheinungen zum Themenbereich grüne Gentechnologie (GG-24)* Printmediale Abbildung des Themenbereichs grüne Gentechnologie (GG-25)* 


\begin{tabular}{|c|c|c|}
\hline Problemfeld & These & Indikatoren \\
\hline $\begin{array}{l}\text { Nutzenvertei- } \\
\text { lung }\end{array}$ & $\begin{array}{l}\text { Der Nutzen der bisherigen kommerziell } \\
\text { verfügbaren Anwendungen der grünen Gen- } \\
\text { technologie liegt eher beim Landwirt und den } \\
\text { beteiligten Firmen als beim Verbraucher. }\end{array}$ & \\
\hline $\begin{array}{l}\text { Stand der Kom- } \\
\text { merzialisierung }\end{array}$ & $\begin{array}{l}\text { In Deutschland und Europa bleibt die Kommer- } \\
\text { zialisierung der grünen Gentechnologie hinter } \\
\text { der internationalen Entwicklung zurück. Ein } \\
\text { kommerzieller Anbau von gv-Pflanzen findet in } \\
\text { Deutschland nicht mehr statt. }\end{array}$ & $\begin{array}{l}\text { Anzahl der in der EU zugelassenen und } \\
\text { nicht mehr gültigen Traits (GG-01) } \\
\text { Umsatz gentechnisch veränderten Saat- } \\
\text { guts weltweit (GG-04) } \\
\text { Flächenanteil gentechnisch veränderter } \\
\text { Pflanzen an der weltweiten Anbauflä- } \\
\text { che (GG-05) } \\
\text { Anteil gentechnisch veränderter Sorten } \\
\text { an zugelassenen Sorten (GG-12) } \\
\text { Anbauflächen einzelner Kulturarten } \\
\text { (GG-13) } \\
\text { Flächenanteile einzelner Arten an der } \\
\text { landwirtschaftlichen Nutzfläche (Kultur- } \\
\text { artendiversität) (GG-14) } \\
\text { Flächenanteil gentechnisch veränderter Sorten } \\
\text { an der landwirtschaftlichen Nutzfläche (GG-15) } \\
\text { Akzeptanz gentechnisch veränderter Pflanzen } \\
\text { bei Landwirten (geäußerte Zustimmung) } \\
\text { (GG-19) } \\
\text { Anzahl als Lebens- und Futtermittel } \\
\text { zugelassener gentechnisch veränderter } \\
\text { Pflanzen (GG-20) } \\
\text { Verteilung der zugelassenen Traits auf } \\
\text { Firmen (GG-22) }\end{array}$ \\
\hline $\begin{array}{l}\text { Transfer in } \\
\text { Produkte }\end{array}$ & $\begin{array}{l}\text { Wissenschaft kann allgemein auch unter } \\
\text { ökonomischen Prämissen bewertet werden. } \\
\text { Das ist vor allem dann möglich, wenn konkrete } \\
\text { Produkte zur Marktreife geführt werden. } \\
\text { Im Bereich der grünen Gentechnologie gibt } \\
\text { es eine rasante Entwicklung der Forschung, } \\
\text { deren Ergebnisse in Teilbereichen bereits in die } \\
\text { Entwicklung von Produkten einfließen. }\end{array}$ & \\
\hline \multicolumn{3}{|c|}{ Ethische Dimension $<>$ Soziale Dimension } \\
\hline $\begin{array}{l}\text { Ernährungssi- } \\
\text { cherung }\end{array}$ & $\begin{array}{l}\text { Eine wachsende Weltbevölkerung verlangt } \\
\text { nach mehr Lebensmitteln bei gleichzeitig } \\
\text { schrumpfenden Anbauflächen. Daher gilt es } \\
\text { zu untersuchen, ob der Einsatz der grünen } \\
\text { Gentechnologie dazu beitragen kann, die Er- } \\
\text { nährungssicherung in der Welt zu verbessern. }\end{array}$ & \\
\hline
\end{tabular}




\begin{tabular}{|c|c|c|}
\hline Problemfeld & These & Indikatoren \\
\hline $\begin{array}{l}\text { gesunde } \\
\text { Ernährung }\end{array}$ & $\begin{array}{l}\text { In Deutschland stellen ernährungsbedingte } \\
\text { Krankheiten ein wachsendes Problem dar. In } \\
\text { Entwicklungsländern ist Mangelernährung ein } \\
\text { großes Problem. Diskutiert wird folglich, inwie- } \\
\text { weit gv-Pflanzen zu einer gesunden Ernährung } \\
\text { beitragen können. }\end{array}$ & \\
\hline $\begin{array}{l}\text { Missbrauchs- } \\
\text { gefahr }\end{array}$ & $\begin{array}{l}\text { Neue Technologien wie die grüne Gentechno- } \\
\text { logie können gegen das Wohl des Menschen } \\
\text { zweckentfremdet werden. Daraus resultiert } \\
\text { die Frage, inwieweit es realistisch ist, dass Me- } \\
\text { thoden der grünen Gentechnologie absichtlich } \\
\text { missbraucht werden? }\end{array}$ & \\
\hline $\begin{array}{l}\text { öffentliche } \\
\text { Wahrnehmung }\end{array}$ & $\begin{array}{l}\text { Der Einsatz und die Etablierung neuer } \\
\text { technologischer Verfahren hängen zentral } \\
\text { von deren gesellschaftlicher Wahrnehmung } \\
\text { ab. Sie zeigen zudem, welche Hoffnungen } \\
\text { und Befürchtungen diesbezüglich in der } \\
\text { Bevölkerung kursieren. Bei Endverbrauchern } \\
\text { treffen die Produkte der grünen Gentechno- } \\
\text { logie auf geringe Akzeptanz. Das Problemfeld } \\
\text { beinhaltet die öffentliche Präsenz und zugleich } \\
\text { Auseinandersetzung mit dem Thema grüne } \\
\text { Gentechnologie. }\end{array}$ & $\begin{array}{l}\text { Verbraucherakzeptanz der grünen } \\
\text { Gentechnologie (GG-17) } \\
\text { Akzeptanz gentechnisch veränderter Pflanzen } \\
\text { bei Landwirten (gentechnikfreie Regionen) } \\
\text { (GG-18) } \\
\text { Akzeptanz gentechnisch veränderter Pflanzen } \\
\text { bei Landwirten (geäußerte Zustimmung) } \\
\text { (GG-19) } \\
\text { Anzahl als Lebensmittel und Futtermit- } \\
\text { tel zugelassener gentechnisch veränder- } \\
\text { ter Pflanzen (GG-20) } \\
\text { Sachbeschädigungen im Zusammenhang } \\
\text { mit der grünen Gentechnologie (GG-21) } \\
\text { Neuerscheinungen zum Themenbereich } \\
\text { grüne Gentechnologie (GG-24)* } \\
\text { Printmediale Abbildung des Themenbe- } \\
\text { reichs grüne Gentechnologie (GG-25)* } \\
\text { Internetpräsenz zum Stichwort grüne } \\
\text { Gentechnologie (GG-26)* }\end{array}$ \\
\hline \multicolumn{3}{|c|}{ Ethische Dimension <> Ökomische Dimension } \\
\hline Alternativen & $\begin{array}{l}\text { Da die grüne Gentechnologie umstritten } \\
\text { ist, wird einerseits versucht, Züchtungsziele } \\
\text { mit alternativen Methoden zu erreichen. } \\
\text { Andererseits werden Alternativen für die } \\
\text { Erreichung gesellschaftspolitischer Ziele wie } \\
\text { der Beseitigung von Hunger und Mangelernäh- } \\
\text { rung gesucht. }\end{array}$ & \\
\hline $\begin{array}{l}\text { Feldzerstörun- } \\
\text { gen }\end{array}$ & $\begin{array}{l}\text { Die Freilandforschung zur grünen Gentechno- } \\
\text { logie wird in Deutschland durch Feldzerstö- } \\
\text { rungen massiv behindert bzw. unmöglich } \\
\text { gemacht. }\end{array}$ & $\begin{array}{l}\text { Sachbeschädigungen im Zusammenhang } \\
\text { mit der grünen Gentechnologie (GG-21) }\end{array}$ \\
\hline
\end{tabular}




\begin{tabular}{|c|c|c|}
\hline Problemfeld & These & Indikatoren \\
\hline $\begin{array}{l}\text { gesundheitliche } \\
\text { Risiken }\end{array}$ & $\begin{array}{l}\text { Gesundheitliche Risiken spielen in der öffent- } \\
\text { lichen Wahrnehmung der grünen Gentechnolo- } \\
\text { gie eine große Rolle. Im Rahmen der Zulassung } \\
\text { eines GMO werden mögliche gesundheitliche } \\
\text { Effekte unter anderem in Fütterungsstudien } \\
\text { untersucht. Kritikern gehen die Untersuchun- } \\
\text { gen jedoch nicht weit genug. }\end{array}$ & \\
\hline $\begin{array}{l}\text { Naturvorstellun- } \\
\text { gen: ethische/ } \\
\text { theologische } \\
\text { Aspekte }\end{array}$ & $\begin{array}{l}\text { Das Überschreiten von Artgrenzen und die } \\
\text { direkte Manipulation des Erbgutes von Pflan- } \\
\text { zen kann in Abhängigkeit von moralischen } \\
\text { Grundüberzeugungen und Glaubensfragen } \\
\text { unterschiedlich bewertet werden. Dabei steht } \\
\text { die Frage zur Disposition, inwieweit es sich } \\
\text { um einen unzulässigen Eingriff in die Natur } \\
\text { bzw. Schöpfung handelt, bzw. wie groß das } \\
\text { Gefährdungspotenzial ist. }\end{array}$ & \\
\hline $\begin{array}{l}\text { ökonomische } \\
\text { Aspekte }\end{array}$ & $\begin{array}{l}\text { Der ökonomischen Verwertbarkeit von } \\
\text { Forschungsergebnissen wird gegenwärtig ein } \\
\text { hoher Stellenwert zugeschrieben: Für ein an } \\
\text { Rohstoffen armes Land wie Deutschland gilt } \\
\text { eine wissensbasierte Bioökonomie als zentral } \\
\text { für den Erhalt wirtschaftlicher Prosperität und } \\
\text { internationaler Wettbewerbsfähigkeit. Zu den } \\
\text { ökonomischen Aspekten gehören mögliche fi- } \\
\text { nanzielle Gewinne von Landwirten und Firmen, } \\
\text { eine Gefahr der Monopolbildung aber auch } \\
\text { mögliche Haftungsfragen. Auch die Sicherung } \\
\text { von Arbeitsplätzen sowie ein finanzieller } \\
\text { Nutzen für Verbraucher werden diskutiert. }\end{array}$ & \\
\hline \multicolumn{3}{|c|}{ Soziale Dimension <>Ökonomische Dimension } \\
\hline $\begin{array}{l}\text { Koexistenz und } \\
\text { Haftungsfragen }\end{array}$ & $\begin{array}{l}\text { Es wird diskutiert, inwieweit die Koexistenz, } \\
\text { also das Nebeneinander von gv-Pflanzen und } \\
\text { konventioneller bzw. ökologischer Land- } \\
\text { wirtschaft, möglich ist. Dabei geht es auch } \\
\text { um spezielle Haftungsregelungen, etwa für } \\
\text { den Fall der Ausbreitung von gv-Pflanzen in } \\
\text { benachbarte Felder. }\end{array}$ & $\begin{array}{l}\text { Flächenanteil des Ökolandbaus an der } \\
\text { gesamten landwirtschaftlichen Nutzflä- } \\
\text { che (GG-16) } \\
\text { Spuren gentechnisch veränderter Orga- } \\
\text { nismen in Lebensmitteln in Deutschland } \\
(\text { GG-23)* }\end{array}$ \\
\hline $\begin{array}{l}\text { landwirtschaftli- } \\
\text { che Strukturen }\end{array}$ & $\begin{array}{l}\text { Es wird befürchtet, dass gv-Pflanzen land- } \\
\text { wirtschaftliche Strukturen ändern und die } \\
\text { Tendenz zu einer industriellen Landwirtschaft } \\
\text { verstärken könnten. }\end{array}$ & \\
\hline Marktstrukturen & $\begin{array}{l}\text { Der Markt für GVO wird von wenigen Firmen } \\
\text { kontrolliert (Monopolbildung). Es werden } \\
\text { Abhängigkeitsstrukturen von Landwirten von } \\
\text { diesen Firmen befürchtet. }\end{array}$ & \\
\hline
\end{tabular}




\begin{tabular}{|l|l|l|}
\hline Problemfeld & These & Indikatoren \\
\hline Rechtsrahmen & $\begin{array}{l}\text { Der rechtliche Rahmen auf nationaler und } \\
\text { europäischer Ebene bestimmt über die } \\
\text { Zulässigkeit von gentechnischen Verfahren und } \\
\text { definiert ihren Einsatz in der wissenschaftli- } \\
\text { chen Praxis bzw. formuliert dafür notwendige } \\
\text { Rahmenbedingungen. Er hat eine Funktion bei } \\
\text { der Vermittlung von einander widersprechen- } \\
\text { den Interessen und Schutzgütern. }\end{array}$ & \\
\hline Wahlfreiheit/ & $\begin{array}{l}\text { Die dem Grundsatz der Wahlfreiheit folgende } \\
\text { Kennzeichnung von gv-Lebensmitteln erlaubt } \\
\text { Verbrauchern die freie Entscheidung, sich für } \\
\text { oder gegen die Gentechnik bei Lebensmitteln } \\
\text { zu entscheiden. }\end{array}$ & \\
\hline
\end{tabular}

Die fett markierten Indikatoren werden nachfolgend anhand detaillierter Datenblätter vorgestellt und grafisch aufbereitet; * kennzeichnet neue Indikatoren im Vergleich zur letzten Veröffentlichung der Daten (vgl. Müller-Röber et al. 2013:181-246).

Die grüne Gentechnologie wird seit dem Bestehen der Arbeitsgruppe beobachtet, 2005 wurden erstmals in diesem Sinne standardisierte Indikatorenblätter publiziert (Hucho et al. 2005:367-370; 384-445). Ein Großteil der hier vorgestellten Daten sind Fortschreibungen von Indikatoren, die bereits im Themenband grüne Gentechnologie (MüllerRöber et al. 2013:181-246, (GG-01 bis GG-22) sowie im „Zweiten Gentechnologiebericht“ (Müller-Röber et al. 2009:286-333 (GG-01 bis GG-20) veröffentlicht wurden. Es konnten jedoch nicht alle dieser Indikatoren weitergeführt werden. Weggefallen sind die Indikatoren GG-06 bis GG-11, GG-15 sowie GG-18 und GG-19. Neu hinzugekommen sind die Indikatoren GG-23 bis GG-26. Die Rubriken „Abgrenzung der Berechnungsgrößen“ und „Aussagefähigkeit“ bilden dabei, wie auch bei den anderen Themen dieses Bandes, den interpretativen Rahmen. 
Laufende Nr:: GG-01

Problemfeld: Stand der Kommerzialisierung

\section{INDIKATOR: ANZAHL DER IN DER EU ZUGELASSENEN UND NICHT MEHR GÜLTIGEN TRAITS}

\section{DATENQUELLE:}

Amtsblatt der Europäischen Union über EUR-Lex. Unter:

http://eur-lex.europa.eu/LexUriServ/LexUriServ.do?uri=0J:L:2001:106:0001:0038:DE:PDF

http://eur-lex.europa.eu/LexUriServ/LexUriServ.do?uri=0J:L:1997:043:0001:0006:DE:PDF

Bundesamt für Verbraucherschutz und Lebensmittelsicherheit. Unter.

http://www.bvl.bund.de/DE/06_Gentechnik/02_Verbraucher/03_Genehmigungen/01_Inverkehrbringen/gentech-

nik_GenehmigungenInverkehrbringen_node.html

Europäische Kommission. Unter:

http://ec.europa.eu/food/dyna/gm_register/index_en.cfm

Veröffentlichung des Forum Bio- und Gentechnologie - Verein zur Förderung der gesellschaftlichen Diskussionskultur

e. V. unter:

http://www.transgen.de/zulassung/gvo/

Zugriff (alle): August 2013, Stand: August 2013

\section{VERFÜGBARKEIT DER DATEN:}

öffentlich

\section{ABGRENZUNG DER BERECHNUNGSGRÖSSEN:}

keine Angabe

\section{GLIEDERUNG DER DARSTELLUNG:}

Anzahl der in der EU zugelassenen und nicht mehr gültigen Traits

\section{BERECHNUNGSHÄUFIGKEIT:}

jährlich

\section{AUSSAGEFÄHIGKEIT:}

Indem der Indikator die Bandbreite einsetzbarer (zugelassener) und nicht mehr gültiger gentechnischer Modifikationen darstellt, ermöglicht er eine Darstellung des Entwicklungsstands der Gentechnologie in der Pflanzenzucht in der EU und Deutschland. Ein früher Entwicklungsstand korreliert mit einer geringen Anzahl von Traits, die bei wachsender Reife der Technologie ansteigt. Erkennbar werden außerdem die Anwendungsschwerpunkte bei der Forschung und Entwicklung. Zu beachten sind folgende Spezifika: Der Messzeitpunkt des Indikators ist die konkrete Zulassung für den EU-Markt; dieser Zeitpunkt liegt somit ganz am Ende der Forschungs- und Entwicklungsphase. Entsprechend besitzt der Indikator keine Aussagekraft für Entwicklungen, die sich derzeit noch in der Forschungspipeline befinden oder die bereits beantragt, aber noch nicht zugelassen wurden. Geographisch ist der Indikator auf die EU eingegrenzt, und die hier erteilten Zulassungen variieren von denen in anderen Ländern. Außerdem gibt der Indikator keine Auskunft über den aktuellen Stand der funktionell charakterisierten Gene in der Grundlagenforschung. Während der Indikator Auskunft über den Stand der Anwendungsreife der grünen Gentechnologie gibt, liefert er keine Informationen über den wirtschaftlichen Entwicklungsstand der grünen Gentechnologie, also über die Bandbreite der Traits beim tatsächlichen Anbau zugelassener Pflanzen. 
产

홇

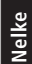

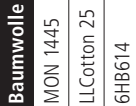

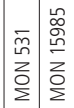

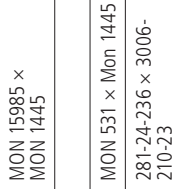

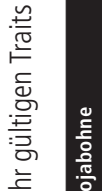

히잉

zo

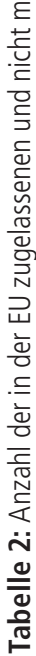

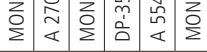

$\Sigma \Sigma$

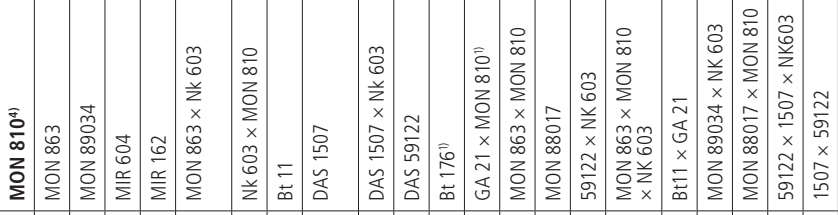




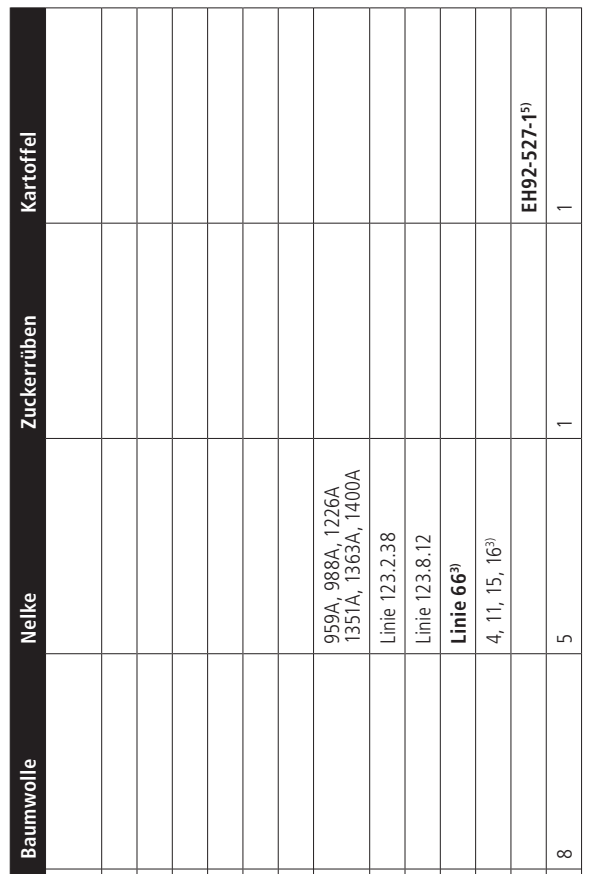

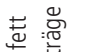

造 它

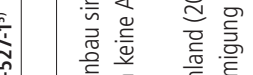

㝎 -

竞

ま

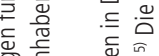

志言 离苋

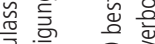

ㄹ. 이 을

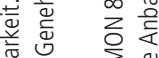

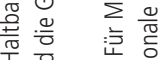

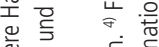

产 它 㐫

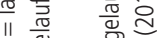

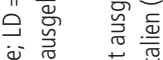

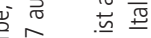

휴 흉휴

志 宛 产

ㅎํ

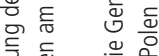

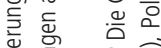

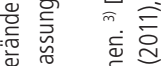

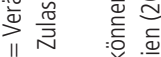

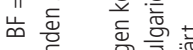

치 क्ष

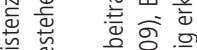

원

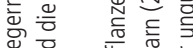

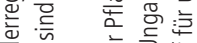

它.

讯

뜰

鵕

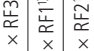

$\stackrel{\infty}{\Sigma} \bar{n} \bar{\Sigma}$

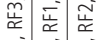

$\stackrel{\infty}{\Sigma} \overline{\bar{n}} \bar{\Sigma}$

6

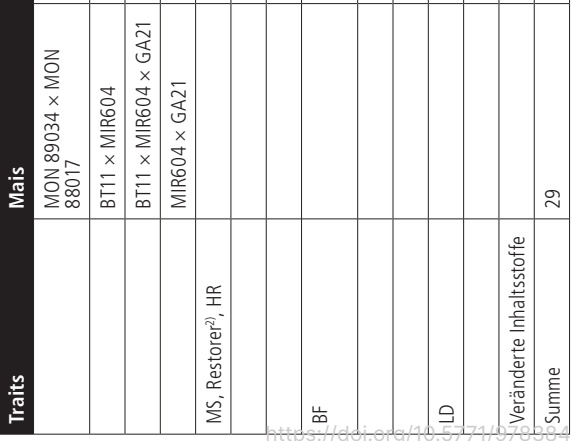

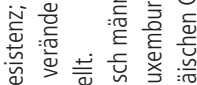

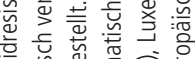

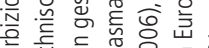

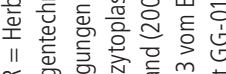

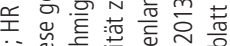

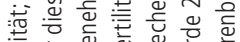

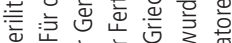

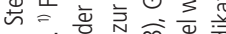

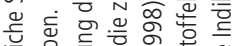

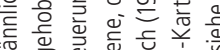

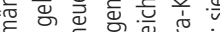
ह

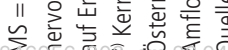


Laufende Nr:: GG-02

Problemfeld: Realisierung wissenschaftlicher Zielsetzungen

\section{INDIKATOR: ANZAHL DER TRAITS IN FREISETZUNGSVERSUCHEN}

\section{DATENQUELLE:}

Bundesamt für Verbraucherschutz und Lebensmittelsicherheit: Freisetzungsregister.

Unter: http://apps2.bvl.bund.de/freisetzung/

Zugriff: August 2013, Stand: August 2013.

VERFÜGBARKEIT DER DATEN:

öffentlich

\section{ABGRENZUNG DER BERECHNUNGSGRÖSSEN:}

Anzahl der Traits bei gentechnisch veränderten Pflanzen, die eine Genehmigung zur Freisetzung in Deutschland erhalten haben. Bakterien wurden nicht berücksichtigt. Ebenfalls nicht einbezogen werden seit 29.04.1991 Markergene als zu testendes Merkmal. Die Angabe erfolgt unabhängig von der Pflanzenart.

GLIEDERUNG DER DARSTELLUNG:

Anzahl der Traits in Freisetzungsversuchen

\section{BERECHNUNGSHÄUFIGKEIT:}

jährlich

\section{AUSSAGEFÄHIGKEIT:}

Indem der Indikator die Bandbreite beforschter Modifikationen in Freisetzungsversuchen darstellt, ermöglicht er eine Abbildung des Entwicklungsstands der Gentechnologie in der Pflanzenzucht in Deutschland. Ein früher Entwicklungsstand geht mit einer geringen Anzahl von Traits einher, die bei wachsender Reife der Technologie ansteigt. Erkennbar werden außerdem die Anwendungsschwerpunkte bei der Forschung und Entwicklung. Zu beachten sind folgende Spezifika: Lediglich ein Anteil gentechnisch erzeugter Pflanzen findet den Weg ins Freiland, somit ist der Indikator kein direktes Maß für die Forschungsaktivitäten in Deutschland. Der Messzeitpunkt des Indikators ist die Genehmigung für eine Freisetzung im Rahmen wissenschaftlicher Forschungsprogramme; dieser Zeitpunkt liegt somit noch vor der Anbauzulassung. Entsprechend besitzt der Indikator eine gute Aussagekraft hinsichtlich Entwicklungen, die sich derzeit noch in der Forschungspipeline befinden. Geographisch ist der Indikator auf Deutschland begrenzt. Offen bleibt, ob und in welchem Maße in Deutschland ansässige Institute und Firmen ihre Freisetzungen in anderen Ländern durchführen (innerhalb wie außerhalb der EU). Während der Indikator ein sehr gutes Bild für die wissenschaftliche Entwicklung zeichnet, liefert er keine Informationen über den wirtschaftlichen Entwicklungsstand der grünen Gentechnologie, also über die Bandbreite der Traits tatsächlich angebauter gentechnisch veränderter Pflanzen. 
Tabelle 3: Anzahl der Traits in Freisetzungsversuchen

\begin{tabular}{|c|c|c|c|c|c|c|c|c|c|c|c|c|c|c|c|}
\hline $\begin{array}{l}\text { Traits/Freisetzungs- } \\
\text { versuche }\end{array}$ & 2000 & 2001 & 2002 & 2003 & 2004 & 2005 & 2006 & 2007 & 2008 & 2009 & 2010 & 2011 & 2012 & 2013 & $\begin{array}{c}\text { Sum- } \\
\text { me }\end{array}$ \\
\hline Herbizidtoleranz & 24 & 26 & 25 & 22 & 22 & 15 & 10 & 6 & 8 & 7 & 4 & 4 & 3 & 2 & 178 \\
\hline $\begin{array}{l}\text { Kohlenhydratstoff- } \\
\text { wechsel }\end{array}$ & 15 & 13 & 16 & 15 & 12 & 10 & 9 & 7 & 4 & 2 & 2 & 2 & 1 & 1 & 109 \\
\hline Fettsäuremuster & 8 & 8 & 2 & 1 & 1 & 1 & 1 & 0 & 0 & 0 & 0 & 0 & 0 & 0 & 22 \\
\hline Virusresistenz & 6 & 6 & 5 & 5 & 4 & 4 & 2 & 0 & 0 & 0 & 0 & 0 & 0 & 0 & 32 \\
\hline Bakterienresistenz & 3 & 2 & 1 & 0 & 0 & 0 & 0 & 0 & 0 & 0 & 0 & 0 & 0 & 0 & 6 \\
\hline Pilzresistenz & 2 & 1 & 1 & 2 & 3 & 1 & 2 & 2 & 3 & 3 & 3 & 2 & 2 & 1 & 28 \\
\hline $\begin{array}{l}\text { Veränderte } \\
\text { Genexpression }\end{array}$ & 0 & 1 & 1 & 0 & 0 & 3 & 1 & 1 & 1 & 1 & 0 & 0 & 0 & 0 & 9 \\
\hline $\begin{array}{l}\text { Veränderte } \\
\text { Inhaltsstoffe }\end{array}$ & 1 & 0 & 0 & 1 & 1 & 2 & 3 & 2 & 1 & 0 & 0 & 0 & 0 & 0 & 11 \\
\hline $\begin{array}{l}\text { Stoffwechsel- } \\
\text { veränderungen }\end{array}$ & 1 & 1 & 0 & 0 & 1 & 2 & 2 & 2 & 2 & 0 & 0 & 0 & 0 & 0 & 11 \\
\hline Insektenresistenz & 0 & 0 & 0 & 0 & 0 & 1 & 1 & 1 & 0 & 0 & 0 & 0 & 0 & 0 & 3 \\
\hline $\begin{array}{l}\text { Entwicklungs- } \\
\text { veränderungen }\end{array}$ & 1 & 1 & 1 & 1 & 0 & 1 & 1 & 0 & 0 & 0 & 0 & 0 & 0 & 0 & 6 \\
\hline $\begin{array}{l}\text { Enzym-/Protein- } \\
\text { produktion }\end{array}$ & 1 & 1 & 0 & 1 & 1 & 1 & 0 & 0 & 0 & 0 & 0 & 0 & 0 & 0 & 5 \\
\hline $\begin{array}{l}\text { Schwermetall- } \\
\text { sanierung }\end{array}$ & 0 & 0 & 1 & 2 & 2 & 1 & 0 & 0 & 0 & 0 & 0 & 0 & 0 & 0 & 6 \\
\hline $\begin{array}{l}\text { Stärkezusammen- } \\
\text { setzung }\end{array}$ & 0 & 0 & 0 & 0 & 3 & 4 & 7 & 8 & 8 & 6 & 6 & 3 & 3 & 3 & 51 \\
\hline $\begin{array}{l}\text { Kohlenhydratstoff- } \\
\text { wechsel/Virus- } \\
\text { resistenz }\end{array}$ & 0 & 1 & 1 & 1 & 1 & 1 & 0 & 0 & 0 & 0 & 0 & 0 & 0 & 0 & 5 \\
\hline $\begin{array}{l}\text { Herbizidtoleranz/ } \\
\text { männliche Sterilität }\end{array}$ & 1 & 1 & 1 & 1 & 1 & 1 & 1 & 1 & 0 & 0 & 0 & 0 & 0 & 0 & 8 \\
\hline $\begin{array}{l}\text { Pilzresistenz/Virus- } \\
\text { resistenz }\end{array}$ & 1 & 1 & 1 & 1 & 1 & 1 & 0 & 0 & 0 & 0 & 0 & 0 & 0 & 0 & 6 \\
\hline $\begin{array}{l}\text { Entwicklungsver- } \\
\text { änderung/Kohlen- } \\
\text { hydratstoffwechsel }\end{array}$ & 1 & 1 & 1 & 1 & 1 & 1 & 1 & 1 & 1 & 0 & 0 & 0 & 0 & 0 & 9 \\
\hline $\begin{array}{l}\text { Herbizidtoleranz/ } \\
\text { Pilzresistenz }\end{array}$ & 1 & 1 & 1 & 1 & 1 & 0 & 0 & 0 & 0 & 0 & 0 & 0 & 0 & 0 & 5 \\
\hline $\begin{array}{l}\text { Kohlenhydratstoff- } \\
\text { wechsel/Pilzresistenz }\end{array}$ & 0 & 0 & 0 & 0 & 0 & 0 & 0 & 1 & 3 & 2 & 2 & 2 & 2 & 0 & 12 \\
\hline $\begin{array}{l}\text { Kohlenhydratstoff- } \\
\text { wechsel/Veränderte } \\
\text { Inhaltsstoffe }\end{array}$ & 2 & 1 & 0 & 0 & 0 & 0 & 0 & 0 & 0 & 0 & 0 & 0 & 1 & 1 & 5 \\
\hline $\begin{array}{l}\text { Kohlenhydratstoff- } \\
\text { wechsel/Aminosäure- } \\
\text { stoffwechsel }\end{array}$ & 0 & 1 & 1 & 1 & 0 & 0 & 0 & 0 & 0 & 0 & 0 & 0 & 0 & 0 & 3 \\
\hline $\begin{array}{l}\text { Pilzresistenz/ } \\
\text { Bakterienresistenz }\end{array}$ & 0 & 0 & 0 & 1 & 1 & 0 & 0 & 0 & 0 & 0 & 0 & 0 & 0 & 0 & 2 \\
\hline $\begin{array}{l}\text { Herbizidtoleranz/ } \\
\text { Insektenresistenz }\end{array}$ & 0 & 0 & 0 & 0 & 0 & 0 & 1 & 4 & 5 & 6 & 8 & 4 & 2 & 1 & 31 \\
\hline
\end{tabular}




\begin{tabular}{|c|c|c|c|c|c|c|c|c|c|c|c|c|c|c|c|}
\hline $\begin{array}{l}\text { Traits/Freisetzungs- } \\
\text { versuche }\end{array}$ & 2000 & 2001 & 2002 & 2003 & 2004 & 2005 & 2006 & 2007 & 2008 & 2009 & 2010 & 2011 & 2012 & 2013 & $\begin{array}{c}\text { Sum- } \\
\text { me }\end{array}$ \\
\hline $\begin{array}{l}\text { Pilzresistenz/Mobili- } \\
\text { sierung von Speicher- } \\
\text { kohlenhydraten }\end{array}$ & 0 & 0 & 0 & 0 & 0 & 0 & 1 & 1 & 1 & 1 & 1 & 0 & 0 & 0 & 5 \\
\hline $\begin{array}{l}\text { Reseratrolsynthese/ } \\
\text { Verringerung des } \\
\text { Sinaptingehalts }\end{array}$ & 0 & 0 & 0 & 0 & 0 & 0 & 1 & 1 & 0 & 0 & 0 & 0 & 0 & 0 & 2 \\
\hline $\begin{array}{l}\text { Biopolymer-Synthese/ } \\
\text { Antigen-Synthese }\end{array}$ & 0 & 0 & 0 & 0 & 0 & 0 & 1 & 1 & 1 & 1 & 1 & 1 & 2 & 0 & 8 \\
\hline $\begin{array}{l}\text { Abschalten pflanzen- } \\
\text { eigener Gene }\end{array}$ & 0 & 0 & 0 & 0 & 1 & 3 & 3 & 5 & 4 & 4 & 4 & 0 & 0 & 0 & 24 \\
\hline $\begin{array}{l}\text { Expression von } \\
\text { Antikörpern }\end{array}$ & 0 & 0 & 0 & 0 & 0 & 0 & 0 & 1 & 0 & 0 & 0 & 0 & 0 & 0 & 1 \\
\hline $\begin{array}{l}\text { Stärkegehalt/Knol- } \\
\text { lenertrag }\end{array}$ & 0 & 0 & 0 & 0 & 0 & 0 & 0 & 1 & 1 & 0 & 0 & 0 & 0 & 0 & 2 \\
\hline Biopolymer-Synthese & 0 & 0 & 0 & 0 & 0 & 0 & 0 & 1 & 1 & 1 & 2 & 2 & 0 & 0 & 7 \\
\hline $\begin{array}{l}\text { Attenuierte } \\
\text { (abgeschwächte) } \\
\text { Impfstämme }\end{array}$ & 0 & 0 & 0 & 0 & 0 & 0 & 0 & 0 & 0 & 0 & 0 & 0 & 1 & 1 & 2 \\
\hline Markierung & 0 & 0 & 0 & 0 & 0 & 0 & 0 & 0 & 0 & 0 & 0 & 0 & 2 & 1 & 3 \\
\hline Summe & 68 & 67 & 59 & 57 & 57 & 53 & 48 & 47 & 44 & 34 & 33 & 20 & 19 & 11 & 617 \\
\hline
\end{tabular}

Genehmigte Freisetzungsversuche, keine Angaben über die Anzahl der Orte, an denen die Freisetzung stattfand (siehe GG-03).

Unterschiede zu früheren Veröffentlichungen trotz gleicher Datenquelle wegen statistischer Änderungen möglich (unter anderem aufgrund von nachgemeldeten Standorten). Quelle: siehe Indikatorenblatt GG-02. 
Laufende Nr:: GG-03

Problemfeld: Realisierung wissenschaftlicher Zielsetzungen

\section{INDIKATOR: ANZAHL DER FREISETZUNGSVERSUCHE}

\section{DATENQUELLE:}

Bundesamt für Verbraucherschutz und Lebensmittelsicherheit: Freisetzungsregister.

Unter: http://apps2.bvl.bund.de/freisetzung/

Zugriff: August 2013, Stand: August 2013.

\section{VERFÜGBARKEIT DER DATEN:}

öffentlich und eigene Recherche

\section{ABGRENZUNG DER BERECHNUNGSGRÖSSEN:}

Freisetzungen gentechnisch veränderter Pflanzen in Deutschland nach Pflanzenarten, beantragten Orten und Jahren. In einem Freisetzungsantrag können mehrere Freisetzungsorte genannt werden, und eine Genehmigung kann für mehrere Jahre gültig sein. Infolgedessen werden weitaus höhere Zahlen genannt als bei einer reinen Auflistung der genehmigten Freisetzungsanträge (vgl. GG-02).

\section{GLIEDERUNG DER DARSTELLUNG:}

a) Anzahl der Freisetzungsversuche (nach Orten)

b) Anzahl der Freisetzungsorte

\section{BERECHNUNGSHÄUFIGKEIT:}

jährlich

\section{AUSSAGEFÄHIGKEIT:}

Der Indikator gibt Auskunft über die Forschungs- und Entwicklungsaktivitäten in Deutschland und stellt dar, welche unterschiedlichen Pflanzenarten im Zentrum der Forschung stehen. Dies ermöglicht einerseits, Schwerpunkte hinsichtlich beforschter Pflanzenarten aufzuzeigen, andererseits steht die Breite gentechnisch veränderter Pflanzen in der Freisetzungsphase für den Entwicklungsgrad der grünen Gentechnologie. Zu beachten sind folgende Spezifika: Der Messzeitpunkt des Indikators ist die Beantragung für eine Freisetzung im Rahmen wissenschaftlicher Forschungsprogramme; dieser Zeitpunkt liegt somit noch vor der Anbauzulassung. Entsprechend besitzt der Indikator eine gute Aussagekraft hinsichtlich Entwicklungen, die sich derzeit noch in der Forschungspipeline befinden. Geographisch ist der Indikator auf Deutschland limitiert. Offen bleibt, ob und in welchem Maße in Deutschland ansässige Institute und Firmen ihre Freisetzungen in anderen Ländern durchführen (innerhalb wie außerhalb der EU). Während der Indikator ein sehr gutes Bild für die wissenschaftliche Entwicklung zeichnet, liefert er keine Informationen über den wirtschaftlichen Entwicklungsstand der grünen Gentechnologie, also über die Bandbreite der tatsächlich angebauten gentechnisch veränderten Pflanzen. In den Jahren 1998 bis 2000 wurden viele Freisetzungen mit Freisetzungszeiträumen von bis zu zehn Jahren beantragt. Dabei handelte es sich unter anderem um Freisetzungen, die im Rahmen von Sortenprüfungen durch das Bundessortenamt durchgeführt werden sollten. Seit einigen Jahren werden die Sortenversuche allerdings lediglich noch mit gentechnisch veränderten Pflanzen durchgeführt, für die eine Genehmigung zum Inverkehrbringen vorliegt. Ein weiterer Aspekt zur Interpretation der vorliegenden Zahlen ist das Inkrafttreten der EU-Freisetzungsrichtlinie (2001/18/ EG) im Oktober 2002 
a) Abbildung 3: Anzahl der Freisetzungsversuche (nach Orten)

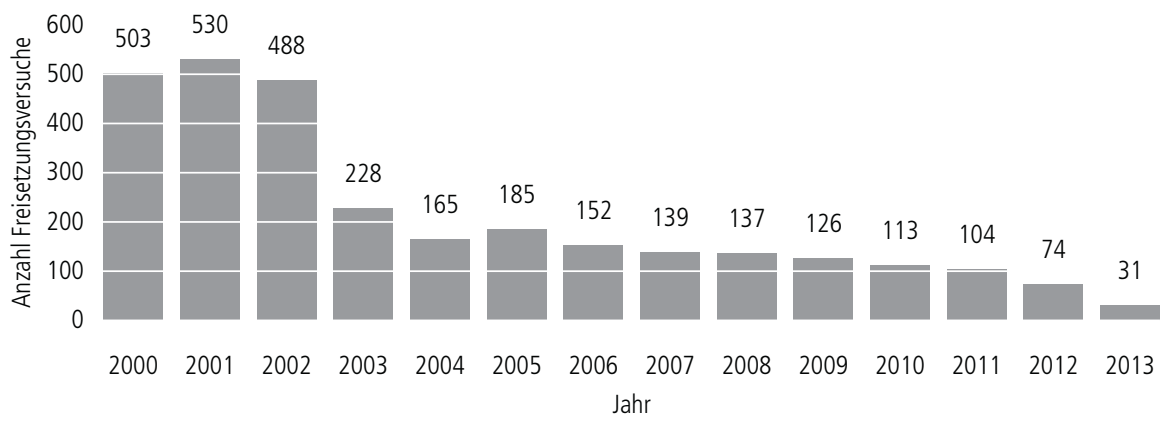

Unterschiede zu früheren Veröffentlichungen trotz gleicher Datenquelle wegen statistischer Änderungen unter anderem aufgrund von nachgemeldeten Standorten möglich. Im Unterschied zu GG-02 werden die Standorte erfasst und nicht die genehmigten Versuche. Deren Durchführung kann an mehreren Standorten erfolgen.

Quelle: siehe Indikatorenblatt GG-03.

b) Tabelle 4: Anzahl der Freisetzungsorte

\begin{tabular}{|l|r|r|r|r|r|r|r|r|r|r|r|r|r|r|r|r|r|r|}
\hline \multicolumn{2}{r|}{} & 2000 & 2001 & 2002 & 2003 & 2004 & 2005 & 2006 & 2007 & 2008 & 2009 & 2010 & 2011 & 2012 & 2013 & $\begin{array}{c}\text { Sum- } \\
\text { me }\end{array}$ \\
\hline Wein & 2 & 2 & 2 & 2 & 2 & 2 & 2 & 2 & 2 & 2 & 2 & 2 & 2 & 0 & 26 \\
\hline Pappel & 2 & 2 & 2 & 4 & 3 & 2 & 0 & 0 & 0 & 0 & 0 & 0 & 0 & 0 & 15 \\
\hline Tabak & 0 & 0 & 0 & 0 & 0 & 0 & 0 & 0 & 0 & 0 & 0 & 0 & 0 & 0 & 0 \\
\hline Petunie & 0 & 0 & 0 & 0 & 0 & 0 & 0 & 0 & 0 & 1 & 1 & 1 & 1 & 0 & 4 \\
\hline Nachtschatten & 0 & 0 & 0 & 0 & 1 & 3 & 3 & 5 & 4 & 4 & 3 & 0 & 0 & 0 & 23 \\
\hline Apfel & 0 & 0 & 0 & 2 & 2 & 2 & 2 & 2 & 2 & 2 & 2 & 0 & 0 & 0 & 16 \\
\hline Weizen & 0 & 0 & 0 & 1 & 1 & 0 & 1 & 1 & 2 & 1 & 1 & 2 & 3 & 3 & 16 \\
\hline Sojabohne & 0 & 0 & 0 & 0 & 1 & 1 & 1 & 1 & 1 & 1 & 0 & 0 & 0 & 0 & 6 \\
\hline Erbse & 1 & 1 & 0 & 0 & 0 & 1 & 1 & 1 & 0 & 0 & 0 & 0 & 0 & 0 & 5 \\
\hline Kartoffel & 34 & 33 & 33 & 36 & 46 & 74 & 75 & 62 & 70 & 48 & 48 & 62 & 54 & 23 & 698 \\
\hline Mais & 47 & 55 & 37 & 15 & 19 & 19 & 15 & 52 & 46 & 56 & 48 & 27 & 9 & 3 & 448 \\
\hline Zuckerrübe & 236 & 245 & 225 & 42 & 22 & 20 & 9 & 8 & 6 & 7 & 8 & 10 & 5 & 2 & 845 \\
\hline Raps & 181 & 192 & 189 & 126 & 68 & 61 & 43 & 5 & 4 & 4 & 0 & 0 & 0 & 0 & 873 \\
\hline Summe & 503 & 530 & 488 & 228 & 165 & 185 & 152 & 139 & 137 & 126 & 113 & 104 & 74 & 31 & 2975 \\
\hline
\end{tabular}

Unterschiede zu früheren Veröffentlichungen trotz gleicher Datenquelle wegen statistischer Änderungen möglich (unter anderem aufgrund von nachgemeldeten Standorten).

Quelle: siehe Indikatorenblatt $\mathrm{G}_{3}-03$. 
Laufende Nr:: GG-04

Problemfeld: Stand der Kommerzialisierung

\section{INDIKATOR: UMSATZ GENTECHNISCH VERÄNDERTEN SAATGUTS WELTWEIT}

\section{DATENQUELLE:}

Global status of Commercialized Biotech/GM crops: ISAAA.

Unter: www.isaaa.org/

www.isaaa.org/resources/publications/briefs/35/executivesummary/default.html www.isaaa.org/resources/publications/briefs/37/executivesummary/default.html www.isaaa.org/resources/publications/briefs/39/executivesummary/default.html www.isaaa.org/resources/publications/briefs/41/executivesummary/default.asp www.isaaa.org/resources/publications/briefs/42/executivesummary/default.asp www.isaaa.org/resources/publications/briefs/43/default.asp www.isaaa.org/resources/publications/briefs/44/executivesummary/default.asp https://www.vci.de/Downloads/Biotechnologie-Statistik.pdf Zugriff (alle): August 2013, Stand: Dezember 2012

\section{VERFÜGBARKEIT DER DATEN:}

öffentlich

\section{ABGRENZUNG DER BERECHNUNGSGRÖSSEN:}

Umsatz gentechnisch veränderter Kulturpflanzen in Mrd. US-Dollar. Die Zahlen basieren auf den Verkaufspreisen des Saatguts gentechnisch veränderter Pflanzen plus den zugehörigen Kosten für Anwendungen (Pflanzenschutz).

\section{GLIEDERUNG DER DARSTELLUNG:}

Umsatz gentechnisch veränderten Saatguts weltweit

\section{BERECHNUNGSHÄUFIGKEIT:}

jährlich

\section{AUSSAGEFÄHIGKEIT:}

Der Indikator ermittelt den wirtschaftlichen Stellenwert, den gentechnisch veränderte Pflanzen weltweit für die/das Saatgutwirtschaft/Agro-Business einnehmen. Grundlage sind weltweite Gesamtumsätze. Bei steigendem Anbau gentechnisch veränderter Pflanzen - wie im Zeitraum 2000 bis 2011 zu beobachten - trifft der Indikator keine Aussage zu der Frage, ob und inwieweit bezogen auf eine konstante Flächengröße eine Kostenreduktion oder -steigerung für die Landwirte durch den Einsatz gentechnisch veränderter Pflanzen auftrat. 
Abbildung 4: Umsatz gentechnisch veränderten Saatguts weltweit

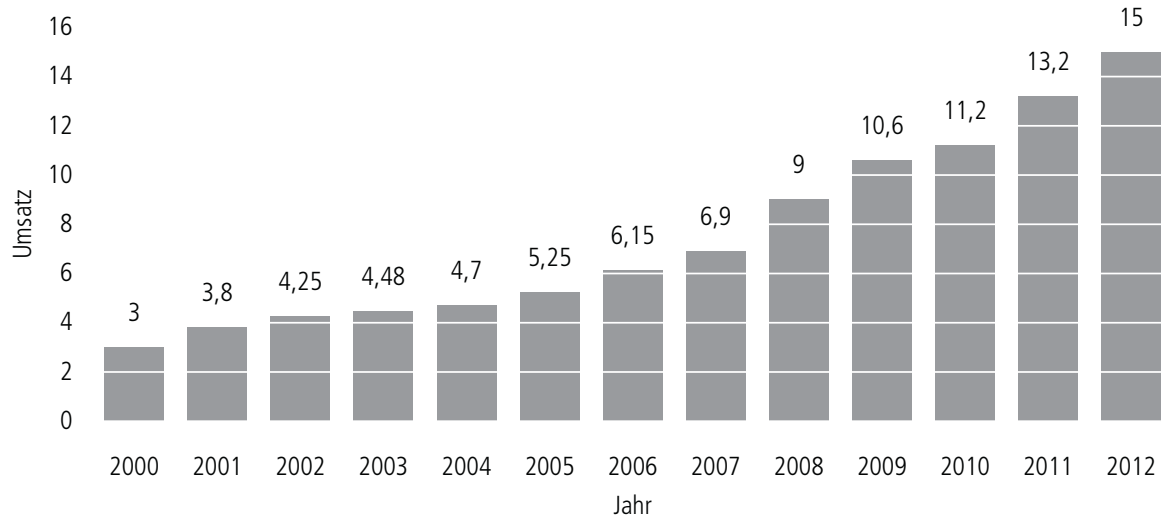

Angabe in Mrd. US-Dollar. Unterschiede zu früheren Veröffentlichungen trotz gleicher Datenquelle wegen statistischer Änderungen möglich.

Quelle: siehe Indikatorenblatt GG-04. 
Laufende Nr:: GG-05

Problemfeld: Stand der Kommerzialisierung

\section{INDIKATOR: FLÄCHENANTEIL GENTECHNISCH VERÄNDERTER PFLANZEN AN DER WELTWEITEN ANBAUFLÄCHE}

\section{DATENQUELLE:}

International Seed Federation. Unter:

http://www.worldseed.org/isf/seed_statistics.html

Food and Agricultural Organization of the United Nations. Unter:

http://faostat3.fao.org/faostat-gateway/go/to/home/E

Foreign Agricultural Service. Unter:

www.fas.usda.gov/psdonline/psdQuery.aspx

Global status of Commercialized Biotech/GM crops: ISAAA. Unter:

www.isaaa.org/

2012: www.isaaa.org/resources/publications/briefs/44/executivesummary/

2011: www.isaaa.org/resources/publications/briefs/43/default.asp

2010: www.isaaa.org/resources/publications/briefs/42/executivesummary/default.asp

2009: www.isaaa.org/resources/publications/briefs/41/executivesummary/default.asp

2008: www.isaaa.org/resources/publications/briefs/39/executivesummary/default.html

2007: www.isaaa.org/resources/Publications/briefs/37/executivesummary/default.html

2006: www.isaaa.org/Resources/publications/briefs/35/executivesummary/default.html

2005: www.isaaa.org/Resources/publications/briefs/34/download/isaaa-brief-34-2005.pdf

2004: www.isaaa.org/kc/Publications/pdfs/isaaabriefs/Briefs\%2032.pdf

2003: www.isaaa.org/kc/Publications/pdfs/isaaabriefs/Briefs\%2030.pdf

2002: www.isaaa.org/kc/Publications/pdfs/isaaabriefs/Briefs\%2027.pdf

2001: www.isaaa.org/kc/Publications/pdfs/isaaabriefs/Briefs\%2024.pdf

2000: www.isaaa.org/kc/Publications/pdfs/isaaabriefs/Briefs\%2021.pdf

Zugriff (alle): August 2013, Stand: August 2013.

\section{VERFÜGBARKEIT DER DATEN:}

öffentlich

\section{ABGRENZUNG DER BERECHNUNGSGRÖSSEN:}

Angaben zu den Hauptkulturarten weltweit: Baumwolle, Kartoffel, Mais, Raps, Reis, Soja, Weizen

\section{GLIEDERUNG DER DARSTELLUNG:}

Flächenanteil gentechnisch veränderter Pflanzen an der weltweiten Anbaufläche

BERECHNUNGSHÄUFIGKEIT:

jährlich

\section{AUSSAGEFÄHIGKEIT:}

Der Indikator betrachtet die weltweiten Anbauanteile gentechnisch veränderter Pflanzen und gibt Auskunft über den Grad der Technikdiffusion, den die grüne Gentechnik weltweit in der Landwirtschaft erreicht. Die detaillierte Aufschlüsselung nach kultivierten Arten ermöglicht eine grobe Differenzierung nach Wirtschaftszweigen (Nahrungsmittel, Futtermittel, industrielle Rohstoffe), wobei bestimmte Kulturarten in verschiedenen Wirtschaftszweigen eine Rolle spielen (z. B. Futtermais, Süßmais). Hiermit wird zum einen der sektorale Stellenwert beziehungsweise die sektorale Technikdiffusion grüner Gentechnik in den globalen Agrarmärkten verdeutlicht, zum anderen werden Schwerpunkte der Entwicklung aufgezeigt. 
Tabelle 5: Flächenanteil gentechnisch veränderter Pflanzen an der weltweiten Anbaufläche

\begin{tabular}{|c|c|c|c|c|c|c|c|c|c|}
\hline & & & $\begin{array}{l}\text { Baum- } \\
\text { wolle }\end{array}$ & Kartoffel & Mais & Raps & Reis & Soja & Weizen \\
\hline & 2000 & Mio ha. & 34 & 20 & 140 & 25 & 154,1 & 72 & 215,4 \\
\hline & 2000 & $\% G V P$ & $16 \%$ & - & $7 \%$ & $11 \%$ & - & $36 \%$ & - \\
\hline & 2001 & Mio ha. & 34 & 19,6 & 140 & 25 & 151,7 & 72 & 214,6 \\
\hline & 2001 & $\% G V P$ & $20 \%$ & - & $7 \%$ & $11 \%$ & - & $46 \%$ & - \\
\hline & 302 & Mio ha. & 34 & 19,1 & 140 & 25 & 147,6 & 72 & 213,8 \\
\hline & 2002 & $\% G V P$ & $20 \%$ & - & $9 \%$ & $12 \%$ & - & $51 \%$ & - \\
\hline & 2003 & Mio ha. & 34 & 18,9 & 140 & 22 & 152,2 & 76 & 208,5 \\
\hline & 2003 & $\% G V P$ & $21 \%$ & - & $11 \%$ & $16 \%$ & - & $55 \%$ & - \\
\hline$\widehat{a}$ & 2004 & Mio ha. & 32 & 19,1 & 143 & 23 & 153,3 & 86 & 217,6 \\
\hline 足 & 2004 & $\% G V P$ & $28 \%$ & - & $14 \%$ & $19 \%$ & - & $56 \%$ & - \\
\hline O & 2005 & Mio ha. & 35 & 18,6 & 147 & 26 & 154 & 91 & 217 \\
\hline है & 2005 & $\% G V P$ & $28 \%$ & - & $14 \%$ & $18 \%$ & - & $60 \%$ & - \\
\hline 总 & 2000 & Mio ha. & 35,2 & 18,8 & 144,4 & 28 & 154,3 & 93 & 216 \\
\hline 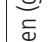 & 2006 & $\% G V P$ & $38 \%$ & - & $17 \%$ & $17 \%$ & - & $63 \%$ & - \\
\hline 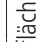 & 2007 & Mio ha. & 33,8 & 19,3 & 157 & 30,2 & 157 & 95 & 217,4 \\
\hline 证 & 2001 & $\%$ GVP & $44 \%$ & - & $22 \%$ & $18 \%$ & - & $60 \%$ & - \\
\hline 莺 & 20 & Mio ha. & 31 & 18,2 & 161,1 & 30,6 & 159,9 & 96,4 & 222,8 \\
\hline 3 & 2008 & $\%$ GVP & $50 \%$ & - & $23 \%$ & $19 \%$ & - & $68 \%$ & - \\
\hline & 2000 & Mio ha. & 30 & 18,6 & 159 & 31,6 & 159 & 99,3 & 225 \\
\hline & 2009 & $\%$ GVP & $54 \%$ & - & $26 \%$ & $20 \%$ & - & $70 \%$ & - \\
\hline & 2010 & Mio ha. & 32 & 18,7 & 161,1 & 31,6 & 161,7 & 102,6 & 217,2 \\
\hline & 2010 & $\%$ GVP & $66 \%$ & - & $29 \%$ & $22 \%$ & - & $71 \%$ & - \\
\hline & 2011 & Mio ha. & 24,7 & 19,2 & 51,0 & 8,2 & 163,1 & 75,4 & 220,9 \\
\hline & 2011 & $\% G V P$ & $74 \%$ & - & $31 \%$ & $25 \%$ & - & $73 \%$ & - \\
\hline & 2012 & Mio ha. & 24,3 & 19,3 & 55,6 & 9,3 & 163,5 & 81 & 216,7 \\
\hline & 2012 & \%GVP & $81 \%$ & - & $35 \%$ & $30 \%$ & - & $81 \%$ & - \\
\hline
\end{tabular}

GVP = Gentechnisch veränderte Pflanzen. Angaben Gesamt: FAO; Angaben für GVP: ISAAA Aufgrund der Datenquelle nur eine zahlenmäßige Erhebung bis 2012 möglich.

Quelle: siehe Indikatorenblatt GG-05. 
Laufende Nr.: GG-06

Problemfeld: Forschungsstandort Deutschland

\section{INDIKATOR: ÖFFENTLICHE FORSCHUNGSAUFWENDUNGEN FÜR DIE GRÜNE GENTECHNOLOGIE}

\section{ANMERKUNG:}

Die Angaben des Indikators bezogen sich auf die öffentlichen Aufwendungen des Bundesministeriums für Bildung und Forschung (BMBF) im Bereich der grünen Gentechnologie. Zurzeit liegen beim BMBF keine „explizit auf das Thema ,Grüne Gentechnik' ausgerichteten Förderrichtlinien” vor (BMBF, Fachreferat 617 „Bioökonomie”, pers. E-Mail, 16.07.2014. „Die letzte Förderaktivität mit einem unmittelbaren Bezug zur ,Grünen Gentechnik’ war die ,Biologische Sicherheitsforschung'. Diese Aktivität ist 2012 ausgelaufen” (BMBF, Fachreferat 617 "Bioökonomie”, pers. E-Mail, 16.07.2014). Pflanzenbiotechnologie im weiteren Sinne (beispielsweise ohne gentechnologische Anwendungen im engeren Sinne auskommende Methoden der Genomanalyse oder des SMART Breeding) wird jedoch vom BMBF gefördert, unter anderem im Rahmenprogramm "Pflanzenbiotechnologie der Zukunft" (www.bmbf.de/de/11985.php). Die Forschungsaufwendungen des BMBF für den Zeitraum 2000-2011 wurden zuletzt im Themenband "Grüne Gentechnologie" (Müller-Röber et al., 2013:204ff.) publiziert. Eine Fortschreibung der Daten ist daher momentan nicht möglich, entsprechende Recherchen werden permanent weitergeführt. 
Laufende Nr:: GG-07

Problemfeld: Forschungsstandort Deutschland

\section{INDIKATOR: AUSGABEN ZUR FORSCHUNG UND ENTWICKLUNG IN DEUTSCHLAND}

\section{ANMERKUNG:}

Der Indikator GG-07 wird nicht weitergeführt. Eine letzte Aktualisierung erfolgte im „Zweiten Gentechnologiebericht” (Müller-Röber et al., 2009:308). Die Angaben dieses Indikators bezogen sich auf die seitens der verschiedenen Bundesministerien finanzierten Programme für Forschung und Entwicklung im Bereich der grünen Gentechnologie. Da die Höhe der öffentlichen Forschungsförderung allein keine Auskunft über die finanzierten Programme für die grüne Gentechnologie gibt, wurde der Indikator nicht mehr fortgesetzt.

Laufende Nr:: GG-08

Problemfeld: Forschungsstandort Deutschland

\section{INDIKATOR: ANTEIL DER ÖFFENTLICHEN FORSCHUNGSAUFWENDUNGEN FÜR DIE GRÜNE GENTECHNOLOGIE AN DEN AUSGABEN DES BMBF}

\section{ANMERKUNG:}

Die Angaben des Indikators bezogen sich auf den Anteil der Forschungsaufwendungen für Förderprojekte im Bereich der grünen Gentechnologie an den Gesamtausgaben des Bundesministeriums für Bildung und Forschung (BMBF). Zurzeit liegen beim BMBF keine „explizit auf das Thema ,Grüne Gentechnik' ausgerichteten Förderrichtlinien” vor. „Die letzte Förderaktivität mit einem unmittelbaren Bezug zur ,Grünen Gentechnik' war die ,Biologische Sicherheitsforschung'. Diese Aktivität ist 2012 ausgelaufen“ (BMBF, Fachreferat 617 „Bioökonomie”, pers. E-Mail, 16.07.2014). Pflanzenbiotechnologie im weiteren Sinne (beispielsweise ohne gentechnologische Anwendungen im engeren Sinne auskommende Methoden der Genomanalyse oder des SMART Breeding) wird jedoch vom BMBF gefördert, unter anderem im Rahmenprogramm „Pflanzenbiotechnologie der Zukunft" (www.bmbf.de/de/11985.php). Der Anteil der Forschungsaufwendungen an den Gesamtausgaben des BMBF für den Zeitraum 2005-2012 wurden zuletzt im Themenband "Grüne Gentechnologie" (Müller-Röber et al., 2013:208f.) publiziert. Eine Fortschreibung der Daten ist daher momentan nicht möglich, entsprechende Recherchen werden permanent weitergeführt.

Laufende Nr.: GG-09

Problemfeld: Forschungsstandort Deutschland

\section{INDIKATOR: ANZAHL DER PATENTANMELDUNGEN IM BEREICH GRÜNER GENTECHNOLOGIE}

\section{ANMERKUNG:}

Die Angaben des Indikators bezogen sich auf Patentanmeldungen beim deutschen Patent- und Markenamt, die schwerpunktmäßig dem Bereich der grünen Gentechnologie zuzuordnen sind. Aufgrund einer Vielzahl neuer und veränderter Patentklassen und der damit verbundenen Schwierigkeit, diese dem Themenbereich zuzuordnen, ist ein Fortschreiben der Daten im Rahmen dieses Berichtes derzeit nicht möglich. Die Daten zu Patentanmeldungen im Bereich grüne Gentechnologie wurden zuletzt im Themenband "Grüne Gentechnologie" (Müller-Röber et al., 2013:210ff.) publiziert. Entsprechende Recherchen werden permanent weitergeführt. 
Laufende Nr:: GG-10

Problemfeld: Forschungsstandort Deutschland

\section{INDIKATOR: ANZAHL DER PATENTANMELDENDEN UNTERNEHMEN UND ÖFFENTLICHEN} EINRICHTUNGEN IM BEREICH GRÜNER GENTECHNOLOGIE

\section{ANMERKUNG:}

Die Angaben des Indikators bezogen sich auf die Anzahl von Unternehmen und öffentlichen Einrichtungen, die im Bereich der grünen Gentechnologie Patente beim deutschen Patent- und Markenamt registriert haben. Aufgrund einer Vielzahl neuer und veränderter Patentklassen und die damit verbundene Schwierigkeit diese dem Themenbereich zuzuordnen ist ein Fortschreiben der Daten im Rahmen dieses Berichtes derzeit nicht möglich. Daten zur Anzahl patentanmeldender privatwirtschaflicher und öffentlicher Institutionen wurden zuletzt im Themenband "Grüne Gentechnologie" (Müller-Röber et al., 2013:215) publiziert. Entsprechende Recherchen werden permanent weitergeführt.

Laufende Nr.: GG-11

Problemfeld: Sicherheitsforschung und -prüfung

\section{INDIKATOR: ÖFFENTLICHE AUSGABEN FÜR DIE RISIKOFORSCHUNG IM BEREICH GRÜNER GENTECHNOLOGIE}

\section{ANMERKUNG:}

Die Angaben des Indikators bezogen sich auf den Anteil der öffentlichen Forschungsaufwendungen für die Risikoforschung im Bereich grüner Gentechnologie durch das Bundesministerium für Bildung und Forschung (BMBF) und das Bundesministerium für Umwelt, Naturschutz, Bau- und Reaktorsicherheit (BMUB). Zurzeit liegen beim BMBF keine „explizit auf das Thema ,Grüne Gentechnik' ausgerichteten Förderrichtlinien” vor (BMBF, Fachreferat 617 „Bioökonomie", pers. E-Mail, 16.07.2014). Einschlägige Fördermaßnahmen durch das BMUB liefen bereits im Jahr 2002 aus. Fördermaßnahmen des BMBF, die sich mit der Risikoforschung zur grünen Gentechnologie befassten, liefen 2012 aus (BMBF, Fachreferat 617 „Bioökonomie”, pers. E-Mail 09.09.2013). Vergleichbare Fragestellungen werden nun innerhalb des 7. EU-Forschungsrahmenprogrammes gefördert. Die entsprechenden Aufwendungen des BMBF's und des BMUB's für den Zeitraum 2000-2011 wurden zuletzt im Themenband "Grüne Gentechnologie" (Müller-Röber et al., 2013:216f.) publiziert. Eine Fortschreibung der Daten ist daher momentan nicht möglich, entsprechende Recherchen werden permanent weitergeführt. 
Laufende Nr.: GG-12

Problemfeld: Stand der Kommerzialisierung

\section{INDIKATOR: ANTEIL GENTECHNISCH VERÄNDERTER SORTEN AN ZUGELASSENEN SORTEN}

\section{DATENQUELLE:}

Bundessortenamt; Datenbankabfrage. Unter:

http://www.bundessortenamt.de/internet30/index.php?id=3

http://www.bundessortenamt.de/internet30/fileadmin/Files/PDF/BIfS_Sonderheft.pdf

http://www.bundessortenamt.de/internet30/fileadmin/Files/PDF/BlfS_Sonderheft2011.pdf

http://www.bundessortenamt.de/internet30/fileadmin/Files/PDF/BIfS_Sonderheft2012.pdf

http://www.bundessortenamt.de/internet30/fileadmin/Files/PDF/BIfS_Sonderheft2013.pdf

Veröffentlichung des Forum Bio- und Gentechnologie - Verein zur Förderung der gesellschaftlichen Diskussionskultur

e. V. Unter:

www.transgen.de

Zugriff (alle): September 2013, Stand: April 2013.

VERFÜGBARKEIT DER DATEN:

öffentlich

\section{ABGRENZUNG DER BERECHNUNGSGRÖSSEN:}

Sobald eine neue Sorte in einem Mitgliedsland der EU zugelassen wird, wird die EU-Kommission davon unterrichtet und ersucht, die Sorte durch Veröffentlichung im Amtsblatt in den gemeinsamen Katalog aufzunehmen. Nur die dort verzeichneten Sorten können EU-weit in den Verkehr gebracht werden. Alle anderen Sorten sind nur in dem jeweiligen Mitgliedsstaat vertriebsfähig, in dem sie zugelassen sind. Die Abfrage der Datenbank des Bundessortenamtes erfolgte für diejenigen landwirtschaftlichen Nutzpflanzenarten, für die transgene Pflanzen in Deutschland angebaut wurden und für die in Deutschland eine Sortenzulassung nach dem Saatgutverkehrsgesetz (SaatG) existiert (Mais). Im April 2009 hat Deutschland den Anbau von MON 810-Mais verboten, sodass die zugelassenen Sorten, die sämtlich die Transformante MON 810 enthalten (pers. Kommunikation Bundessortenamt am 29.9.2014), faktisch nicht angebaut werden dürfen.

\section{GLIEDERUNG DER DARSTELLUNG:}

Anteil gentechnisch veränderter Sorten an nach dem SaatG zugelassenen Sorten

\section{BERECHNUNGSHÄUFIGKEIT:}

jährlich

\section{AUSSAGEFÄHIGKEIT:}

Mit der Einführung gentechnisch veränderter Pflanzensorten wird sowohl die Ausdehnung der Sortenvielfalt verbunden, als auch die Gefahr, dass sich der Anbau auf wenige Pflanzenarten und -sorten beschränkt und die Biodiversität abnimmt. Der Indikator bezieht sich auf die im Sortenkatalog gelisteten Sorten. Da für die Sortenzulassung wie für die Zulassungserneuerung Gebühren für die Saatgutzüchter anfallen, erscheinen nicht alle existierenden Sorten (gerade vorhandene ältere Sorten) im Sortenkatalog. Keine Aussage trifft der Indikator hinsichtlich des tatsächlichen Anbaus gentechnisch veränderter Sorten. 
Tabelle 6: Anteil gentechnisch veränderter Sorten an zugelassenen Sorten

\begin{tabular}{|c|c|c|c|c|}
\hline \multirow{5}{*}{2004} & & & & Mais \\
\hline & & Insg. & D & 205 \\
\hline & \multirow{3}{*}{ GVO } & D & & \\
\hline & & $\%$ & & \\
\hline & & EU & & 17 \\
\hline \multirow{4}{*}{2005} & & Insg. & D. & 227 \\
\hline & \multirow{3}{*}{ GVO } & D & & 5 \\
\hline & & $\%$ & & 2,2 \\
\hline & & EU & & 31 \\
\hline \multirow{4}{*}{2006} & & Insg. & D & 258 \\
\hline & \multirow{3}{*}{ GVO } & D & & 5 \\
\hline & & $\%$ & & 2,2 \\
\hline & & EU & & ca. 40 \\
\hline \multirow{4}{*}{2007} & & Insg. & D & 256 \\
\hline & \multirow{3}{*}{ GVO } & D & & 5 \\
\hline & & $\%$ & & 2 \\
\hline & & EU & & 54 \\
\hline \multirow{4}{*}{2008} & & Insg. & D & 244 \\
\hline & \multirow{3}{*}{ GVO } & D & & 7 \\
\hline & & $\%$ & & 2,9 \\
\hline & & EU & & 70 \\
\hline \multirow{4}{*}{ 20091) } & & Insg. & D & 247 \\
\hline & \multirow{3}{*}{ GVO } & $\mathrm{D}$ & & 11 \\
\hline & & $\%$ & & 4,5 \\
\hline & & EU & & 99 \\
\hline \multirow{4}{*}{2010} & & Insg. & D & 245 \\
\hline & \multirow{3}{*}{ GVO } & D & & 11 \\
\hline & & $\%$ & & 4,5 \\
\hline & & EU & & 99 \\
\hline \multirow{4}{*}{2011} & & Insg. & D & 247 \\
\hline & \multirow{3}{*}{ GVO } & $\mathrm{D}$ & & 12 \\
\hline & & $\%$ & & 4,9 \\
\hline & & EU & & 2) \\
\hline \multirow{4}{*}{2012} & & Insg. & D & 263 \\
\hline & \multirow{3}{*}{ GVO } & D & & 12 \\
\hline & & $\%$ & & 4,6 \\
\hline & & EU & & 2) \\
\hline \multirow{4}{*}{2013} & & Insg. & D & 270 \\
\hline & \multirow{3}{*}{ GVO } & D & & 8 \\
\hline & & $\%$ & & 3 \\
\hline & & EU & & 2) \\
\hline
\end{tabular}

Unterschiede zu früheren Veröffentlichungen trotz gleicher Datenquelle wegen statistischer Änderungen möglich.

1) Im April 2009 hat Deutschland den Anbau von MON 810-Mais vorerst verboten.

2) Für 2011 bis 2013 liegen keine aktuellen Daten vor.

Quelle: siehe Indikatorenblatt GG-12. 
Laufende Nr.: GG-13

Problemfeld: Stand der Kommerzialisierung

\section{INDIKATOR: ANBAUFLÄCHEN EINZELNER KULTURARTEN}

\section{DATENQUELLE:}

Statistisches Bundesamt. Unter:

www.destatis.de

2010-2013: https://www.destatis.de/DE/ZahlenFakten/Wirtschaftsbereiche/LandForstwirtschaftFischerei/FeldfruechteGruenland/Tabellen/AckerlandHauptfruchtgruppenFruchtarten.html

Zugriff: August 2013, Stand: August 2013.

VERFÜGBARKEIT DER DATEN:

öffentlich

ABGRENZUNG DER BERECHNUNGSGRÖSSEN:

keine Angabe

GLIEDERUNG DER DARSTELLUNG:

Anbauflächen einzelner Arten in Deutschland 2000-2013

\section{BERECHNUNGSHÄUFIGKEIT:}

jährlich

\section{AUSSAGEFÄHIGKEIT:}

Der Indikator misst Veränderungen in der landwirtschaftlichen Produktion und kann Hinweise darauf geben, ob und in welchem Maße durch den Anbau gentechnisch veränderter Pflanzen (GG-12) der Anbau einzelner Arten zu- oder abnimmt. Einbezogen ist dabei die Möglichkeit, dass die ackerbauliche Flächennutzung insgesamt durch Zu- oder Abnahme anderer Formen der Flächennutzung variieren kann. Zu beachten ist, dass solche Veränderungen auch andere Ursachen haben können (z. B. Agrarpolitik, Verkaufspreise, Klima, neue konventionelle Sorten), so dass der Indikator vor allem Hintergrundinformationen für andere Indikatoren bereithält. 
Abbildung 5: Anbauflächen einzelner Arten in Deutschland 2000-2013

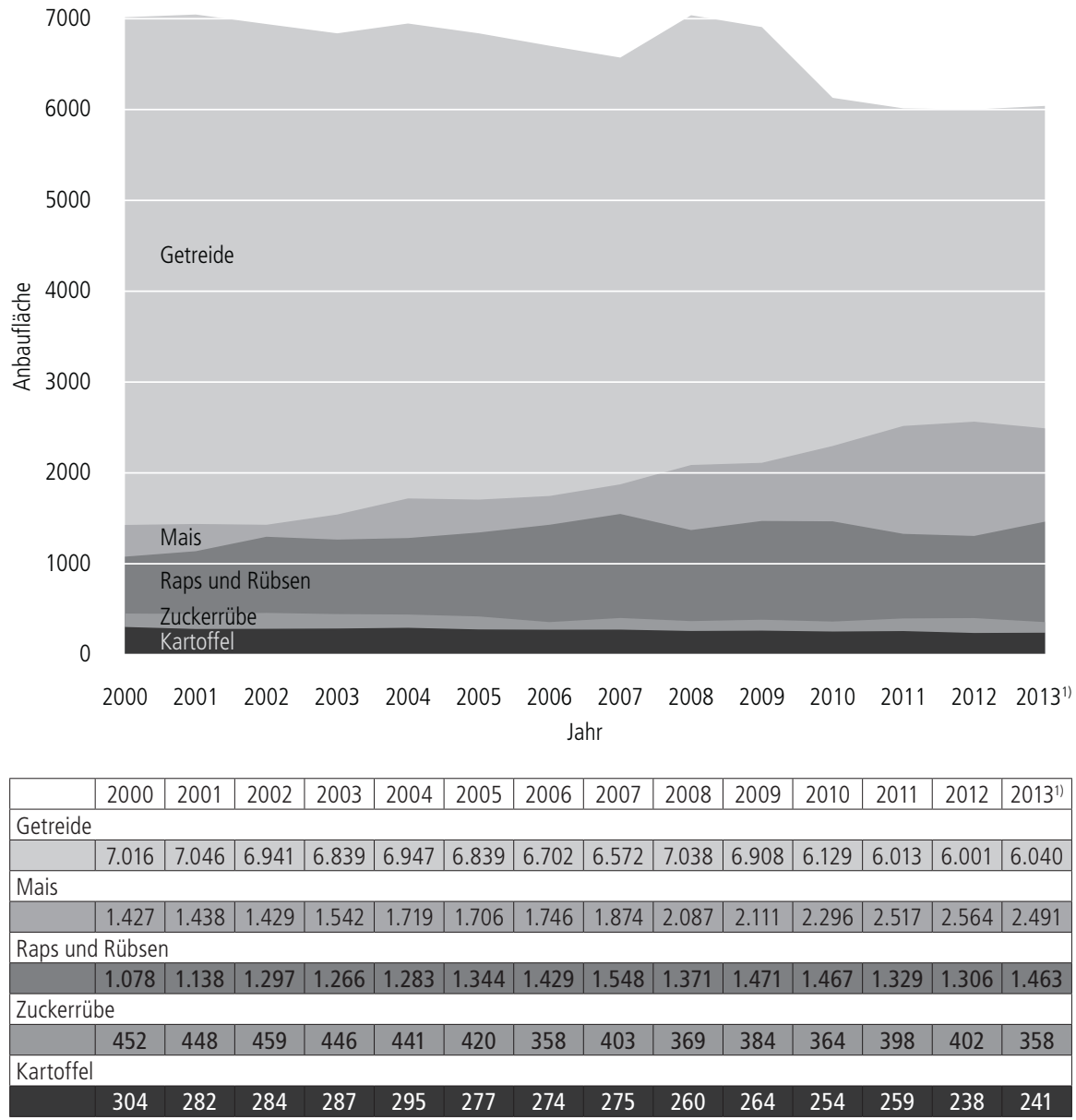

Angaben in 1.000 ha.

1) Vorläufiges Ergebnis der Bodennutzungshaupterhebung 2013.

Quelle: siehe Indikatorenblatt GG-13. 
Laufende Nr.: GG-14

Problemfeld: Stand der Kommerzialisierung

INDIKATOR: FLÄCHENANTEILE EINZELNER ARTEN AN DER LANDWIRTSCHAFTLICHEN NUTZFLÄCHE (KULTURARTENDIVERSITÄT)

\section{DATENQUELLE:}

Statistisches Bundesamt. Unter:

www.destatis.de

https://www.destatis.de/DE/ZahlenFakten/Wirtschaftsbereiche/LandForstwirtschaftFischerei/FeldfruechteGruenland/

FeldfruechteGruenland.html

Zugriff: August 2013, Stand: August 2013.

\section{VERFÜGBARKEIT DER DATEN:}

öffentlich, eigene Berechnung

\section{ABGRENZUNG DER BERECHNUNGSGRÖSSEN:}

keine Angabe

\section{GLIEDERUNG DER DARSTELLUNG:}

Flächenanteile einzelner Arten an der landwirtschaftlichen Nutzfläche in Deutschland 2000-2013

\section{BERECHNUNGSHÄUFIGKEIT:}

jährlich

\section{AUSSAGEFÄHIGKEIT:}

Der Indikator misst Veränderungen in der landwirtschaftlichen Produktion und kann Hinweise darauf geben, ob und in welchem Maße durch den Anbau gentechnisch veränderter Pflanzen der Anbau einzelner Arten zu- oder abnimmt. Zu beachten ist, dass solche Veränderungen auch andere Ursachen haben können (z. B. Agrarpolitik, Verkaufspreise, Klima, neue konventionelle Sorten), so dass der Indikator vor allem Hintergrundinformationen für andere Indikatoren bereithält. 
Abbildung 6: Flächenanteile einzelner Arten an der landwirtschaftlichen Nutzfläche in Deutschland 2000-2013

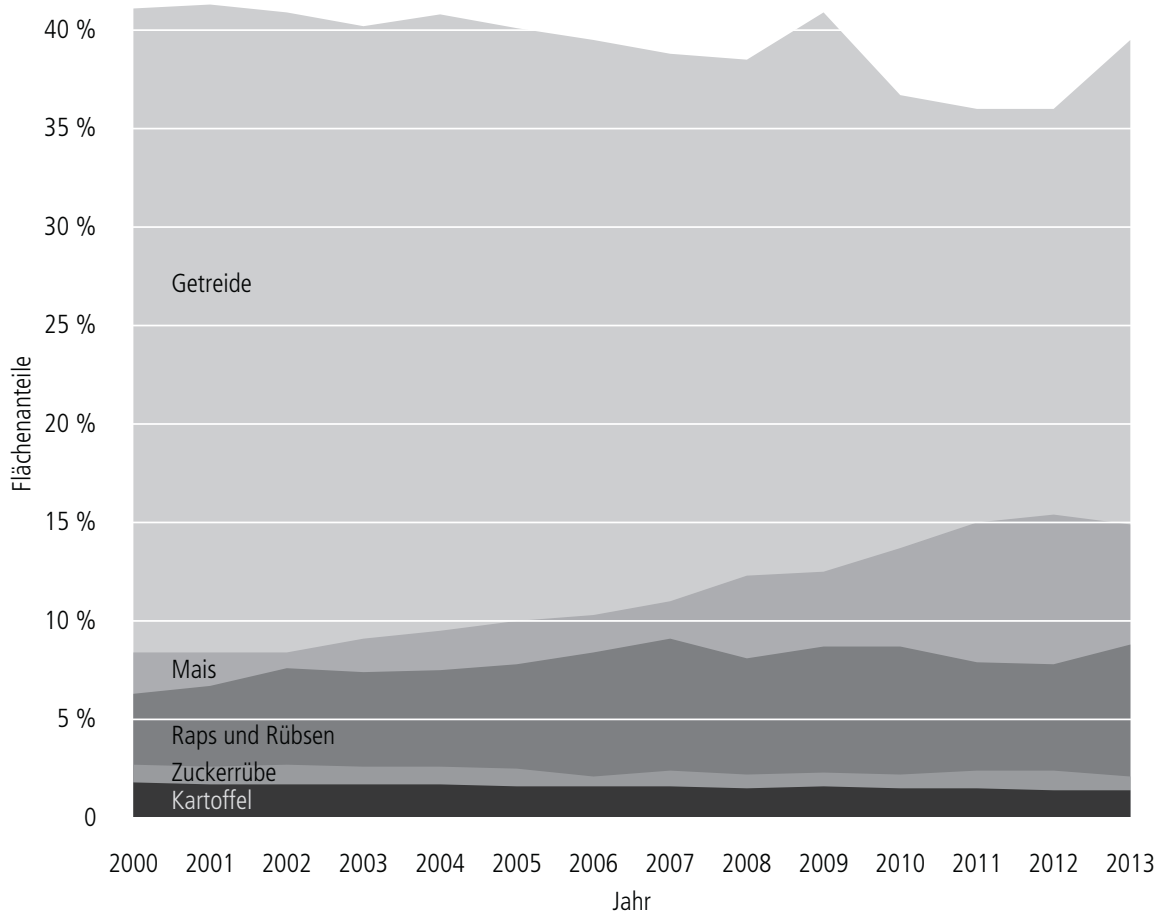

\begin{tabular}{|l|l|l|l|l|l|l|l|l|l|l|l|l|l|l|}
\hline & 2000 & 2001 & 2002 & 2003 & 2004 & 2005 & 2006 & 2007 & 2008 & 2009 & 2010 & 2011 & 2012 & 2013 \\
\hline Getreide \\
\hline & 41,1 & 41,3 & 40,9 & 40,2 & 40,8 & 40,1 & 39,5 & 38,8 & 38,5 & 40,9 & 36,7 & 36 & 36 & 39,5 \\
\hline Mais & 8,4 & 8,4 & 8,4 & 9,1 & 9,5 & 10 & 10,3 & 11 & 12,3 & 12,5 & 13,7 & 15 & 15,4 & 14,9 \\
\hline & 8,10 & \\
\hline
\end{tabular}

Angaben in \%.

Quelle: siehe Indikatorenblatt GG-14. 
Laufende Nr.: GG-15

Problemfeld: Stand der Kommerzialisierung

\section{INDIKATOR: FLÄCHENANTEIL GENTECHNISCH VERÄNDERTER SORTEN AN DER LANDWIRTSCHAFTLICHEN NUTZFLÄCHE}

\section{ANMERKUNG:}

Der Indikator GG-15 wird nicht weitergeführt. Die Angaben des Indikators bezogen sich auf die Anteile der Anbauflächen mit gentechnisch veränderten Sorten in Relation zur landwirtschaftlichen Nutzfläche. Der Indikator wurde zuletzt im Themenband "Grüne Gentechnologie" (Müller-Röber et al., 2013:224f.) veröffentlicht. Eine Fortschreibung der Daten ist derzeit nicht aussagefähig, da seit 2012 in Deutschland insgesamt kein Anbau von gentechnisch veränderten Sorten stattfindet; entsprechende Recherchen werden permanent weitergeführt. 
Laufende Nr.: GG-16

Problemfeld: Koexistenz und Haftungsfragen

\section{INDIKATOR: FLÄCHENANTEIL DES ÖKOLANDBAUS AN DER GESAMTEN LANDWIRTSCHAFTLICHEN NUTZFLÄCHE}

\section{DATENQUELLE:}

Veröffentlichung der Bundesanstalt für Landwirtschaft und Ernährung (BLE). Unter:

www.oekolandbau.de

Zugriff: Februar 2013, Stand: Juni 2012

\section{VERFÜGBARKEIT DER DATEN:}

\section{öffentlich}

Die Daten werden jährlich von der Bundesanstalt für Landwirtschaft und Ernährung (BLE) im Rahmen des Bundesprogramms "Ökologischer Landbau und andere Formen nachhaltiger Landwirtschaft" (BLÖN) erhoben. Das Programm wurde Ende 2001 als Bundesprogramm „Ökologischer Landbau” (BLÖ) initiiert und im November 2010 auf andere Formen der nachhaltigen Landwirtschaft erweitert. Die für den Indikator relevanten Daten werden in aufbereiteter Form von der BLE, auf der Internetplattform „oekolandbau.de", die Teil des Bundesprogramms ist, in der Rubrik „Ökolandbau in Zahlen" veröffentlicht.

\section{ABGRENZUNG DER BERECHNUNGSGRÖSSEN:}

Zu Grunde gelegt wird die Fläche, die in Deutschland gemäß der "Verordnung (EG) Nr. 834/2007 des Rates vom 28. Juni 2007 über die ökologische/biologische Produktion und die Kennzeichnung von ökologischen/biologischen Erzeugnissen und zur Aufhebung der Verordnung (EWG) Nr. 2092/91 und ihren Durchführungsbestimmungen" bewirtschaftet wird. Die vom BLE angegebenen Verhältniswerte beziehen sich auf die „Landwirtschaftlich genutzte Fläche" (LF) in Deutschland, die jährlich vom Statistischen Bundesamt veröffentlicht wird.

\section{GLIEDERUNG DER DARSTELLUNG:}

Flächenanteil des Ökolandbaus an der gesamten landwirtschaftlichen Nutzfläche in Deutschland

\section{BERECHNUNGSHÄUFIGKEIT:}

jährlich

\section{AUSSAGEFÄHIGKEIT:}

Der ökologische Anbau wird von vielen Kritikern der grünen Gentechnik als alternative Landwirtschaftsform herausgestellt und bevorzugt. Der Indikator ist insbesondere hinsichtlich der Koexistenz beider Anbauformen von Interesse, und im Vergleich mit den Anbauflächen gentechnisch veränderter Pflanzen gibt er Hinweise auf verschiedene Wechselwirkungen: So könnte die Auskreuzung von Transgenen aufgrund der für ökologische Produkte geltenden Garantie der vollständigen Gentechnikfreiheit zu Absatzproblemen und zu einem Rückgang des ökologischen Anbaus führen. Bei hohem Haftungsrisiko der Landwirte, die gentechnisch veränderte Pflanzen anbauen, könnte bei der Auskreuzung von Transgenen die Wechselwirkung in entgegengesetzte Richtung wirken und ein Hemmnis für den Anbau gentechnisch veränderter Pflanzen darstellen. Andererseits könnte der kommerzielle Anbau gentechnisch veränderter Pflanzen parallel auch eine verstärkte Nachfrage nach gentechnikfreien Produkten auslösen und damit zu einer Ausdehnung der Ökoanbaufläche beitragen. Zu beachten ist, dass der Anbau gentechnisch veränderter Sorten nicht den einzigen Faktor darstellt, der die Fläche des Ökolandbaus beeinflusst; wichtige Einflussfaktoren sind beispielsweise die Agrarpolitik und die Nachfrageseite. 
Abbildung 7: Flächenanteil des Ökolandbaus an der gesamten landwirtschaftlichen Nutzfläche in Deutschland

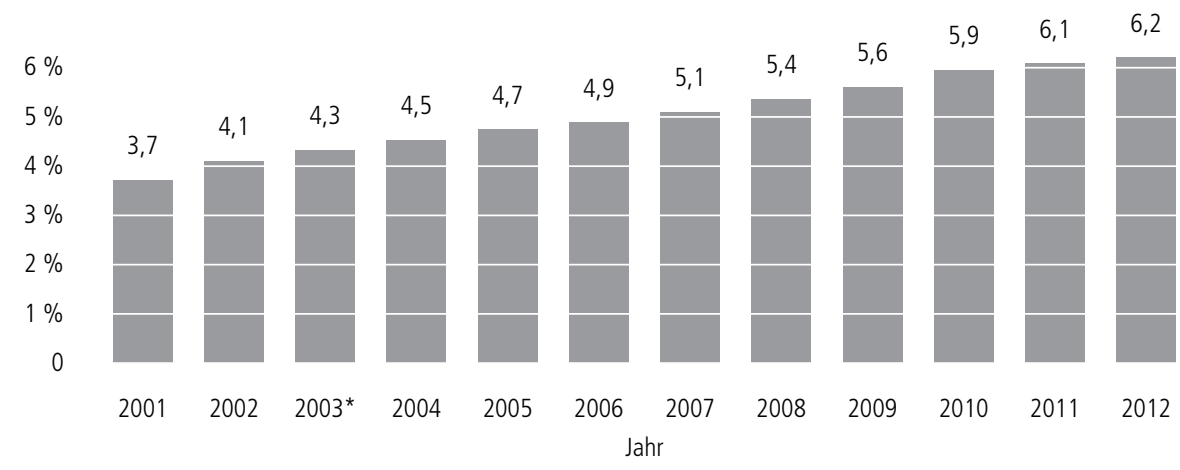

* Aufgrund geänderter Erfassung in Thüringen mit den Vorjahren nicht voll vergleichbar. Quelle: siehe Indikatorenblatt GG-16. 
Laufende Nr.: GG-17

Problemfeld: Öffentliche Wahrnehmung

\section{INDIKATOR: VERBRAUCHERAKZEPTANZ DER GRÜNEN GENTECHNOLOGIE}

\section{DATENQUELLE:}

(1) Greenpeace e.V.: Ergebnisse einer Emnid-Studie (November bis Dezember 2003). Unter:

www.greenpeace.de/ueber_uns/jahresrueckblick/jahresrueckblick_2003/artikel/aktionen_november_und_dezember_2003/

(2) Institut für Demoskopie Allensbach (2001): Verändertes Meinungsklima gegenüber der Gentechnologie. Quelle online nicht mehr verfügbar.

(3) Eurobarometer 58.0 (2002). Unter: http://ec.europa.eu/public_opinion/archives/ebs/ebs_180_en.pdf

(4) Eurobarometer 64.3 (2005). Unter:

www.ec.europa.eu/research/press/2006/pdf/pr1906_eb_64_3_final_report-may2006_en.pdf

(5) Forsa-Umfrage (2005). Unter:

www.keine-gentechnik.de/bibliothek/basis/studien/forsa_umfrage_geenfood_050730.pdf

(6) Consumerchoice, King's College London (2008). Unter:

http://www.kcl.ac.uk/medicine/research/divisions/dns/projects/consumerchoice/downloads.aspx

(7) Umweltbewusstsein in Deutschland, Umweltbundesamt. Unter:

2000: http://www.umweltbundesamt.de/sites/default/files/medien/publikation/long/3268.pdf

2002: http://www.umweltbundesamt.de/sites/default/files/medien/publikation/long/3269.pdf

2004: http://www.umweltbundesamt.de/sites/default/files/medien/publikation/long/2792.pdf

2006: http://www.umweltbundesamt.de/sites/default/files/medien/publikation/long/3113.pdf

2008: http://www.umweltbundesamt.de/sites/default/files/medien/publikation/long/3678.pdf

2010: http://www.umweltbundesamt.de/sites/default/files/medien/publikation/long/4045.pdf

2012: http://www.umweltbundesamt.de/sites/default/files/medien/publikation/long/4396.pdf

(8) Eurobarometer 68.2 (2008). Unter: http://ec.europa.eu/public_opinion/archives/ebs/ebs_295_de.pdf

(9) Eurobarometer 73.1 (2010). Unter: http://ec.europa.eu/public_opinion/archives/ebs/ebs_341_de.pdf

(10)Fresenius Verbraucherstudie (2010). Unter:

www.gentechnikfreie-regionen.de/fileadmin/content/studien/umfragen/20100721_umfrage_fresenius_verbraucherstudie.pdf

(11) Forsa-Umfrage (2011). Unter:

www.keine-gentechnik.de/fileadmin/files/Infodienst/Dokumente/Umfrage\%20forsa_ohne_gt.pdf

(12) Emnid-Umfrage im Auftrag von Greenpeace (2010). Unter:

www.keine-gentechnik.de/fileadmin/files/Infodienst/Dokumente/10_01_greenpeace_umfrage_gen_mais.pdf

(13) http://de.statista.com/statistik/daten/studie/5268/umfrage/kauf-von-preiswerten-gentechnisch-veraendertenlebensmitteln/

(14) http://de.statista.com/statistik/daten/studie/5274/umfrage/bevorzugung-von-gentechnisch-geschmacksverbessertem-obst/

(15) dimap-Studie: Gentechnik in der Landwirtschaft (2013). Unter:

www.gruenevernunft.de/sites/default/files/meldungen/Tabellarische\%20\%C3\%9Cbersicht\%20der\%20Studie\%20

Gentechnik\%20in\%20der\%20Landwirtschaft\%5B2\%5D.pdf

(16) GfK-Umfrage im Auftrag von Greenpeace (2014). Unter:

www.greenpeace.de/fileadmin/gpd/user_upload/themen/gentechnik/Umfrage_1507_Ergebnisse_03.pdf

(17) TNS- Emnid-Umfrage des BMEL: Einkaufs- und Ernährungsverhalten in Deutschland (2014). Unter:

www.bmelv.de/SharedDocs/Downloads/Umfragen/TNS-Emnid-EinkaufsErnaehrungsVerhaltenInDeutschland.

pdf?__blob=publicationFile

Zugriff (alle): Januar 2014, Stand: Dezember 2013 


\section{VERFÜGBARKEIT DER DATEN:}

öffentlich

\section{ABGRENZUNG DER BERECHNUNGSGRÖSSEN:}

Akzeptanzuntersuchungen mit Fragestellungen zu gentechnisch veränderten Pflanzen und gentechnisch veränderten Lebensmitteln für Deutschland. Die Daten sind wegen unterschiedlicher Fragestellung und Arbeitsmethoden nur eingeschränkt miteinander vergleichbar.

\section{GLIEDERUNG DER DARSTELLUNG:}

a) Umfrageergebnisse zur Verbraucherakzeptanz der grünen Gentechnologie

b) Kaufbereitschaft für Lebensmittel mit gentechnisch veränderten Inhaltsstoffen

\section{BERECHNUNGSHÄUFIGKEIT:}

einmalig/zweijährig/mehrjährig

\section{AUSSAGEFÄHIGKEIT:}

Die Verbraucherakzeptanz landwirtschaftlicher Produkte, die unmittelbar oder mittelbar aus gentechnisch veränderten Pflanzen gewonnen wurden, ist von entscheidender Bedeutung für den kommerziellen Erfolg gentechnisch veränderter Pflanzen. Trotz des prinzipiellen methodischen Problems der Übertragbarkeit geäußerter Angaben auf reales Verhalten dienen quantitative Akzeptanzuntersuchungen Befürwortern wie Kritikern der grünen Gentechnologie gleichermaßen als Argumentationshilfe: Erstere greifen Akzeptanzsteigerungen und die Zustimmung zu konkreten Anwendungszielen der grünen Gentechnologie auf, letztere sehen konstant niedrige oder fallende Akzeptanzwerte als Bestätigung ihrer kritischen Haltung. Vor diesem Hintergrund empfiehlt es sich, erstens anwendungsbezogene Fragen von pauschalen Einschätzungen zu unterscheiden sowie zweitens Aussagen zu gentechnisch veränderten Pflanzen von solchen über gentechnisch veränderte Lebensmittel zu trennen. Generell sind die vom Indikator erfassten quantitativen Ergebnisse hinsichtlich gewählter Arbeits- und Auswertungsmethodik zu bewerten. Direkt vergleichbar sind nur periodisch wiederkehrende Untersuchungen mit gleichem Aufbau, gleichen Fragen und gleicher Auswertungsmethodik. 
a) Tabelle 7: Umfrageergebnisse zur Verbraucherakzeptanz der grünen Gentechnologie

\begin{tabular}{|c|c|c|c|c|}
\hline Untersuchte Frage & $\begin{array}{l}\text { Untersu- } \\
\text { chungsjahr } \\
\text { (Quelle) }\end{array}$ & Stimmen zu & Lehnen ab & $\begin{array}{l}\text { Gesamt- } \\
\text { befragte }\end{array}$ \\
\hline $\begin{array}{l}\text { Würden Sie sich mit genetisch veränderten Nahrungsmitteln } \\
\text { ernähren? }\end{array}$ & $2003(1)$ & $19,50 \%$ & $74,40 \%$ & 4.042 \\
\hline $\begin{array}{l}\text { Wie wichtig finden Sie eine Kennzeichnung von genetisch } \\
\text { veränderten Nahrungsmitteln? }\end{array}$ & $2003(1)$ & $\begin{array}{l}88,4 \% \text { findet } \\
\text { wichtig }\end{array}$ & $\begin{array}{l}2,6 \% \text { findet } \\
\text { unwichtig }\end{array}$ & 4.042 \\
\hline Ist die Kennzeichnung „ohne Gentechnik“ sinnvoll? & 2011 (11) & $82 \%$ & $16 \%$ & 1.001 \\
\hline $\begin{array}{l}\text { Würden Sie sich beim Einkauf an der Kennzeichnung "ohne } \\
\text { Gentechnik" orientieren? }\end{array}$ & $2011(11)$ & $75 \%$ & $24 \%$ & 1.001 \\
\hline $\begin{array}{l}\text { Wie wichtig finden Sie beim Einkauf von Lebensmitteln Anga- } \\
\text { ben auf der Verpackung zur Produktion ohne Gentechnik? }\end{array}$ & $2014(17)$ & $\begin{array}{l}75 \% \text { findet } \\
\text { wichtig }^{2)}\end{array}$ & & 1.000 \\
\hline $\begin{array}{l}\text { Stimmen Sie persönlich der Vermischung von Saatgut mit Gen- } \\
\text { Samen zu oder lehnen Sie dies ab? }\end{array}$ & $2003(1)$ & $10,30 \%$ & $68,30 \%$ & 4.042 \\
\hline $\begin{array}{l}\text { Stimmen Sie persönlich der Verwendung von gentechnisch } \\
\text { verändertem Tierfutter zu oder lehnen Sie dies ab? }\end{array}$ & $2003(1)$ & $9,70 \%$ & $72,10 \%$ & 4.042 \\
\hline \multirow{3}{*}{$\begin{array}{l}\text { Finden Sie die Nutzung der Gentechnologie gut zur Züchtung } \\
\text { von Getreide und anderen Pflanzen, um sie gegen Schädlinge } \\
\text { und Krankheiten immun zu machen? }\end{array}$} & $1998(2)$ & $38 \%$ & $37 \%$ & 2.049 \\
\hline & $2001(2)$ & $46 \%$ & $31 \%$ & 2.049 \\
\hline & $2013(15)$ & $35 \%$ & $60 \%$ & 1.000 \\
\hline \multirow{2}{*}{$\begin{array}{l}\text { Finden Sie die Nutzung der Gentechnologie gut zur Züchtung } \\
\text { von Getreide und anderen Pflanzen, um die Ernteerträge zu } \\
\text { erhöhen? }\end{array}$} & $1998(2)$ & $29 \%$ & $48 \%$ & 2.049 \\
\hline & $2001(2)$ & $37 \%$ & $41 \%$ & 2.049 \\
\hline $\begin{array}{l}\text { Es sollten rasche Fortschritte gemacht werden um mit Hilfe } \\
\text { der Gentechnik Pflanzen und Getreidesorten zu entwickeln, } \\
\text { die auch in kargen Gegenden der Dritten Welt angepflanzt } \\
\text { werden können. }\end{array}$ & $2001(2)$ & $67 \%$ & $20 \%$ & 2.049 \\
\hline $\begin{array}{l}\text { Es sollten rasche Fortschritte gemacht werden um mit Hilfe der } \\
\text { Biotechnologie Obst- und Gemüsesorten zu entwickeln, die } \\
\text { lange frisch bleiben. }\end{array}$ & $2001(2)$ & $26 \%$ & $57 \%$ & 2.049 \\
\hline \multirow{2}{*}{$\begin{array}{l}\text { Würden Sie GV-Nahrungsmittel kaufen und essen? (Annahme } \\
\text { unterschiedlicher Gründe wie weniger Pestizide enthaltend, } \\
\text { umweltfreundlicher, besserer Geschmack, Angebot in einem } \\
\text { Restaurant, weniger Fett enthaltend, sind billiger) }\end{array}$} & $2002(3)$ & $24-40 \%$ & $48-65 \%$ & $\begin{array}{l}\text { mehrere } \\
\text { Tausend }\end{array}$ \\
\hline & $2005(4)$ & $36-58 \%$ & $38-58 \%$ & \\
\hline $\begin{array}{l}\text { Kauf von garantiert gentechnikfreien Lebensmitteln auch bei } \\
\text { höheren Preisen }\end{array}$ & $2011(11)$ & $77 \%$ & $18 \%$ & 1.001 \\
\hline \multirow[t]{3}{*}{$\begin{array}{l}\text { Unterstützung gentechnisch veränderter Pflanzen (mehrere } \\
\text { Einzelfragen) in Deutschland. }\end{array}$} & $1999(3)$ & $69 \% 1)$ & & $\begin{array}{l}\text { mehrere } \\
\text { Tausend }\end{array}$ \\
\hline & $2002(3)$ & $67 \%{ }^{1)}$ & & \\
\hline & 2005 (4) & k. A. & & \\
\hline \multirow[t]{4}{*}{$\begin{array}{l}\text { Unterstützung gentechnisch veränderter Lebensmittel (mehre- } \\
\text { re Einzelfragen) in Deutschland. }\end{array}$} & $1999(4)$ & $49 \%{ }^{1)}$ & & $\begin{array}{l}\text { mehrere } \\
\text { Tausend }\end{array}$ \\
\hline & $2002(3)$ & $48 \%{ }^{11}$ & & \\
\hline & $2005(4)$ & $30 \%{ }^{1)}$ & & \\
\hline & $2010(9)$ & $22 \% 11$ & & 1.531 \\
\hline $\begin{array}{l}\text { Sind Sie persönlich für oder gegen die Nutzung von gentech- } \\
\text { nisch veränderten Organismen? }\end{array}$ & $2008(8)$ & $21 \%$ & $58 \%$ & $\begin{array}{l}\text { mehrere } \\
\text { Tausend } \\
\text { (EU-27) }\end{array}$ \\
\hline $\begin{array}{l}\text { Würden Sie GV-Nahrungsmittel kaufen, wenn sie besser } \\
\text { schmecken? }\end{array}$ & $1999(4)$ & $22 \%$ & $66 \%$ & 16.082 \\
\hline Würden Sie mehr für Nicht-GV-Nahrungsmittel bezahlen? & $1999(4)$ & $53 \%$ & $36 \%$ & 16.082 \\
\hline \multirow{2}{*}{$\begin{array}{l}\text { Lehnen Sie gentechnisch veränderte Bestandteile in der } \\
\text { Nahrung ab? (ganz Deutschland) }\end{array}$} & $2005(5)$ & $79 \%$ & $17 \%$ & 1.001 \\
\hline & $956-30$ & $6.04 .2023,12$ & $\begin{array}{l}\text { (ist es egal, } \\
\text { wenn der } \\
\text { Preis stimmt) }\end{array}$ & \\
\hline
\end{tabular}




\begin{tabular}{|c|c|c|c|c|}
\hline Untersuchte Frage & $\begin{array}{l}\text { Untersu- } \\
\text { chungsjahr } \\
\text { (Quelle) }\end{array}$ & Stimmen zu & Lehnen ab & $\begin{array}{l}\text { Gesamt- } \\
\text { befragte }\end{array}$ \\
\hline $\begin{array}{l}\text { Ich mache mir beim Einkauf Sorgen, dass ein Produkt gentech- } \\
\text { nisch veränderte Zutaten enthält. }\end{array}$ & $2010(10)$ & $55 \%$ & & 1.827 \\
\hline $\begin{array}{l}\text { Würden Sie Lebensmittel kaufen, die gentechnisch veränderte } \\
\text { Inhaltsstoffe enthalten? }\end{array}$ & $2008(6)$ & $12,90 \%$ & $74,40 \%$ & 317 \\
\hline Unterstützung für transgene Äpfel & $2010(9)$ & $26 \%$ & & 1.531 \\
\hline Unterstützung für cisgene Äpfel & $2010(9)$ & $49 \%$ & & 1.531 \\
\hline $\begin{array}{l}\text { Sollte der Anbau von Gen-Mais in Deutschland weiterhin } \\
\text { verboten bleiben? }\end{array}$ & $2010(12)$ & $79 \%$ & $15 \%$ & 1.005 \\
\hline $\begin{array}{l}\text { Angenommen der Mais „1507“ würde für den Anbau in der } \\
\text { EU zugelassen, sollte dann Ihrer Meinung nach der Landwirt- } \\
\text { schaftsminister in Deutschland den Anbau verbieten? }\end{array}$ & $2014(16)$ & $73,7 \%$ & $21,9 \%$ & 982 \\
\hline $\begin{array}{l}\text { Sollte Bundeslandwirtschaftsministerin Ilse Aigner den Anbau } \\
\text { der Gentechnik-Kartoffel Amflora in Deutschland verbieten? }\end{array}$ & $2010(12)$ & $77 \%$ & $11 \%$ & 1.005 \\
\hline $\begin{array}{l}\text { Man sollte die Gentechnik in der Landwirtschaft verbieten, } \\
\text { weil sie Risiken birgt, die wir nicht abschätzen können. }\end{array}$ & $2013(15)$ & $71 \%$ & $27 \%$ & 1.000 \\
\hline $\begin{array}{l}\text { Inwieweit erwarten Sie, dass die Landwirtschaft keine Gen- } \\
\text { technik einsetzt? }\end{array}$ & $2014(17)$ & $\begin{array}{l}83 \% \text { findet } \\
\text { wichtig }{ }^{2)}\end{array}$ & & 1.000 \\
\hline $\begin{array}{l}\text { Sollte es deutschen Landwirten freigestellt sein, gentechnisch } \\
\text { veränderte Pflanzen anzubauen? }\end{array}$ & $2013(15)$ & $35 \%$ & $62 \%$ & 1.000 \\
\hline $\begin{array}{l}\text { Sollen in Deutschland gentechnisch veränderte Pflanzen } \\
\text { angebaut werden? }\end{array}$ & 2014 (16) & $8,6 \%$ & $88,1 \%$ & 982 \\
\hline
\end{tabular}

1) Prozentangaben in Bezug auf "decided public" 1999: 49\% aller Befragten; 2002: 45\% aller Befragten: 2005: 49\% aller Befragten. ${ }^{2)}$ relevante Kategorien ("sehr wichtig", „eher wichtig") wurden zusammengefasst.

Quelle: siehe Indikatorenblatt GG-17.

b) Tabelle 8: Kaufbereitschaft für Lebensmittel mit gentechnisch veränderten Inhaltsstoffen

\begin{tabular}{|c|c|c|c|c|c|c|c|}
\hline Angaben in $\%$ & $2000^{1)}$ & $2002^{1)}$ & $2004^{2)}$ & $2006^{21}$ & $2008^{21}$ & $2009 a^{3)}$ & $2009 b^{4)}$ \\
\hline Ja & 6 & 5 & 6 & 7 & 8 & 19 & 8 \\
\hline Eventuell (2009b: vielleicht) & 19 & 21 & 17 & 21 & 21 & & 29 \\
\hline eher nicht & 32 & 35 & 31 & 33 & 32 & & \\
\hline überhaupt nicht & 43 & 39 & 46 & 40 & 33 & 54 & 56 \\
\hline Anzahl der Gesamtbefragten & 2.018 & 2.316 & 2.018 & 2.034 & 2.021 & 1.000 & 1.000 \\
\hline
\end{tabular}

1) Erhebung aus Quelle (7). Frage bis 2002: In jüngster Zeit wird viel über gentechnisch behandelte und gentechnisch hergestellte Lebensmittel und Lebensmittelzusätze diskutiert. Würden Sie solche Lebensmittel kaufen?

2) Ab 2004 leicht veränderte Frage gegenüber Vorjahren: In den kommenden Jahren ist damit zu rechnen, dass der Anbau von gentechnisch veränderten Pflanzen auch in Europa von den Behörden genehmigt wird. Würden Sie Lebensmittel aus gentechnisch veränderten Organismen kaufen? Ab 2010 wird die Frage so nicht mehr gestellt, sodass die Tabelle in dieser Form und mit derselben Quelle nicht mehr aktualisiert werden kann.

3) Frage in Quelle (13): Würden Sie gentechnisch veränderte Lebensmittel kaufen, wenn diese deutlich billiger angeboten würden?

4) Frage in Quelle (14): Wenn es möglich wäre, den Geschmack Ihrer Lieblingsfrüchte gentechnisch erheblich zu verbessern, würden Sie diese Früchte bevorzugen? Aktuellere Fragen zur Kaufbereitschaft (Quellen (11) und (12)) wurden anders formuliert und können daher nicht in dieser Tabelle dargestellt werden. Sie sind in Tabelle 9 aufgenommen. Quelle: siehe Indikatorenblatt GG-17. 
Laufende Nr.: GG-18

Problemfeld: Öffentliche Wahrnehmung

\section{INDIKATOR: AKZEPTANZ GENTECHNISCH VERÄNDERTER PFLANZEN BEI LANDWIRTEN} (GENTECHNIKFREIE REGIONEN)

\section{ANMERKUNG:}

Der Indikator GG-18 wird nicht weitergeführt. Die Angaben des Indikators evaluierten indirekt die Akzeptanz von Landwirten, gentechnisch veränderte Pflanzen anzubauen. Der Indikator wurde zuletzt im Themenband "Grüne Gentechnologie" (Müller-Röber et al., 2013:233f.) veröffentlicht. Eine Fortschreibung der Daten ist derzeit nicht aussagefähig, da seit 2012 in Deutschland insgesamt kein Anbau von gentechnisch veränderten Sorten stattfindet; entsprechende Recherchen werden permanent weitergeführt.

Laufende Nr.: GG-19

Problemfeld: Öffentliche Wahrnehmung + Stand der Kommerzialisierung

\section{INDIKATOR: AKZEPTANZ GENTECHNISCH VERÄNDERTER PFLANZEN BEI LANDWIRTEN} (GEÄUSSERTE ZUSTIMMUNG)

\section{ANMERKUNG:}

Der Indikator GG-19 wird nicht mehr weitergeführt. Die Angaben des Indikators bezogen sich auf die in Umfragen geäußerte Zustimmung von Landwirten zu gentechnisch verändertem Saatgut und dessen Einsatz. Die Ergebnisse von Umfragen aus den Jahren 2002 und 2006 wurden zuletzt im Themenband "Grüne Gentechnologie" (Müller-Röber et al., 2013:235) publiziert. Eine Fortschreibung ist derzeit nicht möglich; entsprechende Recherchen werden permanent weitergeführt. 
Laufende Nr:: GG-20

Problemfeld: Öffentliche Wahrnehmung + Stand der Kommerzialisierung

\section{INDIKATOR: ANZAHL ALS LEBENSMITTEL UND FUTTERMITTEL ZUGELASSENER GENTECHNISCH VERÄNDERTER PFLANZEN}

\section{DATENQUELLE:}

Veröffentlichung der Europäischen Kommission. Unter:

http://ec.europa.eu/food/dyna/gm_register/index_en_new.cfm

Veröffentlichung des Forum Bio- und Gentechnologie - Verein zur Förderung der gesellschaftlichen Diskussionskultur

e. V. Unter:

http://www.transgen.de/zulassung/gvo/

Zugriff (alle): März 2014, Stand: März 2014

\section{VERFÜGBARKEIT DER DATEN:}

öffentlich

Die für den Indikator relevanten Daten werden in regelmäßigen Abständen von der Europäischen Kommission im „EURegister für die zugelassenen genetisch veränderten Organismen (GVO)“ aufgelistet. Die zugelassenen GVO werden auf ausführlichen Datenblättern vorgestellt, aus denen der Umfang der Zulassung hervorgeht. Die Datenbank liefert darüber hinaus Angaben über ausgelaufene und zurückgezogene Zulassungen. Um aktuelle Entwicklungen - wie z. B. das Verbot der Kartoffelsorte "Amflora” - zu registrieren, erfolgte ein Abgleich der Daten des EU-Registers mit den Einträgen der Datenbank des „Forum Bio- und Gentechnologie e. V. “ unter "transgen.de”, da diese regelmäßiger aktualisiert wird. Grundlage der Transgen-Datenbank bildet ebenfalls das EU-Register, jedoch werden von den Betreibern weitere Quellen (z. B. Pressemeldungen) einbezogen.

\section{ABGRENZUNG DER BERECHNUNGSGRÖSSEN:}

Berücksichtigt werden alle GVO, die als Lebensmittel, Lebensmittelzusatzstoff, Futtermittel sowie zum Anbau und Import in der Europäischen Union (EU) im jeweiligen Jahr, gemäß der "Verordnung Nr. 1829/2003 des Europäischen Parlamentes und des Rates vom 22. September 2003 über genetisch veränderte Lebensmittel und Futtermittel" bzw. gemäß der „Richtlinie 2001/18/EG des Europäischen Parlaments und des Rates vom 12. März 2001 über die absichtliche Freisetzung genetisch veränderter Organismen in die Umwelt und zur Aufhebung der Richtlinie 90/220/EWG des Rates", zugelassen waren. Markteinführungen vor 1997 unterliegen der "Richtlinie des Rates vom 23. April 1990 über die absichtliche Freisetzung genetisch veränderter Organismen in die Umwelt" (90/220/EWG). Auflistungen zwischen 1997 und 2003 fallen unter die „Verordnung Nr. 258/97 des Europäischen Parlaments und des Rates vom 27. Januar 1997 über neuartige Lebensmittel und neuartige Lebensmittelzutaten". Nationale Verbote, die für einzelne GVO vorliegen können, werden nicht berücksichtigt.

\section{GLIEDERUNG DER DARSTELLUNG:}

a) Anzahl der als Lebensmittel, Lebensmittelzusatzstoffe und Futtermittel zugelassenen GVO in der EU

b) Anzahl der für den Anbau und Import zugelassenen GVO in der EU

\section{BERECHNUNGSHÄUFIGKEIT:}

jährlich 


\section{AUSSAGEFÄHIGKEIT:}

Der Indikator zeigt die Summe der als Lebensmittel, Futtermittel und Lebensmittelzusatzstoff zugelassenen gentechnisch veränderten Pflanzen. Bei den Zulassungen wird differenziert zwischen dem Anbau gentechnisch veränderter Pflanzen in der EU, der Einfuhr gentechnisch veränderter Pflanzen in die EU und der Verwendung der gentechnisch veränderten Pflanzen als Lebens- oder Futtermittel. Der Indikator erlaubt Rückschlüsse auf die Akzeptanz und die Kommerzialisierung von GVO. Insbesondere der starke Anstieg der Zulassungen als Futtermittel und der damit einhergehende Anstieg der Importe ab 2007 geben einen Hinweis auf die Akzeptanz innerhalb der Futtermittelindustrie und der Landwirtschaft. Rückschlüsse auf die Verbraucherakzeptanz sind nur bedingt möglich, da ein Anstieg der Zulassungen als Lebensmittel bzw. Lebensmittelzusatzstoff nicht positiv mit einer erhöhten Akzeptanz korreliert sein muss (siehe auch GG-17). Die niedrige Kommerzialisierungsrate im Sinne von Anbauzulassungen und dem gänzlich fehlenden Anbau von GVO in Deutschland (siehe GG-15) könnten Hinweise auf wissenschaftliche sowie politische Unsicherheiten im Hinblick auf die ökologische und biologische Risikobewertung von GVO liefern. 
a) Abbildung 8: Anzahl der als Lebensmittel, Lebensmittelzusatzstoffe und Futtermittel zugelassenen GVO in der EU

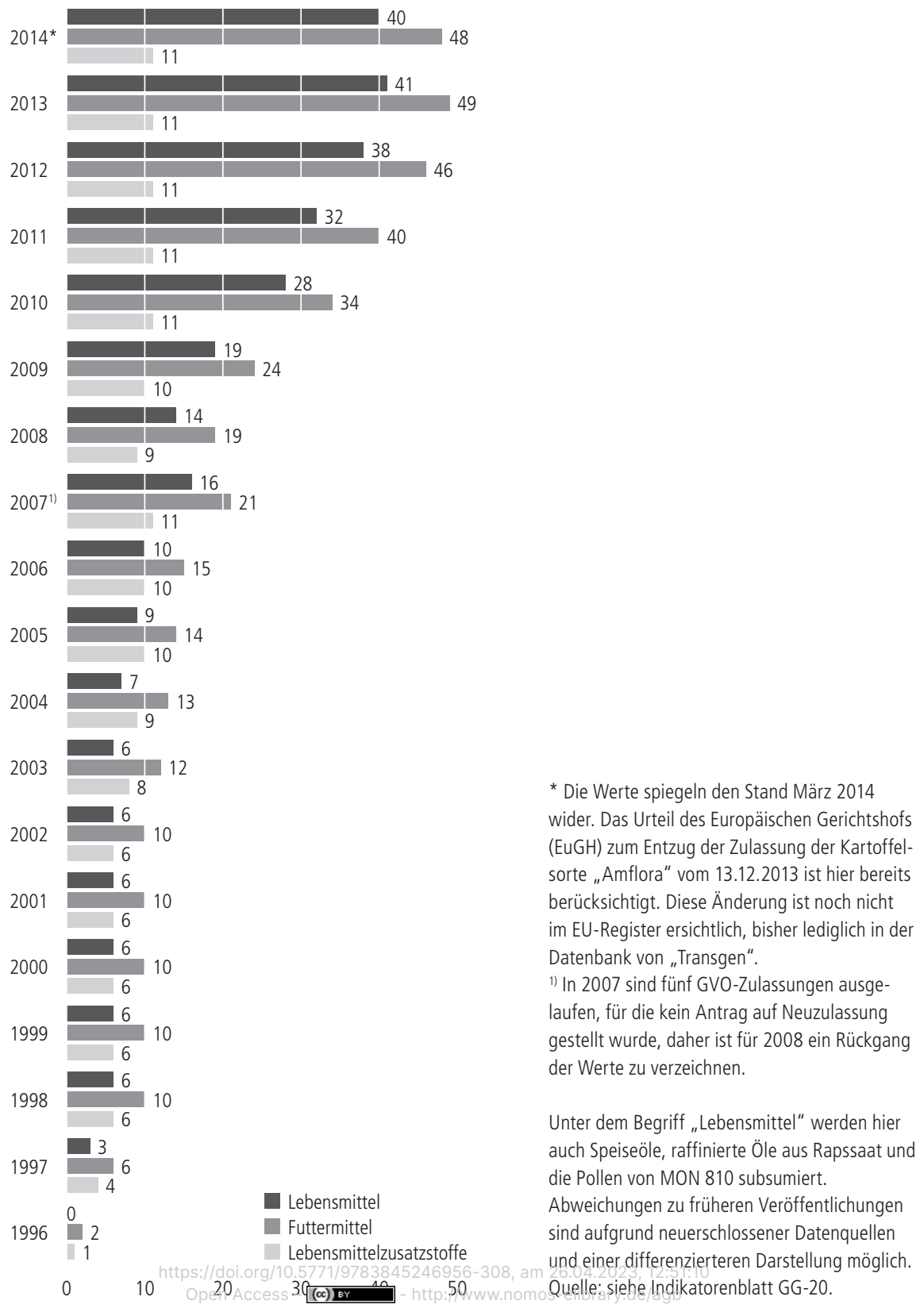


b) Abbildung 9: Anzahl der für den Anbau und Import zugelassenen GVO in der EU

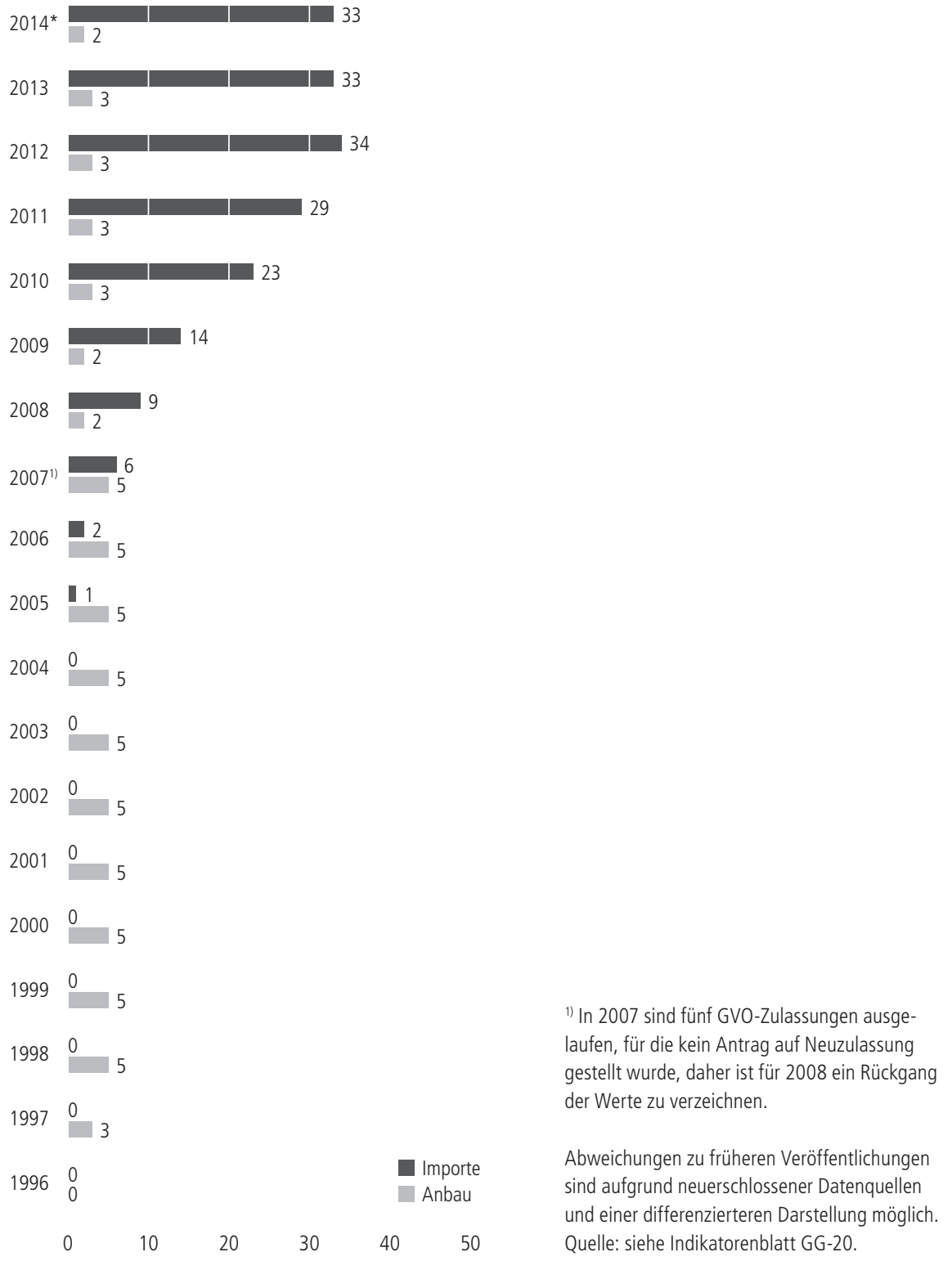


Laufende Nr.: GG-21

Problemfeld: Öffentliche Wahrnehmung + Feldzerstörungen

\section{INDIKATOR: SACHBESCHÄDIGUNGEN IM ZUSAMMENHANG MIT DER GRÜNEN GENTECHNOLOGIE}

\section{DATENQUELLE:}

Anfrage Bundeskriminalamt.

Zugriff: September 2014, Stand: Dez 2013

\section{VERFÜGBARKEIT DER DATEN:}

nicht öffentlich

\section{ABGRENZUNG DER BERECHNUNGSGRÖSSEN:}

Es handelt sich um alle bundesweit erfassten, politisch motivierten Straftaten der Sachbeschädigung ( $\$ 303$ StGB) und Gemeinschädlichen Sachbeschädigung (§304 StGB), die mit Bezug zum Thema "Gentechnologie" erfasst wurden. Unter diesen Fällen können sich neben Angriffen auf Felder jedoch auch andere Sachbeschädigungen im Zusammenhang mit dem Thema Gentechnologie befinden. Hierbei handelt es sich derzeit im Wesentlichen um Fälle, die die grüne Gentechnologie betreffen.

Eine detaillierte Aufgliederung ist anhand der erhobenen Daten nicht möglich.

\section{GLIEDERUNG DER DARSTELLUNG:}

Sachbeschädigungen im Zusammenhang mit der Gentechnologie

\section{BERECHNUNGSHÄUFIGKEIT:}

jährlich

\section{AUSSAGEFÄHIGKEIT:}

Der Indikator ist ein Maß für die Intensität des öffentlichen Konfliktes und den Widerstand, auf den die Einführung gentechnisch veränderter Pflanzen in Deutschland trifft. Er trifft keine Aussage darüber, inwieweit die illegalen Handlungen auf einer breiteren gesellschaftlichen Unterstützung basieren oder nur von einer radikalen Minderheit getragen werden. Zugleich reflektiert der Indikator das öffentliche Meinungsklima gegenüber der grünen Gentechnologie, das gleichermaßen relevant für privatwirtschaftliche Investitionen und politische Handlungen sein kann. 
Tabelle 9: Sachbeschädigungen im Zusammenhang mit der Gentechnologie

\begin{tabular}{|c|c|c|c|c|c|}
\hline Jahr & Delikt/Phänomenbereich & $\begin{array}{c}\S 303 \mathrm{StGB} \\
\text { Sachbeschädigung }\end{array}$ & $\begin{array}{c}\S 304 \text { StGB } \\
\text { Gemeinschädliche } \\
\text { Sachbeschädigung }\end{array}$ & & \\
\hline \multirow{3}{*}{2005} & L & 5 & 0 & 5 & \multirow{3}{*}{11} \\
\hline & $R$ & 0 & 0 & 0 & \\
\hline & $\mathrm{N}$ & 6 & 0 & 6 & \\
\hline \multirow{3}{*}{2006} & L & 14 & 3 & 17 & \multirow{3}{*}{20} \\
\hline & $\mathrm{R}$ & 0 & 0 & 0 & \\
\hline & $\mathrm{N}$ & 3 & 0 & 3 & \\
\hline \multirow{3}{*}{2007} & $\mathrm{~L}$ & 21 & 3 & 24 & \multirow{3}{*}{27} \\
\hline & $R$ & 0 & 0 & 0 & \\
\hline & $\mathrm{N}$ & 3 & 0 & 3 & \\
\hline \multirow{3}{*}{2008} & L & 35 & 1 & 36 & \multirow{3}{*}{42} \\
\hline & $R$ & 0 & 1 & 1 & \\
\hline & $\mathrm{N}$ & 5 & 0 & 5 & \\
\hline \multirow{3}{*}{2009} & L & 16 & 3 & 19 & \multirow{3}{*}{19} \\
\hline & $R$ & 0 & 0 & 0 & \\
\hline & $\mathrm{N}$ & 0 & 0 & 0 & \\
\hline \multirow{3}{*}{2010} & L & 7 & 0 & 7 & \multirow{3}{*}{7} \\
\hline & $\mathrm{R}$ & 0 & 0 & 0 & \\
\hline & $\mathrm{N}$ & 0 & 0 & 0 & \\
\hline \multirow{3}{*}{2011} & L & 4 & 0 & 4 & \multirow{3}{*}{4} \\
\hline & $\mathrm{R}$ & 0 & 0 & 0 & \\
\hline & $\mathrm{N}$ & 0 & 0 & 0 & \\
\hline \multirow{3}{*}{2012} & L & 2 & 1 & 3 & \multirow{3}{*}{4} \\
\hline & $R$ & 1 & 0 & 1 & \\
\hline & $\mathrm{N}$ & 0 & 0 & 0 & \\
\hline \multirow{3}{*}{2013} & L & 3 & 0 & 3 & \multirow{3}{*}{3} \\
\hline & $R$ & 0 & 0 & 0 & \\
\hline & $\mathrm{N}$ & 0 & 0 & 0 & \\
\hline$\Sigma$ & & 125 & 12 & & 137 \\
\hline
\end{tabular}

L=Linksextrem, R=Rechtsextrem, N=Sonstige/nicht zuzuordnen. Quelle: siehe Indikatorenblatt GG-21. 
Laufende Nr:: GG-22

Problemfeld: Stand der Kommerzialisierung

\section{INDIKATOR: VERTEILUNG DER ZUGELASSENEN TRAITS AUF FIRMEN}

\section{DATENQUELLE:}

Veröffentlichung des Forum Bio- und Gentechnologie - Verein zur Förderung der gesellschaftlichen Diskussionskultur e. V. Unter:

www.transgen.de/zulassung/gvo/

Zugriff: August 2013, Stand: August 2013

\section{VERFÜGBARKEIT DER DATEN:}

öffentlich

\section{ABGRENZUNG DER BERECHNUNGSGRÖSSEN:}

keine Angabe

\section{GLIEDERUNG DER DARSTELLUNG:}

Anzahl der Zulassungen pro Unternehmen in der EU

\section{BERECHNUNGSHÄUFIGKEIT:}

jährlich

\section{AUSSAGEFÄHIGKEIT:}

Der Indikator zeigt, welche Firmen über zugelassene Traits verfügen und spiegelt wider, wie viele und welche Unternehmen auf dem Marktfeld gentechnisch veränderten Saatguts aktiv sind. Neben der reinen Anzahl von Firmen kann mit Hilfe der relativen Anteile die Marktkonzentration dargestellt werden, also ob und in welcher Größenordnung eine einzelne oder mehrere Firmen derzeit über besonders große Anteile an diesem Marktfeld verfügen. Beides gibt Hinweise auf die Offenheit des Marktfeldes für kleine oder neue Anbieter. Ferner ist ein Vergleich der Marktstrukturen zwischen den USA und der EU möglich.

Der Indikator zeigt nicht, welche Traits real von den Landwirten nachgefragt werden und wie groß die jeweiligen Marktanteile der Traits sind. Zu beachten ist außerdem, dass in der EU die meisten Traits nur über eine Zulassung für den Import, zur Lebensmittelverarbeitung oder als Futtermittel verfügen, aber keine Zulassung für den Anbau besteht. Die Verteilung der zugelassenen Traits zwischen den Firmen ist deswegen nur bedingt geeignet, deren reale Marktanteile abzuschätzen. Ebenfalls nicht abgedeckt sind Märkte außerhalb der USA und der EU; hierbei können auch die international agierenden Konzerne regional sehr unterschiedliche Schwerpunkte hinsichtlich ihres Engagements aufweisen. 
Tabelle 10: Anzahl der Zulassungen pro Unternehmen in der EU

\begin{tabular}{|c|c|c|c|}
\hline Unternehmen & 2010 & 2012 & 2013 \\
\hline Bayer Crop Science 1) & $11 \%$ & $11 \%$ & $13 \%$ \\
\hline Dow Agrosciences ${ }^{2)}$ & $9 \%$ & $11 \%$ & $8 \%$ \\
\hline Syngenta ${ }^{3)}$ & $11 \%$ & $14 \%$ & $15 \%$ \\
\hline BASF & $2 \%$ & $2 \%$ & $3 \%$ \\
\hline Florigene & $7 \%$ & $5 \%$ & $5 \%$ \\
\hline Monsanto & $46 \%$ & $41 \%$ & $42 \%$ \\
\hline Pioneer & $13 \%$ & $16 \%$ & $12 \%$ \\
\hline KWS Saat & $2 \%$ & $2 \%$ & $2 \%$ \\
\hline
\end{tabular}

Bei Zulassungen in Kooperation werden diese für jede beteiligte Firma gezählt.

1) Amylogen HB, heute zu BASF Plant Science gehörend.

2) Mycogen Seeds ist ein Tochterunternehmen von Dow AgroScience.

3) Syngenta Seeds S.A.S in Vertretung von Syngenta Crop Protection AG, Basel.

Quelle: siehe Indikatorenblatt GG-22. 
Laufende Nr.: GG-23

Problemfeld: Koexistenz und Haftungsfragen

\section{INDIKATOR: SPUREN GENTECHNISCH VERÄNDERTER ORGANISMEN IN LEBENSMITTELN IN} DEUTSCHLAND

\section{DATENQUELLE:}

Forum Bio- und Gentechnologie - Verein zur Förderung der gesellschaftlichen Diskussionskultur e. V. Unter:

http://www.transgen.de/aktuell/1671.doku.html

http://www.transgen.de/lebensmittel/ueberwachung/688.doku.html

http://www.transgen.de/lebensmittel/ueberwachung/

Zugriff (alle): September 2013, Stand: Dezember 2012

\section{VERFÜGBARKEIT DER DATEN:}

öffentlich

\section{ABGRENZUNG DER BERECHNUNGSGRÖSSEN:}

Dargestellt wird der Prozentsatz der Stichproben von soja- bzw. maishaltigen Lebensmitteln, die GVO-Spuren enthalten.

\section{GLIEDERUNG DER DARSTELLUNG:}

Anteil der GVO-Spuren in Lebensmittelproben in Deutschland 2000-2012

\section{BERECHNUNGSHÄUFIGKEIT:}

jährlich

\section{AUSSAGEFÄHIGKEIT:}

Der Indikator stellt die Ergebnisse von Lebensmittelkontrollen aus den Bundesländern im Zeitverlauf dar. Angegeben wird der durchschnittliche Prozentsatz GVO-positiver Proben. Die Prozentzahlen schwanken dabei deutlich zwischen den verschiedenen Bundesländern. Die gemessenen Werte lagen jedoch in der Regel an der technischen Nachweisgrenze um die $0,1 \%$.

Abbildung 10: Anteil der GVO-Spuren in Lebensmittelproben in Deutschland 2000-2012

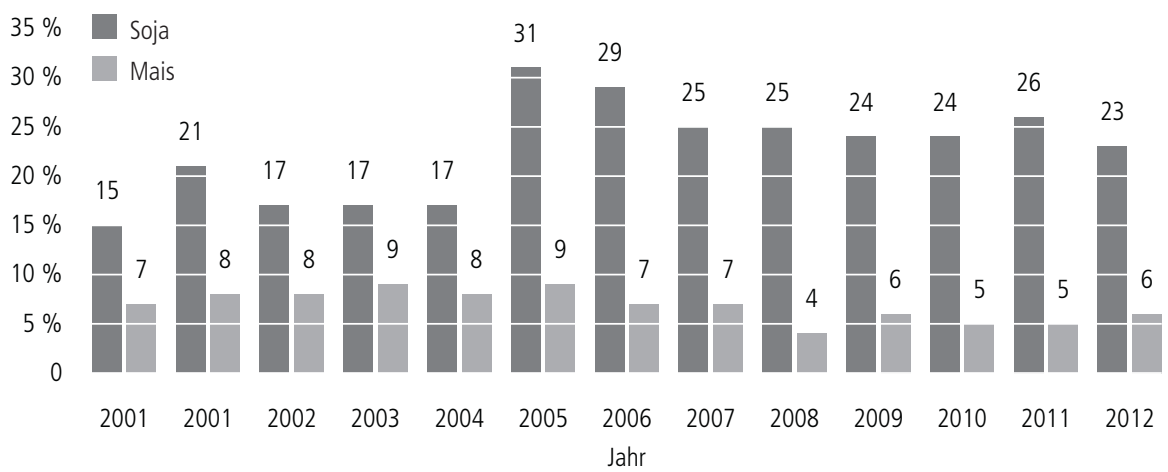


Laufende Nr:: GG-24

Problemfeld: Öffentliche Wahrnehmung + Forschungstandort Deutschland

\section{INDIKATOR: NEUERSCHEINUNGEN ZUM THEMENBEREICH GRÜNE GENTECHNOLOGIE}

\section{DATENQUELLE:}

Online-Katalog der Deutschen Nationalbibliothek. Unter:

https://portal.dnb.de

Zugriff: August 2014, Stand: k. A.

\section{VERFÜGBARKEIT DER DATEN:}

\section{öffentlich}

Die Nationalbibliothek (DNB) ist eine bundesunmittelbare Anstalt des öffentlichen Rechts. Ihre Aufgabe ist die Archivierung und bibliografische Erfassung in Deutschland veröffentlichter Medienwerke (Monografien, Zeitungen, Zeitschriften, Loseblattwerke, Karten, Musikalien, Tonträger, elektrische Publikationen). Darüber hinaus werden auch im Ausland veröffentlichte deutschsprachige Medienwerke, im Ausland veröffentlichte Übersetzungen deutschsprachiger Medienwerke, fremdsprachige Medienwerke über Deutschland sowie Exilpublikationen deutschsprachiger Emigranten zwischen 1933 und 1950 erfasst. Seit 2006 werden zusätzlich Online-Publikationen systematisch berücksichtigt. Der Katalog der Deutschen Nationalbibliothek erlaubt eine kostenlose Recherche innerhalb der umfassenden Bibliotheksbestände seit 1913. Nach Anbieterangaben werden eingegangene Publikationen mit einer Bearbeitungszeit von ca. einem Monat in den Katalog und in die Deutsche Nationalbibliografie eingetragen.

\section{ABGRENZUNG DER BERECHNUNGSGRÖSSEN:}

Für die Recherche relevanter Titel wurden die Suchbegriffe "grüne* Gentechnologie" und "grüne* Gentechnik" im Modus „Expertensuche" im gesamten Bestand des Katalogs der Deutschen Nationalbibliothek ab 2001 (Beginn des Gentechnologieberichts) gesucht. Es wurde mit beiden Begriffen gesucht, weil diese in der öffentlichen Debatte häufig synonym verwendet werden. Da es sich um eine Suche nach einem speziellen Begriff handelt, wurde die über die Titelfelder hinausgehende Suchfunktion (Index=woe) verwendet. Im Bestand vermerkte Hochschulschriften wurden explizit ausgenommen, da sie für den interessierten Laien schwer zugänglich sind. Generell ausgeschlossen wurden Periodika sowie Normdaten für einzelne Personen, Organisationen, Veranstaltungen, Geografika, Sachbegriffe und Werktitel, die im Katalog der DNB geführt werden. Es wurde keine weiterführende qualitative Filterung der Suchergebnisse vorgenommen.

\section{GLIEDERUNG DER DARSTELLUNG:}

Anzahl an Neuerscheinungen zum Themenbereich grüne Gentechnologie

\section{BERECHNUNGSHÄUFIGKEIT:}

jährlich

\section{AUSSAGEFÄHIGKEIT:}

Der Indikator dokumentiert die publizistische Dichte für die jeweils in der Recherche genutzen Stichworte. Er zählt diejenigen Materialien, die auch der interessierten Öffentlichkeit frei zur Verfügung stehen. Über die (etwa in Fachjournalen geführte) wissenschaftsinterne Aushandlung liefert er keine Aussage. 
Abbildung 11: Anzahl an Neuerscheinungen zum Themenbereich grüne Gentechnologie

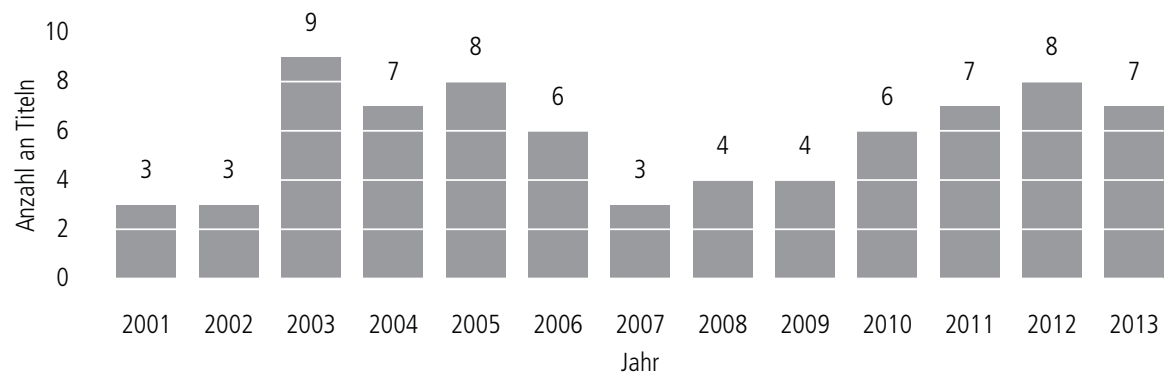

Erfassung der im DNB-Katalog verzeichneten Titel bis zum Stichtag am 06.08.2014. Erweiterter Recherchemodus; Unterschiede zu früheren Veröffentlichungen möglich.

Quelle: siehe Indikatorenblatt GG-24. 
Laufende Nr:: GG-25

Problemfeld: Öffentliche Wahrnehmung

\section{INDIKATOR: PRINTMEDIALE ABBILDUNG DES THEMENBEREICHS GRÜNE GENTECHNOLOGIE}

\section{DATENQUELLE:}

Frankfurter Allgemeine Zeitung. Unter: www.faz.net

Süddeutsche Zeitung. Unter: www.sueddeutsche.de

Die Zeit. Unter: www.zeit.de

Der Spiegel. Unter: www.spiegel.de

Zugriff (alle): August 2014, Stand: August 2014

\section{VERFÜGBARKEIT DER DATEN:}

mehrheitlich öffentlich

Die Recherche in den Online-Archiven der ausgewählten deutschen Zeitungen und Zeitschriften ist mit Ausnahme der Süddeutschen Zeitung (SZ) kostenlos zugänglich. Beiträge zu ausgewählten Suchbegriffen können hier tagesaktuell recherchiert werden, jedoch können die Presseartikel der Frankfurter Allgemeinen Zeitung (F.A.Z.) mehrheitlich nur kostenpflichtig abgerufen werden.

\section{ABGRENZUNG DER BERECHNUNGSGRÖSSEN:}

Für die Recherche relevanter Printartikel wurden die Stichworte "grüne* Gentechnologie" und "grüne* Gentechnik" im Volltext ab 2001 (Beginn der IAG Gentechnologiebericht) überregional gesucht. Es wurde mit beiden Begriffen gesucht, weil diese in der öffentlichen Debatte häufig synonym verwendet werden. Ausschließlich online erschienene Presseartikel, Artikel in Sonderheften sowie regionale und in anderen Medien erschienene Beiträge wurden dabei nicht berücksichtigt. Es wurde keine weiterführende qualitative Filterung der Suchergebnisse vorgenommen.

\section{GLIEDERUNG DER DARSTELLUNG:}

Anzahl an Printartikeln zu den Stichworten "grüne* Gentechnologie" und "grüne* Gentechnik"

\section{BERECHNUNGSHÄUFIGKEIT:}

jährlich

\section{AUSSAGEFÄHIGKEIT:}

Der Indikator dokumentiert die Dichte der öffentlichen Berichterstattung zum Themenbereich im dargestellen Zeitraum in ausgewählten überregionalen Printmedien. Diese erreichen - das dokumentieren die Auflagezahlen - eine Vielzahl an Menschen in ganz Deutschland, die sich auf diesem Weg über den Themenbereich informieren können. 
Abbildung 12: Anzahl an Printartikeln zu den Stichworten "grüne Gentechnologie" und "grüne Gentechnik"

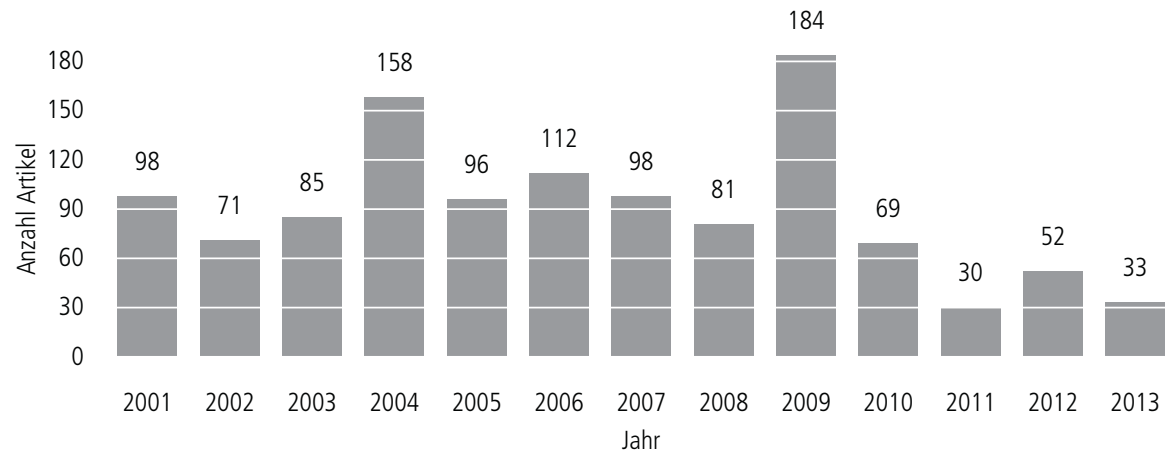

Quelle: siehe Indikatorenblatt GG-25. 
Laufende Nr:: GG-26

Problemfeld: Öffentliche Wahrnehmung

\section{INDIKATOR: INTERNETPRÄSENZ ZUM STICHWORT GRÜNEN GENTECHNOLOGIE}

\section{DATENQUELLE:}

Google - Suchmaschine. Unter:

www.google.de

Zugriff: Oktober 2014, Stand: k. A.

\section{VERFÜGBARKEIT DER DATEN:}

öffentlich

\section{ABGRENZUNG DER BERECHNUNGSGRÖSSEN:}

Für die Recherche wurde das Stichwort "grüne Gentechnologie" mit der Suchmaschine "Google" gesucht; diese Suchmaschine stellt das am häufigsten in Deutschland genutzte Portal für die Online-Recherche dar. Es werden monatlich die Anzahl an gefundenen Webseiten gemittelt; es erfolgt keine weiterführende qualitative Auswertung der Suchergebnisse. Die Datenerhebung erfolgt seit April 2011. Es muss darauf hingewiesen werden, dass der Internetauftritt der Suchmaschine ständig weiterentwickelt wird und dadurch bedingte Abweichungen zwischen den einzelnen Monaten möglich sind.

\section{GLIEDERUNG DER DARSTELLUNG:}

Trefferanzahl bei der Stichwortsuche unter Google

\section{BERECHNUNGSHÄUFIGKEIT:}

monatlich

\section{AUSSAGEFÄHIGKEIT:}

Der Indikator dokumentiert die öffentliche Präsenz und zugleich Auseinandersetzung mit dem Thema grüne Gentechnologie anhand von verfügbaren Webseiten im Internet. Die interessierte Öffentlichkeit kann sich auf diesem Weg weiterführend über das Forschungsfeld informieren. Es ist allerdings möglich, dass die von der Suchmaschine vorgeschlagenen Webseiten sich nicht ausschließlich mit relevanter Forschung befassen, sondern dass grüne Gentechnologie nur als randständiges Thema auftritt. Außerdem ist die Qualität der online präsentierten Informationen nicht unmittelbar einschätzbar. 
Abbildung 13: Trefferanzahl bei der Stichwortsuche in Google

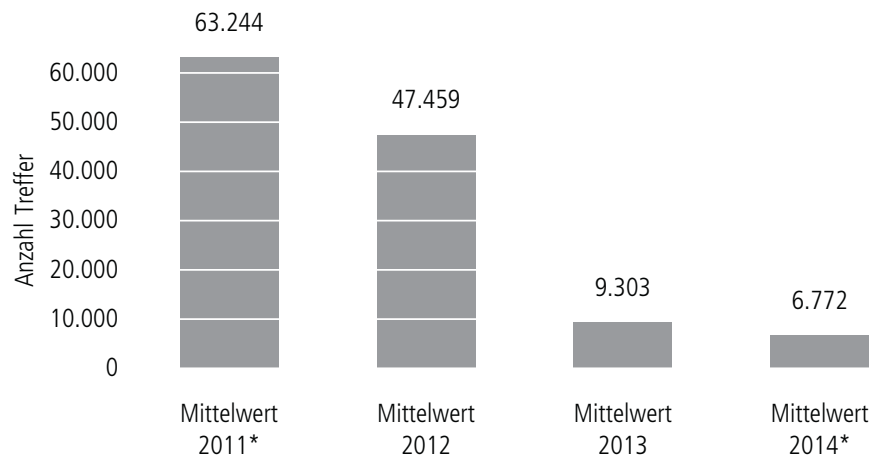

* Daten ab April 2011 bzw. bis Oktober 2014

Quelle: siehe Indikatorenblatt GG-26. 


\subsubsection{Zusammenfassung}

Es ergibt sich in der Gesamtschau folgendes Bild der grünen Gentechnologie:

- Es sind derzeit in der EU nur sehr wenige Traits für den Anbau zugelassen (GG-01).

- Die Anzahl der Traits in Freisetzungsversuchen (GG-02) sowie die Anzahl der Freisetzungsversuche und Freisetzungsorte (GG-03) in Deutschland sind im Berichtszeitraum stetig gesunken. Ein kommerzieller Anbau findet in Deutschland seit 2012 nicht mehr statt. Zu einer anteilsmäßigen Veränderung der Anbauflächen einzelner Arten durch den Anbau gentechnisch veränderter Sorten kommt es daher nicht (GG-13 und GG-14, siehe unten).

- Ganz im Gegensatz zur Entwicklung in Deutschland steigt global gesehen der Umsatz gentechnisch veränderten Saatgutes im Berichtszeitraum deutlich an (GG-04). Auch der Flächenanteil von gv-Pflanzen an der weltweit verfügbaren Anbaufläche ist weiter angestiegen (GG-05). Ein Zuwachs ist sowohl bei Baumwolle, Mais, Raps als auch bei Soja zu verzeichnen.

- Der Anteil gentechnisch veränderter Mais-Sorten an nach dem Saatgutverkehrsgesetz (SaatG) zugelassenen Sorten ist im Berichtszeitraum stetig gesunken und lag 2013 bei 3 \% (GG-12). Ihr tatsächlicher Anbau ist in Deutschland seit 2009 verboten.

- Eine anteilsmäßige Veränderung der Anbauflächen einzelner Arten durch den Anbau gentechnisch veränderter Sorten findet nicht statt (GG-13 und GG-14, siehe oben).

- Im Berichtszeitraum ist der Flächenanteil des Ökolandbaus an der gesamten landwirtschaftlichen Nutzfläche in Deutschland leicht angestiegen und liegt nun bei circa $6,2 \%$ (GG-16).

- Die grüne Gentechnologie wird auch weiterhin von der Öffentlichkeit in Deutschland eher als negativ bewertet, die Akzeptanz ist gering. Verbraucherinnen und Verbraucher sehen gentechnisch veränderte Lebensmittel in Umfragen kritisch. Ein Großteil der Befragten spricht sich für das Anbauverbot für gentechnisch veränderten Mais aus und unterstützt eine Kennzeichnung gentechnisch veränderter Nahrungsmittel sowie die Kennzeichnung „ohne Gentechnik“ (GG-17).

- Die Anzahl der als Lebensmittel und Futtermittel zugelassenen gentechnisch veränderten Pflanzen ist seit 2010 leicht angestiegen. Derzeit sind 33 GVO für den Import und zwei für den Anbau in der EU zugelassen (Stand März 2014) (GG-20).

- Die Zahl der politisch motivierten Straftaten mit Bezug zur grünen Gentechnologie ist im Berichtszeitraum gesunken (GG-21), was auch mit dem Rückgang der Anzahl der Freisetzungsversuche zusammen hängen kann. 
- Die Zulassungen von gv-Pflanzen in Europa konzentrieren sich auf wenige Unternehmen (GG-22).

- Spuren gentechnisch veränderter Organismen finden sich in Lebensmitteln in Deutschland. Bei Soja liegt der Anteil über $20 \%$, bei Mais über $5 \%$ der Lebensmittelproben. Allerdings lagen die gemessenen Werte in der Regel an der technischen Nachweisgrenze um die 0,1 \% (GG-23).

- Im Berichtszeitraum erschienen konstant zwischen sechs und acht Bücher pro Jahr zum Thema, die mit den Stichworten „Grüne* Gentechnologie“ und „Grüne* Gentechnik“ in der Nationalbibliothek auffindbar sind (GG-24).

- Die Anzahl an Printartikeln zu den Stichworten „Grüne Gentechnologie“ und „Grüne Gentechnik" schwankt im Zeitverlauf. Im Berichtszeitraum waren es zwischen 69 (2010) und 33 (2013) Artikel (GG-25).

- Das Thema grüne Gentechnologie ist im Internet präsent (GG-26).

\subsection{Literatur}

Agarwal, P. K. et al. (2013): Bioengineering for salinity tolerance in plants: state of the art. In: Mol. Biotechnol 54(1):102-123.

Ahmad, P. et al. (2012): Role of transgenic plants in agriculture and biopharming. In: Biotechnol. Adv 30(3):524-540.

Arabidopsis Interactome Mapp. Consortium (2011): Evidence for network evolution in an Arabidopsis interactome map. In: Science 333(6042):601-607.

Banerjee, A. (2011): Food, feed, fuel: transforming the competition for grains. In: Dev Change 42(2):529-557.

Barampuram, S./Zhang, Z. J. (2011): Recent advances in plant transformation. In: Methods Mol Biol 701:1-35.

Barrell, P. J. et al. (2013): Applications of biotechnology and genomics in potato improvement. In: Plant Biotechnol. J. 11(8):907-920.

Bashir, K. et al. (2013): The road to micronutrient biofortification of rice: progress and prospects. In: Front Plant Sci 4:15.

Beauregard, P. B. et al. (2013): Bacillus subtilis biofilm induction by plant polysaccharides. In: Proc Natl Acad Sci USA 110(17):E1621-1630.

Bendahmane, M. et al. (2013): Genetics and genomics of flower initiation and development in roses. In: J Exp Bot 64(4):847-857.

Bengough, A. G. et al. (2011): Root elongation, water stress, and mechanical impedance: a review of limiting stresses and beneficial root tip traits. In: J Exp Bot 62(1):59-68.

Berla, B. M. et al. (2013): Synthetic biology of cyanobacteria: unique challenges and opportunities. In: Front Microbiol 4:246. 
Berlec, A. (2012): Novel techniques and findings in the study of plant microbiota: search for plant probiotics. In: Plant Sci (193-194):96-102.

Bhullar, N. K./Gruissem, W. (2013): Nutritional enhancement of rice for human health: the contribution of biotechnology. In: Biotechnol Adv 31(1):50-57.

Bock, R. (2013): Strategies for metabolic pathway engineering with multiple transgenes. In: Plant Mol Biol 83(1-2):21-31.

Bock, R. (2014): Genetic engineering of the chloroplast: novel tools and new applications. In: Curr. Opin. Biotechnol. 26:7-13.

Broeders, S. R. M. et al. (2012): How to deal with the upcoming challenges in GMO detection in food and feed. In: J Biomed Biotechnol 2012:402418. Online Publikation 21.10.2012. DOI:10.1155/2012/402418.

Byrt, C. S. et al. (2011): C4 plants as biofuel feedstocks: optimising biomass production and feedstock quality from a lignocellulosic perspective. In: J Integr Plant Biol 53(2):120-135.

Cabrera-Bosquet, L. et al. (2012): High-throughput phenotyping and genomic selection: The frontiers of crop breeding converge. In: J Integr Plant Biol 54(5):312-320.

Carvalhais, L. C. et al. (2013): Activation of the jasmonic acid plant defence pathway alters the composition of rhizosphere bacterial communities. In: PLoS ONE 8(2):e56457.

Ceasar, S. A./Ignacimuthu, S. (2012): Genetic engineering of crop plants for fungal resistance: role of antifungal genes. In: Biotechnol Lett 34(6):995-1002.

Chagné, D. et al. (2014): The draft genome sequence of European pear (Pyrus communis L. „Bartlett"). In: PLoS ONE 9(4):e92644.

Chandel, A. K./Singh, O. V. (2011): Weedy lignocellulosic feedstock and microbial metabolic engineering: advancing the generation of „Biofuel“. In: Appl Microbiol Biotechnol 89(5):1289-1303.

Chandler, S. F./Sanchez, C. (2012): Genetic modification; the development of transgenic ornamental plant varieties. In: Plant Biotechnol J 10(8):891-903.

Chen, K./Gao, C. (2013): TALENs: customizable molecular DNA scissors for genome engineering of plants. In: J Genet Genomics 40(6):271-279.

Chen, L. et al. (2014): Progress in TILLING as a tool for functional genomics and improvement of crops. In: J Integr Plant Biol 56(5):425-443.

Clemente, M./Corigliano, M. G. (2012): Overview of plant-made vaccine antigens against malaria. In: J Biomed Biotechnol 2012:206918.

Cobb, J. N. et al. (2013): Next-generation phenotyping: requirements and strategies for enhancing our understanding of genotype-phenotype relationships and its relevance to crop improvement. In: Theor Appl Genet 126(4):867-887.

Cong, L. et al. (2013): Multiplex genome engineering using CRISPR/Cas systems. In: Science 339(6121):819-823.

D’Aoust, M.-A. et al. (2010): The production of hemagglutinin-based virus-like particles in plants: a rapid, efficient and safe response to pandemic influenza. In: Plant Biotechnol J 8(5):607-619.

Daetwyler, H. D. et al. (2014): Genomic prediction for rust resistance in diverse wheat landraces. In: Theor. Appl. Genet. Jun 26 [Epub ahead of print].

Dalrymple, O. K. et al. (2013): Wastewater use in algae production for generation of renewable resources: a review and preliminary results. In: Aquat Biosyst 9(1):2.

Day, A./Goldschmidt-Clermont, M. (2011): The chloroplast transformation toolbox: selectable markers and marker removal, In: Plant Biotechnol.59(5):540-553.6.04.2023, 12:51:10 
Deikman, J. et al. (2012): Drought tolerance through biotechnology: improving translation from the laboratory to farmers' fields. In: Curr Opin Biotechnol 23(2):243-250.

Demurtas, O. C. et al. (2013): A Chlamydomonas-derived Human Papillomavirus 16 E7 vaccine induces specific tumor protection. In: PLoS ONE 8(4):e61473.

Desta, Z. A./Ortiz, R. (2014): Genomic selection: genome-wide prediction in plant improvement. In: Trends Plant Sci. Jun 23 [Epub ahead of print].

Dhar, M. K. et al. (2011): Towards the development of better crops by genetic transformation using engineered plant chromosomes. In: Plant Cell Rep 30(5):799-806.

DiCarlo, J. E. et al. (2013): Genome engineering in Saccaromyces cerevisiae using CRISPR-Cas systems. In: Nucleic Acids Res 41(7):4336-4343.

Dirks, R. et al. (2009): Reverse breeding: a novel breeding approach based on engineered meiosis. In: Plant Biotechnol J 7(9):837-845

Domingo, J. L./Giné Bordonaba, J. (2011): A literature review on the safety assessment of genetically modified plants. In: Environment International 37(4):734-742.

Dubouzet, J. G. et al. (2013): Potential transgenic routes to increase tree biomass. In: Plant Sci. 212:72101.

Ducat, D. C. et al. (2011): Engineering cyanobacteria to generate high-value products. In: Trends Biotechnol 29(2):95-103.

EFSA Panel on Genetically Modified Organisms (GMO) (2012): Scientific Opinion addressing the safety assessment of plants developed through cisgenesis and intragenesis. In: EFSA Journal 10(2):25612594.

Egan, A. N. et al. (2012): Applications of next-generation sequencing in plant biology. In: Am J Bot 99(2):175-185.

Egelkrout, E. et al. (2012): Overproduction of recombinant proteins in plants. In: Plant Sci 184:83-101. Ehrhardt, D. W./Frommer, W. B. (2012): New technologies for 21st century plant science. In: Plant Cell 24(2):374-394.

Erdei, B. et al. (2010): Ethanol production from mixtures of wheat straw and wheat meal. In: Biotechnol Biofuels 3:16.

Farré, G. et al. (2011): Nutritious crops producing multiple carotenoids--a metabolic balancing act. In: Trends Plant Sci 16(10):532-540.

Feng, Z. et al. (2014): Multigeneration analysis reveals the inheritance, specificity, and patterns of CRISPR/Cas-induced gene modifications in Arabidopsis. In: Proc. Natl. Acad. Sci. U.S.A. 111(12):4632-4637.

Fesenko, E./Edwards, R. (2014): Plant synthetic biology: a new platform for industrial biotechnology. In: J. Exp. Bot. 65(8):1927-1937.

Flassig, R. J. et al. (2013): An effective framework for reconstructing gene regulatory networks from genetical genomics data. In: Bioinformatics 29(2):246-254.

Furbank, R. T./Tester, M. (2011): Phenomics-technologies to relieve the phenotyping bottleneck. In: Trends Plant Sci 16(12):635-644.

Gaeta, R. T. et al. (2012): Synthetic Chromosome Platforms in Plants. In: Annual Review of Plant Biology 63(1):307-330. 
Gaeta, R. T./Krishnaswamy, L. (2011): Engineered plant minichromosomes. In: Methods Mol Biol 701:131-146.

Gambino, G./Gribaudo, I. (2012): Genetic transformation of fruit trees: current status and remaining challenges. In: Transgenic Res 21(6):1163-1181.

Gao, M. et al. (2012): Stable plastid transformation for high-level recombinant protein expression: promises and challenges. In: J Biomed Biotechnol 2012:158232.

García-Sogo, B. et al. (2012): Production of engineered long-life and male sterile Pelargonium plants. In: BMC Plant Biol 12:156.

Gaskell, G. et al./European Commission (2010): Europeans and Biotechnology in 2010. Winds of Change? Brüssel. Unter: http://ec.europa.eu/public_opinion/archives/ebs/ebs_341_winds_en.pdf [23.11.2012].

Gong, Y. et al. (2011): Microalgae as platforms for production of recombinant proteins and valuable compounds: progress and prospects. In: J Ind Microbiol Biotechnol 38(12):1879-1890.

Guan, Z. et al. (2013): Recent advances and safety issues of transgenic plant-derived vaccines. In: Appl. Microbiol. Biotechnol. 97(7):2817-2840.

Hamilton, J. P./Buell, C. R. (2012): Advances in plant genome sequencing. In: Plant J 70(1):177-190.

Han, K. M. et al. (2011): Gibberellin-associated cisgenes modify growth, stature and wood properties in Populus. In: Plant Biotechnol J 9(2):162-178.

Hane, J. K. et al. (2014): Genome sequencing and comparative genomics of the broad host-range pathogen Rhizoctonia solani AG8. In: PLoS Genet. 10(5):e1004281.

Harfouche, A. et al. (2010): Protecting innovation: genomics-based intellectual property for the development of feedstock for second-generation biofuels. In: Recent Pat DNA Gene Seq 4(2):94-105.

Harfouche, A. et al. (2011): Tree genetic engineering and applications to sustainable forestry and biomass production. In: Trends Biotechnol 29(1):9-17.

Harfouche, A. et al. (2012): Accelerating the domestication of forest trees in a changing world. In: Trends Plant Sci 17(2):64-72.

Hauser, M.-T. et al. (2011): Transgenerational epigenetic inheritance in plants. In: Biochim Biophys Acta 1809(8):459-468.

He, Y. et al. (2011): Large-scale production of functional human serum albumin from transgenic rice seeds. In: Proc Natl Acad Sci USA 108(47):19078-19083.

Heslot, N. et al. (2012): Genomic Selection in Plant Breeding: A Comparison of Models. In: Crop Science 52(1):146.

Hicks, G. R./Raikhel, N. V. (2012): Small Molecules Present Large Opportunities in Plant Biology. In: Annual Review of Plant Biology. In: Annu Rev Plant Biol 63:261-282.

Hollak, C. E. (2012): An evidence-based review of the potential benefits of taliglucerase alfa in the treatment of patients with Gaucher disease. In: Core Evid 7:15-20.

Holme, I. B. et al. (2012): Cisgenic barley with improved phytase activity. In: Plant Biotechnol J 10(2):237-247.

Holme, I. B. et al. (2013): Intragenesis and cisgenesis as alternatives to transgenic crop development. In: Plant Biotechnol J 11(4):395-407.

Holst-Jensen, A. et al. (2012): Detecting un-authorized genetically modified organisms (GMOs) and derived materials. In: Biotechnol Adv 30(6):1318-1335.

Horvath, P./Barrangou, R. (2013): RNA-guided genome editing à la carte. In: Cell Res 23(6):733-734. 
Hsu, P. D. et al. (2014): Development and Applications of CRISPR-Cas9 for Genome Engineering. In: Cell 157(6):1262-1278.

Huang, S. et al. (2013): Draft genome of the kiwifruit Actinidia chinensis. In: Nat Commun 4:2640.

Hucho, F. et al. (2005): Gentechnologiebericht: Analyse einer Hochtechnologie in Deutschland. München.

Jagtap, U. B. et al. (2011): Role of RNA interference in plant improvement. In: Naturwissenschaften 98(6):473-492.

Jannink, J.-L. et al. (2010): Genomic selection in plant breeding: from theory to practice. In: Brief Funct Genomics 9(2):166-177.

Jia, H./Wang, N. (2014): Targeted genome editing of sweet orange using Cas9/sgRNA. In: PLoS ONE 9(4):e93806. DOI: 10.1371/journal.pone.0093806.

Jinek, M. et al. (2012): A programmable dual-RNA-guided DNA endonuclease in adaptive bacterial immunity. In: Science 337(6096):816-821.

Jinek, M. et al. (2013): RNA-programmed genome editing in human cells. In: eLife 2013(2):e00471.

Jo, K.-R. et al. (2014): Development of late blight resistant potatoes by cisgene stacking. In: BMC Biotechnol. 14(1):50.

Jogaiah, S. et al. (2013): Systems biology-based approaches toward understanding drought tolerance in food crops. In: Crit. Rev. Biotechnol. 33(1):23-39.

Jones, R. M. et al. (2013): A plant-produced Pfs25 VLP malaria vaccine candidate induces persistent transmission blocking antibodies against Plasmodium falciparum in immunized mice. In: PLoS ONE 8(11):e79538.

Joosen, R. V. L. et al. (2009): Advances in genetical genomics of plants. In: Curr Genomics 10(8):540549.

Joosen, R. V. L. et al. (2013): Identifying genotype-by-environment interactions in the metabolism of germinating Arabidopsis seeds using Generalized Genetical Genomics. In: Plant Physiol 162(3):553566.

Joshi, S. G. et al. (2011): Functional analysis and expression profiling of HcrVf1 and HcrVf2 for development of scab resistant cisgenic and intragenic apples. In: Plant Mol Biol 75(6):579-591.

Jung, J. H. et al. (2013): RNA interference suppression of lignin biosynthesis increases fermentable sugar yields for biofuel production from field-grown sugarcane. In: Plant Biotechnol J11(6):709-716.

Kamle, S./Ali, S. (2013): Genetically modified crops: Detection strategies and biosafety issues. In: Gene 522(2):123-132.

Katoch, R./Thakur, N. (2013): Advances in RNA interference technology and its impact on nutritional improvement, disease and insect control in plants. In: Appl Biochem Biotechnol 169(5):1579-1605.

Khan, R. S. et al. (2011): Development of disease-resistant marker-free tomato by R/RS site-specific recombination. In: Plant Cell Rep 30(6):1041-1053.

Khraiwesh, B. et al. (2012): Role of miRNAs and siRNAs in biotic and abiotic stress responses of plants. In: Biochim. Biophys. Acta 1819(2):137-148.

Kim, S. et al. (2014): Genome sequence of the hot pepper provides insights into the evolution of pungency in Capsicum species. In: Nat. Genet. 46(3):270-278.

Kumar, R. (2014): Role of MicroRNAs in Biotic and Abiotic Stress Responses in Crop Plants. In: Appl. Biochem. Biotechnol. May 29 [Epub ahead of print] 
Kuo, Y.-C. et al. (2013): Improving Pharmaceutical Protein Production in Oryza sativa. In: Int J Mol Sci 14(5):8719-8739.

Kurowska, M. et al. (2011): TILLING: a shortcut in functional genomics. In: J Appl Genet 52(4):371-390.

Larkum, A. W. D. et al. (2012): Selection, breeding and engineering of microalgae for bioenergy and biofuel production. In: Trends Biotechnol 30(4):198-205.

Lee, S. J. et al. (2013): Design and development of synthetic microbial platform cells for bioenergy. In: Front Microbiol (19)4:92.

Liang, Z. et al. (2014): Targeted mutagenesis in Zea mays using TALENs and the CRISPR/Cas system. In: J Genet Genomics 41(2):63-68.

Lico, C. et al. (2012): The use of plants for the production of therapeutic human peptides. In: Plant Cell Rep 31(3):439-451.

Lindblad, P. et al. (2012): Design, engineering, and construction of photosynthetic microbial cell factories for renewable solar fuel production. In: Ambio 41 Suppl 2:163-168.

Lindbo, J. A. (2012): A historical overview of RNAi in plants. In: Methods Mol Biol 894:1-16.

Liu, B./Benning, C. (2013): Lipid metabolism in microalgae distinguishes itself. In: Curr. Opin. Biotechnol. 24(2):300-309.

Liu, L./Fan, X.-D. (2014): CRISPR-Cas system: a powerful tool for genome engineering. In: Plant Mol. Biol. 85(3):209-218.

Liu, S. et al. (2014): The Brassica oleracea genome reveals the asymmetrical evolution of polyploid genomes. In: Nat Commun 5:3930. Online Publikation 23. 05. 2014. DOI: 10.1038/ncomms 4930

Lössl, A. G./Waheed, M. T. (2011): Chloroplast-derived vaccines against human diseases: achievements, challenges and scopes. In: Plant Biotechnol J 9(5):527-539.

Lozano-Juste, J./Cutler, S. R. (2014): Plant genome engineering in full bloom. In: Trends Plant Sci. 19(5):284-287.

Lung'aho, M. G. et al. (2011): Genetic and physiological analysis of iron biofortification in maize kernels. In: PLoS ONE 6(6):e20429.

Mahfouz, M. M./Li, L. (2011): TALE nucleases and next generation GM crops. In: GM Crops 2(2):99-103.

Maliga, P./Bock, R. (2011): Plastid biotechnology: food, fuel, and medicine for the 21st century. In: Plant Physiol 155(4):1501-1510.

Manimaran, P. et al. (2011): Suitability of non-lethal marker and marker-free systems for development of transgenic crop plants: present status and future prospects. In: Biotechnol Adv 29(6):703714 .

Marshall, A.-L./Alaimo, P. J. (2010): Useful products from complex starting materials: common chemicals from biomass feedstocks. In: Chemistry 16(17):4970-4980.

Martin, J. A./Wang, Z. (2011): Next-generation transcriptome assembly. In: Nat Rev Genet 12(10):671682.

Martin, C. (2013): The interface between plant metabolic engineering and human health. In: Curr. Opin. Biotechnol. 24(2):344-353.

Marx-Stölting, L. (2012): Ethische Aspekte und öffentliche Akzeptanz der Grünen Gentechnik. In: Bayerische Akademie der Wissenschaften: Rundgespräche der Kommission für Ökologie 40. Pflanzenzucht und Gentechnik in einer Welt mit Hungersnot und knappen Ressourcen. München:101-118. 
Mason, H. S./Herbst-Kralovetz, M. M. (2012): Plant-derived antigens as mucosal vaccines. In: Curr Top Microbiol Immunol 354:101-120.

Menetrez, M. Y. (2012): An overview of algae biofuel production and potential environmental impact. In: Environ Sci Technol 46(13):7073-7085.

Mikschofsky, H./Broer, I. (2012): Feasibility of Pisum sativum as an expression system for pharmaceuticals. In: Transgenic Res 21(4):715-724.

Mittal, V. (2011) (ed.): Renewable Polymers: Synthesis, Processing, and Technology. 1. Aufl. Hoboken, New Jersey.

Miura, K. et al. (2011): The role of QTLs in the breeding of high-yielding rice. In: Trends Plant Sci 16(6):319-326.

Mukhtar, M. S. et al. (2011): Independently evolved virulence effectors converge onto hubs in a plant immune system network. In: Science 333(6042):596-601.

Müller-Röber, B. (2007): Grüne Gentechnologie: Aktuelle Entwicklungen in Wissenschaft und Wirtschaft. 2. Aufl. Limburg.

Müller-Röber, B. et al. (2009): Zweiter Gentechnologiebericht: Analyse einer Hochtechnologie in Deutschland. Dornburg.

Müller-Röber, B. et al. (2013a) (Hrsg.): Grüne Gentechnologie. Aktuelle wissenschaftliche, wirtschaftliche und gesellschaftliche Entwicklungen. 3. völlig neu bearb. Aufl. Dornburg.

Müller-Röber, B. et al. (2013b): Stand der Wissenschaft und der Technik. In: Müller-Röber, B. et al. (Hrsg,): Grüne Gentechnologie. Aktuelle wissenschaftliche, wirtschaftliche und gesellschaftliche Entwicklungen. 3. völlig neu bearb. Aufl. Dornburg:39-94.

Muth, J. et al. (2008): Precision breeding for novel starch variants in potato. In: Plant Biotechnol J 6(6):576-584.

Myers, G. (2012): Why bioimage informatics matters. In: Nat Methods 9(7):659-660.

Nakashima, K. et al. (2014): The transcriptional regulatory network in the drought response and its crosstalk in abiotic stress responses including drought, cold, and heat. In: Front Plant Sci 5:170.

Nakaya, A./Isobe, S. N. (2012): Will genomic selection be a practical method for plant breeding? In: Ann Bot 110(6):1303-1316.

Niederhuth, C. E./Schmitz, R. J. (2014): Covering your bases: inheritance of DNA methylation in plant genomes. In: Mol Plant 7(3):472-480.

Nystedt, B. et al. (2013): The Norway spruce genome sequence and conifer genome evolution. In: Nature 497(7451):579-584.

Olguín, E. J. (2012): Dual purpose microalgae-bacteria-based systems that treat wastewater and produce biodiesel and chemical products within a biorefinery. In: Biotechnol Adv 30(5):1031-1046.

Orzaez, D. et al. (2010): Using genetic variability available in the breeder's pool to engineer fruit quality. In: GM Crops 1(3):120-127.

Parmar, A. et al. (2011): Cyanobacteria and microalgae: a positive prospect for biofuels. In: Bioresour Technol 102(22):10163-10172.

Penney, C. A. et al. (2011): Plant-made vaccines in support of the Millennium Development Goals. In: Plant Cell Rep 30(5):789-798. 
Peralta-Yahya, P. P. et al. (2012): Microbial engineering for the production of advanced biofuels. In: Nature 488(7411):320-328.

Pilacinski, W. et al. (2011): Plants with genetically modified events combined by conventional breeding: an assessment of the need for additional regulatory data. In: Food Chem Toxicol 49(1):1-7.

Poland, J. A. et al. (2012): Development of high-density genetic maps for barley and wheat using a novel two-enzyme genotyping-by-sequencing approach. In: PLoS One 7(2):e32253.

Potato Genome Sequencing Consortium et al. (2011): Genome sequence and analysis of the tuber crop potato. In: Nature 475(7355):189-195.

Potrykus, I. (2012): Golden Rice: Lehren aus einem humanitären GVO-Projekt. In: Bayerische Akademie der Wissenschaften: Rundgespräche der Kommission für Ökologie 40. Pflanzenzucht und Gentechnik in einer Welt mit Hungersnot und knappen Ressourcen. München:81-88.

Que, Q. et al. (2010): Trait stacking in transgenic crops: challenges and opportunities. In: GM Crops 1(4):220-229.

Rafsanjani, M. S. et al. (2012): Application of novel nanotechnology strategies in plant biotransformation: a contemporary overview. In: Recent Pat Biotechnol 6(1):69-79.

Rahman, H. et al. (2011): Molecular mapping of quantitative trait loci for drought tolerance in maize plants. In: Genet Mol Res 10(2):889-901.

Raschke, M. et al. (2011): Enhanced levels of vitamin B(6) increase aerial organ size and positively affect stress tolerance in Arabidopsis. In: Plant J. 66(3):414-432.

Ratha, S. K./Prasanna, R. (2012): Bioprospecting microalgae as potential sources of „green energy“challenges and perspectives (review). In: Prikl Biokhim Mikrobiol 48(2):133-149.

Reddy, C. A./Saravanan, R. S. (2013): Polymicrobial multi-functional approach for enhancement of crop productivity. In: Adv Appl Microbiol 82:53-113.

Resende, M. D. V. et al. (2012): Genomic selection for growth and wood quality in Eucalyptus: capturing the missing heritability and accelerating breeding for complex traits in forest trees. In: New Phytol 194(1):116-128.

Richards, E. J. (2011): Natural epigenetic variation in plant species: a view from the field. In: Curr Opin Plant Biol 14(2):204-209.

Rigano, M. M. et al. (2012): Unsolved problems in plastid transformation. In: Bioengineered 3(6):329333.

Rigano, M. M. et al. (2013): Production of pharmaceutical proteins in solanaceae food crops. In: Int J Mol Sci 14(2):2753-2773.

Rischer, H. et al. (2013): Plant Cells as Pharmaceutical Factories. In: Curr. Pharm. Des 19(31):5640-5660.

Rivera, A. L. et al. (2012): Physical methods for genetic plant transformation. In: Phys Life Rev 9(3):308-345.

Rodriguez-Furlán, C. et al. (2014): Chemical genomics: characterizing target pathways for bioactive compounds using the endomembrane trafficking network. In: Methods Mol. Biol. 1174:317-328.

Rosales-Mendoza, S. et al. (2012): Chlamydomonas reinhardtii as a viable platform for the production of recombinant proteins: current status and perspectives. In: Plant Cell Rep. 31(3):479-494.

Rosellini, D. (2011): Selectable marker genes from plants: reliability and potential. In: In Vitro Cellular \& Developmental Biology - Plant 47(2):222-233.

Runo, S. (2011): Engineering host-derived resistance against plant parasites through RNA interference: challenges and opportunities. In; Bioeng Bugs 2(4):208-21326.04.2023, 12:51:10 
Runo, S. et al. (2011): RNA interference as a resistance mechanism against crop parasites in Africa: a „Trojan horse“ approach. In: Pest Manag Sci 67(2):129-136.

Sablok, G. et al. (2011): Artificial microRNAs (amiRNAs) engineering - On how microRNA-based silencing methods have affected current plant silencing research. In: Biochem Biophys Res Commun 406(3):315-319.

Sadhukhan, A. et al. (2012): Chemical genomics in plant biology. In: Indian J. Biochem Biophys 49(3):143-154.

Sanger, F. et al. (1977): DNA sequencing with chain-terminating inhibitors. In: Proc Natl Acad Sci U S A. 74(12):5463-5467.

Sasso, S. et al. (2012): Microalgae in the postgenomic era: a blooming reservoir for new natural products. In: FEMS Microbiol Rev 36(4):761-785.

Schmitz, R. J./Zhang, X. (2011): High-throughput approaches for plant epigenomic studies. In: Curr Opin Plant Biol 14(2):130-136.

Schmutz, J. et al. (2014): A reference genome for common bean and genome-wide analysis of dual domestications. In: Nat. Genet. 46(7):707-713.

Schneeberger, K./Weigel, D. (2011): Fast-forward genetics enabled by new sequencing technologies. In: Trends Plant Sci 16(5):282-288.

Scotti, N. et al. (2012): Production of foreign proteins using plastid transformation. In: Biotechnol Adv 30(2):387-397.

Segal, D. J. (2013): Bacteria herald a new era of gene editing. In: eLife 2013(2):e00563. Online Publikation 29.1. 2013. DOI: 10.7554/eLife.00563.

Shaaltiel, Y. et al. (2007): Production of glucocerebrosidase with terminal mannose glycans for enzyme replacement therapy of Gaucher's disease using a plant cell system. In: Plant Biotechnol J 5(5):579-590.

Sharp, P./Dong, C. (2014): TILLING for plant breeding. In: Methods Mol. Biol. 1145:155-165.

Simić, D. et al. (2012): Quantitative trait loci for biofortification traits in maize grain. In: J Hered 103(1):47-54.

Skarjinskaia, M. et al. (2013): Hairy roots as a vaccine production and delivery system. In: Adv. Biochem. Eng. Biotechnol. 134:115-134.

Slovak, R. et al. (2014): A Scalable Open-Source Pipeline for Large-Scale Root Phenotyping of Arabidopsis. In: Plant Cell. Jun 10 [Epub ahead of print].

Snoek, L. B. et al. (2012): Genetical genomics reveals large scale genotype-by-environment interactions in Arabidopsis thaliana. In: Front Genet 3:317. Online Publikation 10.01.2013. DOI: 10.3389/ fgene.2012.00317.

Srivastava, S. K. et al. (2014): The genome sequence of the fungal pathogen Fusarium virguliforme that causes sudden death syndrome in soybean. In: PLoS ONE 9(1):e81832.

Sun, X. et al. (2014): Advances in identification and validation of plant microRNAs and their target genes. In: Physiol Plant. Online Publikation 18.03.2014. DOI: 10.1111/ppl.12191 [Epub ahead of Print].

Tang, G. et al. (2012): $\beta$-Carotene in Golden Rice is as good as $\beta$-carotene in oil at providing vitamin A to children. In: Am. J. Clin. Nutr. 96(3):658-664.

Thao, N. P./Tran, L.-S. P. (2012): Potentials toward genetic engineering of drought-tolerant soybean. In: Crit. Rev. Biotechnol. 32(4):349-362. 
The Tomato Genome Consortium (2012): The tomato genome sequence provides insights into fleshy fruit evolution. In: Nature 485(7400):635-641.

Thomas, D. R. et al. (2011): Evolution of plant-made pharmaceuticals. In: Int J Mol Sci 12(5):3220-3236. Thudi, M. et al. (2012): Current state-of-art of sequencing technologies for plant genomics research. In: Brief Funct Genomics 11(1):3-11.

Tollefson, J. (2011): Brazil cooks up transgenic bean. In: Nature News 478(7368):168-168.

Tuteja, N. et al. (2012): Recent advances in development of marker-free transgenic plants: Regulation and biosafety concern. In: J Biosci 37(1):167-197.

Vanblaere, T. et al. (2011): The development of a cisgenic apple plant. In: J Biotechnol 154(4):304-311.

Vanblaere, T. et al. (2014): Molecular characterization of cisgenic lines of apple „Gala" carrying the Rvi6 scab resistance gene. In: Plant Biotechnol. J. 12(1):2-9.

Vanderschuren, H. et al. (2013): Strategies for vitamin B6 biofortification of plants: a dual role as a micronutrient and a stress protectant. In: Front Plant Sci 4:143.

Vanyushin, B. F./Ashapkin, V. V. (2011): DNA methylation in higher plants: past, present and future. In: Biochim Biophys Acta 1809(8):360-368.

Varshney, R. K./May, G. D. (2012): Next-generation sequencing technologies: opportunities and obligations in plant genomics. In: Brief Funct Genomics 11(1):1-2.

Venkatesh, J./Park, S. W. (2012): Plastid genetic engineering in Solanaceae. In: Protoplasma 249(4):981-999.

Waheed, M. T. et al. (2012): Plant-derived vaccines: An approach for affordable vaccines against cervical cancer. In: Hum Vaccin Immunother 8(3):403-406.

Wang, B. et al. (2012a): Application of synthetic biology in cyanobacteria and algae. In: Front Microbiol 2013(3):344.

Wang, T. L. et al. (2012b): TILLING in extremis. In: Plant Biotechnol J 10(7):761-772.

Wang, X. et al. (2012c): Two-step method for constructing Arabidopsis artificial microRNA vectors. In: Biotechnol Lett 34(7):1343-1349.

Wang, D. et al. (2014a): Nannochloropsis genomes reveal evolution of microalgal oleaginous traits. In: PLoS Genet. 10(1):e1004094. Online-Publikation 09.01.2014. DOI: 10.1371/journal.pgen.1004094.

Wang, Y. et al. (2014b): The accuracy of prediction of genomic selection in elite hybrid rye populations surpasses the accuracy of marker-assisted selection and is equally augmented by multiple field evaluation locations and test years. In: BMC Genomics 15(1):556.

Wijnker, E. et al. (2012): Reverse breeding in Arabidopsis thaliana generates homozygous parental lines from a heterozygous plant. In: Nat Genet 44(4):467-470.

Wijnker, E. et al. (2014): Hybrid recreation by reverse breeding in Arabidopsis thaliana. In: Nat Protoc 9(4):761-772.

Würschum, T. et al. (2013): Genomic selection in sugar beet breeding populations. In: BMC Genet. 14:85.

Xiao, D. et al. (2014): Genetic dissection of leaf development in Brassica rapa using a genetical genomics approach. In: Plant Physiol. 164(3):1309-1325.

Xie, Z. et al. (2012): Small RNAs in Plants. In: Sunkar, R. (ed.): MicroRNAs in Plant Development and Stress Responses. Heidelberg/Dordrecht/London/New York:1-28. 
$\mathrm{Xu}$, R. et al. (2014): Gene targeting using the Agrobacterium tumefaciens-mediated CRISPR-Cas system in rice. In: Rice (N Y) 7(1):5. Online Publikation 02.05.2014. DOI: 10.1186/s12284-014-0005-6.

Yau, Y.-Y./Stewart, C. N., Jr (2013): Less is more: strategies to remove marker genes from transgenic plants. In: BMC Biotechnol 13(1):36. Online Publikation 23.04.2013. DOI: 10.1186/1472-6750-13-36.

Yusibov, V. et al. (2011): Clinical development of plant-produced recombinant pharmaceuticals: vaccines, antibodies and beyond. In: Hum Vaccin 7(3):313-321.

Zamioudis, C. et al. (2013): Unraveling root developmental programs initiated by beneficial Pseudomonas spp. bacteria. In: Plant Physiol 162(1):304-318.

Zhang, B./Wang, Q. (2014): MicroRNA-based Biotechnology for Plant Improvement. In: J. Cell. Physiol. Jun 9 . [Epub ahead of print].

Zhang, C./Galbraith, D. W. (2012): RNA interference-mediated gene knockdown within specific cell types. In: Plant Mol Biol 80(2):169-176.

Zhang, Y. et al. (2013): Transcription activator-like effector nucleases enable efficient plant genome engineering. In: Plant Physiol 161(1):20-27.

Zhou, J. et al. (2013): Universal vectors for constructing artificial microRNAs in plants. In: Biotechnol Lett 35(7):1127-1133.

Zuccaro, A. et al. (2011): Endophytic life strategies decoded by genome and transcriptome analyses of the mutualistic root symbiont Piriformospora indica. In: PLoS Pathog. 7(10):e1002290. Online Publikation 13.10.2011. DOI: 10.1371/journal.ppat.1002290. 